$1010 \%$

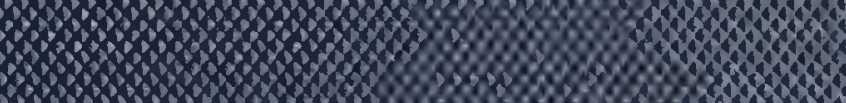

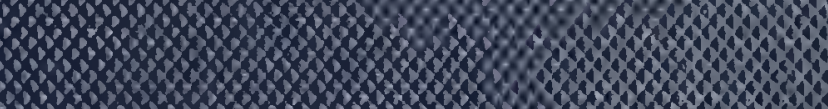

10

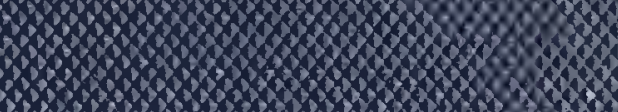

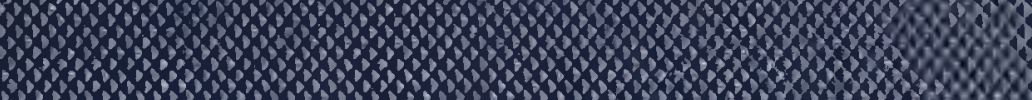

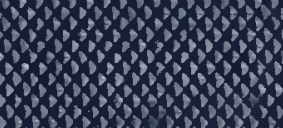

10

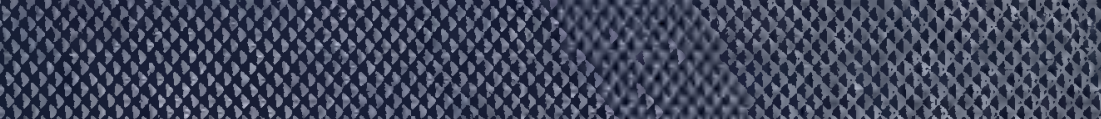

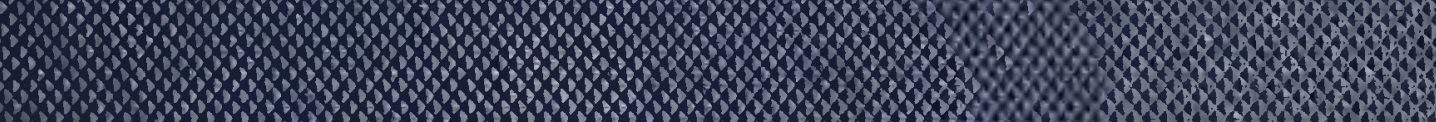
$100 \mathrm{~m}$ (1) 10 


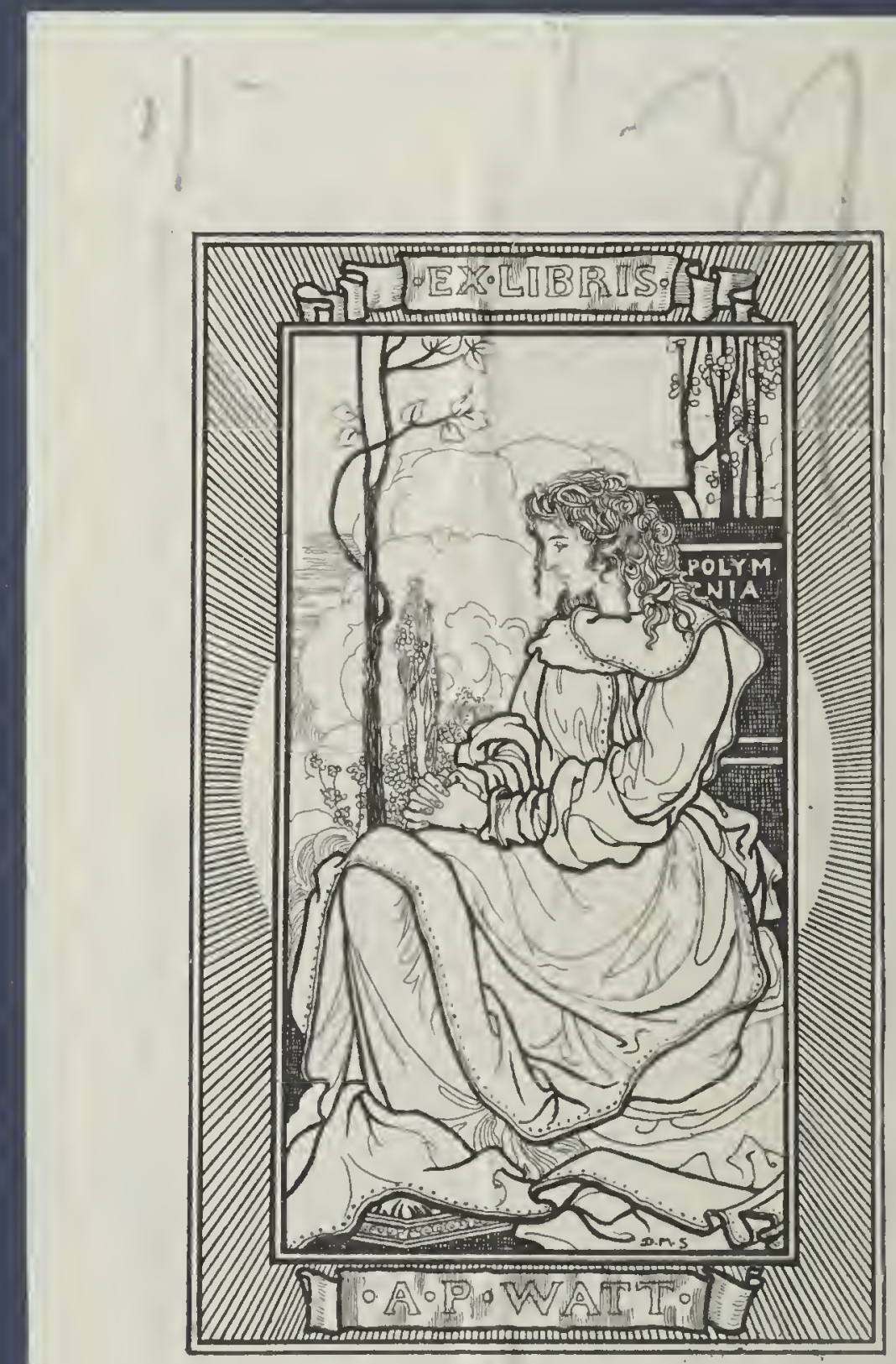





Digitized by the Internet Archive in 2020 with funding from University of Toronto 


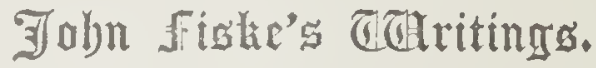

MYTHS AND MYTH MAKERS: O1d Tales and Superstitions interpreted by Comparative Mythology. I Ith Edition. I2mo, $\$ 2.00$.

OUTLINES OF COSMIC PHILOSOPHY. Based on the Doctrine of Evolution, with Criticisms on the Positive Philosophy. Isth Edition. 2 vols., Svo, \$6.00

THE UNSEEN WORLD, and other Essays. I3th Edition. I $2 \mathrm{mo}, \$ 2.00$.

EXCURSIONS OF AN EVOLUTIONIST. I6th Edition. I2mo, \$2.cO.

DARWINISM, and other Essays. qth Edition. $12 \mathrm{mo}, \$ 2.00$.

THE DESTINY OF MAN, viewed in the Light of His Origin. 20th Edition. I6mo, $\$ \mathrm{I} .00$.

THE IDEA OF GOD, as affected by Modern Knowledge. A Sequel to "The Destiny of Man." I4tin Thorsand. 16mo, $\$ 1.03$.

THE CRITICAL PERIOD OF AMERICAN HISTORY. I7 $3_{3}-$ I799. I2th Edition. Crown Svo, \$2.00.

THE BEGINNINGS OF NEW ENGLAND or the Puritan Theocracy in its Relations to Civil and Religious Liberty. roth '17rousand. Crown Svo, \$2.00.

THE WAR OF INDEPENDENCE. In Riverside Library for Young People. I6mo, 75 cents.

THE DISCOVERY AND SPANISH CONQUEST OF AMERICA. With Maps. T2th Thousant. 2 vols., crown 8 vo, $\$ 4.00$.

THE AMERICAN REVOLUTION. 9th Thousand. 2 vols., crown 8Vo, \$4.00.

CIVIL GOVERNMENT IN THE UNITED STATES. ConsidERED WITH SOME REFERENCE TOITS ORIGINS. 56th Thonsand. Crown 8vo, \$1.00, net.

HOUGHTON, MIFFLIN \& CO.

Boston AND New YORK.

AMERICAN POLITICAL IDEAS, viewed from the Stand-point of Universal History. Fifth Thonsand. I2mo, \$1.00. HARPER \& BRotiers, New York. 


\section{DARWINISM, AND OTHER ESSAYS}

\section{By JOHN FISKE}

SVEW EDITION, REVISED AND ENLARGED

"Qui itaque suos affectus et appetitus ex solo libertatis amore moderari studet, is, quantum potest, nitetur, virtutes earumque causas noscere, et animum gaudio, quod ex earum vera cognitione oritur, implere." - SPINOzA

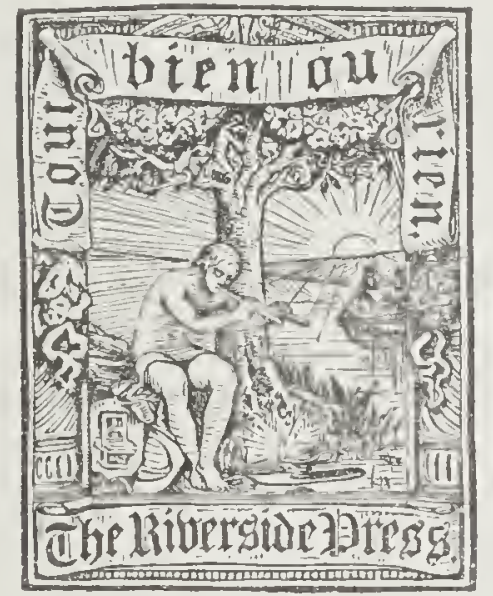

BOSTON AND NEW YORK HOUGHTON, MIFFLIN AND COMPANY

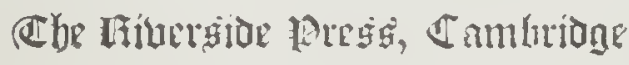
$189+$ 
Copyright, 1879 and 1886,

BY JOHN FISKE.

All rights reserved.

NINTH EDITION.

The Riverside Press, Cambridge, MTass., U. S. A.

Electrotyped and Printed by H. O. Houghton \& Company. 
To

\section{THOMAS HENRY HUXLEY,}

IN REMEMBRANCE OF

THREE HAPPY DAYS AT PETERSHAM,

AMONG THE BLUE HLLS OF MASSACHUSETTS,

AND OF MANY

PLEASANT FIRESIDE CHATS IN LONDON,

I dedicate

THSS LITTLE BOOK.

Loxpos, June 30, 1879. 



\section{PREFATORY NOTE}

TO THE SECOND EDITION.

My dear Huxley: - In publishing a new edition of this collection of essays, which has been for some time out of print, I have taken occasion to add three articles not heretofore reprinted. It was with some hesitation that in originally making up the book I included the article on "Mr. Buckle's Fallacies," which was the first writing of mine that ever appeared in print, and naturally bears many marks of immaturity in thought and style. It was partly because so many friends had expressed a desire to see it again that I decided to include it; partly also because it is to me associated with the beginnings of two of the most treasured friendships of my life, - first with Herbert Spencer, and afterwards, through a somewhat longer but still unmistakable chain of causation, with yourself. Those noctes canceque Deum of the old times in London 
become more and more sacred in memory as the years pass by, even while it is hoped there may be yet others like them in reserve; and whatever recalls them, however indirectly, becomes endeared to me.

Having for such reasons, largely personal, republished this article, I have found it so well received and so kindly mentioned that it has seemed worth while to look up and add to this somewhat miscellaneous collection three other youthful writings. The brief remarks on "Comte's Positive Philosophy" serve to explain some crude expressions in the paper on Buckle which might otherwise be interpreted as the words of a "Positivist." After twenty years of vigorous and untiring protest, I believe we may congratulate ourselves that we have got that wretched label pretty thoroughly torn off. "Agnostic," which seems for the time to have replaced it, is meaningless enough, and $I$ for one no more accept it than I accepted the old epithet. But its utter vagueness render's it comparatively harmless, whereas "Positivist" was a word brimful of meaning. It connoted almost everything in the shape of hasty superficial generalization and overweening intellectual arrogance which the true servant and interpreter of Nature instinctively and rightly abhors. We may 
rejoice that the time has come at last when a man may abandon old mythologies and devote himself to the disinterested pursuit of science, without being supposed to be an aider and abettor of the colossal vagaries of the vainest of mociern. Frenchmen.

The two other early papers, on "Liberal Education" and "University Reform," deal with subjects about which we used sometimes to talk together; and on looking them over, they seem to contain suggestions not wholly withont a bearing upon questions just now warmly discussed at our Cambrilge. I have therefore added them to the book. In some of the twelve essays of the original edition I have made a few slight changes.

I say now, as I said before, that I wish it were a better book I were offering you. But, such as it is, it is offered with all my heart.

Ever faithfully yours,

JOHN FISKE.

Petersiham, October 14, 1885. 



\section{CONTEN'TS.}

PAGE

I. DARWINISMI VERIFIED . . . . . . 1

II. Mr. Mivart on Darwinism . . . . 33

III. Dr. Bateilan on Darwinisir . • . . 40

IV. Dr. Büchner on Darwinisit • . • • 50

V. A Crumb for the "Modern Symposium" • . 56

VI. Chauncey Wright • • • • • . 79

VII. What is Inspiration? . • • • . . 111

VIII. Modern WitchCraft . . . . . . 120

IX. Conte's Positive Pillosophy • • • . 131

X. Mr. Buckle's Fallacies • . • • • 143

XI. Postscritt on Mr. Buchle . . . . 207

XiI. The Races of the Danube • • • . 219

XiII. Liberal Education • • • • • . 253

XIV. Uxiversity Refora . . . . • . 287

XV. A LIBRARIAN's WORK • . . . . . . 332 



\section{DARWINISM AND OTHER ESSAYS.}

I.

DARWINISMI VERIFIED.

IT is not often that the propounder of a new and startling scientific theory has lived to see his daring innovations accepted by the scientific world in general. Harvey's great discovery of the circulation of the blood was scoffed at for nearly a whole generation; and Newton's law of gravitation, though proved by the strictest mathematical proof, received from many eminent men but a slow and grudging acquiescence. Even Leibnitz, who, as a mathematician hardly inferior to Newton himself, might have been expected to be convinced on simple inspection of the theory, was prevented from accepting it by the theo. logical objection that it appeared to substitute the action of a physical force for the direct action of the Deity. In France, where ideas not of French origin are very apt to be but slowly 
apprehended, the opposition to the Newtonian theory was not silenced till 1759, when Clairaut and Lalande, by calculating the retardation of Halley's comet, furnished such crucial proof as could not possibly be overcome. At this time Newton had been thirty-two years in his grave; seventy-two years had elapsed since the publication of the "Principia," and ninety-four since the hypothesis was first definitely conceived.

In the present age, when the number of scientific inquirers has greatly increased and the in. terchange of thoughts has become rapid and constant, it takes much less time for a new generalization to make its way into people's minds. It is now barely eighteen years since Mr. Darwin's views on the origin of species were announced in a book which purported to be only the rough preliminary sketch of a greater work in course of preparation. But, though greeted at the beginning with ridicule and opprobrium, the theory of natural selection has already won a complete and overwhelming victory. One could count on one's finger's the number of eminent naturalists who still decline to adopt it, and the hesitancy of these appears to be determined in the main by theological or metaphysical, and therefore not strictly relevant, objections. But 
it is not simply that the great body of naturalists have accepted the Darwinian theory: it has become part and parcel of their daily thoughts, an element in every investigation which cannot be got rid of. With a tacit consent that is almost unanimous, the classificatory relations among plants and animals have come to be recognized as representing degrees of genetic kinship. One needs but to read constantly such scientific journals as "Nature," or to peer into the proceedings of scientific societies, to see how thoroughly all contemporary inquiry is permeated by the conception of natural selection. The record of research, whether in embryology, in palæontology, or in the study of the classification and distribution of organized beings, has come to be the registration of testimony in support of Mr. Darwin's hypothesis. So deeply, indeed, has this mighty thinker impressed his thoughts on the mind of the age that in order fully to unfold the connotations of the word "Darwinism" one could hardly stop short of making an index to the entire recent literature of the organic sciences. The sway of natural selection in biology is hardly less complete than that of gravitation in astronomy; and thus it is probably true that no other scientific discoverer has within his own lifetime 
obtained so magnificent a triumph as Mr. Darwin.

The comparison of the doctrine of natural selection with the Newtonian theory is made advisedly, as I wish to call attention to some differences in the aspect of the proofs by which two such different hypotheses are established. First, however, as the point will not hereafter come up for consideration in this paper, it may be well to notice the theological objection which has been urged against Mr. Darwin, as it was once urged against Newton, and to show briefly why, as above hinted, it cannot be regarded as properly relevant to the discussion of the scientific hypothesis. The theological objection to natural selection, which has weight with many minds, is precisely the same objection that Leibnitz made to gravitation,that the action of physical forces appears to be substituted for the direct action of the Deity. This has, indeed, been a very common objection to theories which enlarge and define what is called the action of secondary causes, but it has been peculiarly unfortunate in this respect, that with the progress of inquiry it has invariably been overruled without practical detriment to theism. It regularly happens that the so-called atheistical theory becomes accepted as part and 
pareel of science, and yet men remain as firm theists as ever. The objection is, therefore, evidently fallacious, and the fallacy is not difficult to point out. It lies in a metaphysical misconception of the words "force" and "cause." "Force" is implicitly regarded as a sort of entity or dæmon which has a mode of action distinguishable from that of universal Deity; otherwise it is meaningless to speak of substituting the one for the other. But such a personification of "force" is a remnant of barbaric thought, and is in no wise sanctioned by physical science. When astronomy speaks of two planets as attracting each other with a "force" which varies directly as their masses and inversely as the squares of their distances apart, it simply uses the phrase as a convenient metaphor by which to describe the manner in which the observed movements of the two bodies occur. It explains that in presence of each other the two bodies are observed to change their positions in a certain specified way, and this is all that it means. This is all that a strictly scientific hypothesis can possibly allege, and this is all that observation can possibly prove. Whatever goes beyond this, and imagines or asserts a kind of "pull" between the two bodies, is not science, but metaphysics. An atheistic 
metaphysics may imagine such a "pull," -and may interpret it as the "action" of something that is not Deity, but such a conclusion can find no support in the scientific theorem, which is simply a generalized description of phenomena. The general considerations upon which the belief in the existence and direct action of Deity are otherwise founded are in no wise disturbed by the establishment of any such scientific theorem. The theological question is left just where it was before. We are still at perfect liberty to maintain that it is the direct action of Deity which is manifested in the planetary movements; having done nothing more with our Newtonian hypothesis than to construct a happy formula for expressing the mode or order of the manifestation. We may have learned something new concerning the manner of Divine action; we certainly have not "substituted" any other kind of action for it. And what is thus obvious in this simple astronomical example is equally true in principle in every case whatever in which one set of phenomena is interpreted by comparison with another set. In no case whatever can science use the words "force" or "cause" except as metaphorically descriptive of some observed or observable sequence of phenomena. And consequently at 
no imaginable future time, so long as the essential conditions of human thinking are maintained, can science even attempt to substitute the action of any other power for the direct action of Deity. Darwinism may convince us that the existence of highly complicated organisms is the result of an infinitely diversified aggregate of circumstances so minute as severally to seem trivial or accidental; yet the consistent theist will always occupy an impregnable position in maintaining that the entire series in each and every one of its incidents is an immediate manifestation of the creative action of God.

From an obverse point of view it might be argued that since a philosophical theism must regard Divine power as the immediate source of all phenomena alike, therefore science cannot properly explain any particular group of phenomena by a direct reference to the action of Deity. Such a reference is not an explanation, since it adds nothing to our previous knowledge either of the phenomena or of the manner of Divine action. The business of science is simply to ascertain in what manner phenomena co-exist with each other or follow each other, and the only kind of explanation with which it can properly deal is that which refers one set of phenomena to another set. In 
pursuing this its legitimate business, science does not trench on the province of theology in any way, and there is no conceivable occasion for any conflict between the two. From this and the previous considerations, taken together, it follows not only that such explanations as are contained in the Newtonian and Darwinian theories are entirely consistent with theism, but also that they are the only kind of explanations with which science can properly concern itself at all. To say that complex organisms were directly created by the Deity is to make an assertion which, however true in a theistic sense, is utterly barren. It is of no profit to theism, which must be taken for granted before the assertion can be made; and it is of no profit to science, which must still ask its question, "How?" 1

Setting aside, then, the theological criticism as irrelevant to the question really at stake, the Darwinian theory, like the Newtonian, remains to be tested by strictly scientific considerations. In the more recent instance, as in the earlier, the relevant question is how far the course of events as sketched by the hypothesis agrees with the ob-

1 I have repeated this argument, and surrounded it with its proper philosophical context, in The Idea of God, as affected by Modern Knovoleage, section VII. 


\section{Darwinism Verified.}

served phenomena of nature. But in the directness with which this question can be answered there is great difference between the two theories. The Newtonian hypothesis asserted the existence of a general physical property of matter, and could therefore be tested by a single crucial instance, such as was afforded by the simple case of the planetary motions. Kepler's three laws comprised in succinct form a very complete description of the movements of the planets; and when it was shown that these movements were just such as must occur according to the theory of gravitation, the theory was rightly regarded as verified. Further confirmatory instances could but repeat the same lesson, as when the irregularities of movement, due to the attractions exercised by the various planets upon each other, were likewise seen to conform strictly to the hypothesis. Nor was any alteration or enlargement of the original theory required in order to obtain the supreme triumph of verified prediction, as when Clairaut foretold the precise amount of delay in the reappearance of Halley's comet, caused by the interfering attractions of Jupiter and Saturn, or as when Leverrier and Adarns discovered the existence of Neptune through its effects upon the motions of Uranus. In all these cases the physical principle involved 
was simple, and admitted of precise mathematical treatment; and it is owing to this that the law of gravitation has become the most illustrious example which the history of science can furnish of a completely rerified hypothesis.

To look for similar conciseness of verification in the case of the Darwinian theory would be to mistake entirely the conditions under which scientific evidence can be procmed. To estimate properly the value of any hypothesis, it is necessary that we should know what kind and degree of proof to expect; and in the present case we must not look for a demonstration that shall be direct and simple. Instead of a universal property of matter, so conspicuous as to be recognized at once by the inspection of a few striking instances, we have in the theory of natural selection to deal with a very complex process, working results of endless diversity throughout the organic world, and often masked in its action by accompanying processes, some of which we can detect without being able to estimate their relative potency, while other's, no doubt, have thus far escaped our attention altogether. Accordingly, while we may consider it as certain that natural selection is ca. pable of working specific changes in organisms, we may at the same time find it impossible to give a 
complete account of the origin of any one particular species through natural selection, because we can never be sure that we have taken due notice of all the innumerable concrete circumstances involved in such an event. The theory, therefore, cannot be adequately tested by any single striking instance, but must depend for its support on the cumulative evidence afforded by its general harmony with the processes of organic nature.

If we consider the Darwinian theory as a whole, it must be admitted that such cumulative evidence has already been brought forward in sufficient quantity to amount to a satisfactory demonstration. The convergence of proofs is too persistent and unmistakable to allow of any alternative hypothesis being put in the field. But, in exhibiting this, it is desirable that there should be no confusion of thought as to the full import of the Darwinian theory. Mr. Mivart's way of describing that theory as an attempt to account for the origin of all the various forms of life through the operation of natural selection alone is a gross misrepresentation. Mr. Darwin has never urged his hypothesis in this limited shape. The essential theorems of Darwinism are, first, that forms of life now widely unlike have been produced from a common original through the ac- 
cumulated inheritance of minute individual mod. ifications; and, secondly, that such modifications have been accumulated mainly, or in great part, through the selection of individuals best fitted to survive and transmit their peculiarities to their offspring. But that this survival of the fittest individuals has been the sole agency concerned in bringing about the present wondrous variety of living beings Mr. Darwin has nowhere asserted or implied, having even in the earliest edition of his great work explicitly pointed out certain other agencies as involved in the complex result. Yet other agencies, hitherto unsuspected, may be discovered in the future; but such discoveries, however far they may go in supplementing the Darwinian theory, can only strengthen the central position as regards the rise of specific differences through gradual modifications.

That natural selection is a true cause, and one capable of accumulating variations to an indefinite extent, is now held to be beyond question. The wonders wrought by artificial selection in the breeding of domestic animals and cultivated plants are such that one might well have attributed great results to the exercise of a similar selection by Nature through countless ages, could any such process be detected. Few, however, 


\section{Darwinism Verified.}

save those instructed naturalists who have frequent occasion to ponder the subject, are aware what a tremendous reality natural selection is. As I have elsewhere observed, "a single codfish has been known to lay six million eggs within a year. If these eggss were all to become adult codfishes, and the multiplication were to continue at this rate for three or four years, tine ocean would not afford room for the species. Yet we have no reason to suppose that the race of codfishes is actually increasing in numbers to any notable extent. With the codfish, as with animal species in general, the numbers during many successive generations oscillate about a point which is fixed, or moves but slowly forward or backward. Instead of a geometrical increase with a ratio of six millions, there is practically no marked increase at all. Now this implies that out of the six million embryo codfish a sufficient number will survive to replace their two parents, and to replace a certain small proportion of those contemporary codfishes who leave no progeny. Perhaps a dozen may suffice for this, perhaps a hundred. The rest of the six million must die." I The amount of destruction is not so great as this in all parts of the animal kingdom. Among the higher birds and

1 Outlines of Cosmic Philosophy, vol. ii. p. 12. 
mammals the preservation of the individual bears a very much higher ratio to the preservation of the race. But with the immense classes of fishes, insects, and crustaceans, as well as the sub-kingdom of mollusks, - which taken together make up by far the greater portion of the animal world, - the destruction continually going on is probably not less than that which is described in the example cited. Even if we were to take account only of the individuals which survive the embryo or larva state, but do not succeed in leaving offspring behind them, the cases of destruction would still bear an enormous ratio to the cases of preservation. But in maintaining the characteristics of a race only those individuals can be counted who produce offspring. It is obvious, then, that each species of organisms, as we know it, consists only of a few favoured individuals selected out of countless multitudes who have been tried and rejected as unworthy to live. No selection that is exercised by man compares in rigour with this. It is somewhat as if a breeder of race-horses were to choose, with infallible accuracy of judgment, the two or three fleetest out of each hundred thousand, destroying all the rest, that the high standard of the breed might run no possible risk of deterioration. In such a rigorous competition 
as this, no individual peculiarity can be so slight that we are entitled to regard it as unimportant. No peculiarity is really slight that enables its possessor to survive until he transmits it to possterity.

In view of all this we see how misleading it is to describe natural selection (as Mr. Mivart does) as a process which operates only occasionally upon variations assumed to be fortuitous. We see that natural selection, like a power that slumbers not nor sleeps, is ever preserving the stability of species by seizing all individual peculiarities that oscillate within narrow limits on either side of the mean that is most advantageous to the species, while cutting off all such peculiarities as transgress these limits. Domesticated animals, protected from the exigencies of wild life, often exhibit great varieties in colouring, while wild animals of the same genus or species are monotonously coloured, because only one kind of colouring will aid them in catching prey or eluding enemies, and all the variations are killed ont. Who can doubt that antelopes are so fleet only because all but the fleetest individuals are sure to be overtaken and eaten by lions? Protected from the lions, a thousand generations might well make them as lazy and clumsy as sheep. 
Operating in this stern way, natural selection. secures the general adaptation of each race of organisms to the conditions of life which surround it. And so long as a species continues surrounded by circumstances that are tolerably persistent, natural selection maintains its stability of character. Thus what the older naturalists called the "fixity of species" is fully accounted for. But a "fixity of species" that is maintained only under such conditions is really no fixity at all. Change the surrounding circumstances, and the average character of the species must clange. Slight peculiarities that once insured survival will now insure destruction, and tendencies to vary that once would have been nipped short will now be encouraged and exaggerated. In this way the strong tendency, hereditary in all mammals, toward the growth of hair on the surface, was greatly exaggerated in the Siberian mammoth, while checked in his brethren, the elepliants of India and Africa. In this way a peculiar curve in the contour of butterflies' wings, which is persistently killed out in India and Java, is with equal persistency selected for preservation in Celebes. How far such alterations in the direction of natural selection may work deep-seated changes in the structure of an organism one can- 
not accurately define; but there is no doubt that they go very far indeed, when taken in connection with the facts of what is called "correlation of growth." An organism is not a mere aggregation of parts, of which one can be altered without affecting the others. Increase in the size and weight of a deer's horns entails an increase in the size of the cervical vertebræ and muscles, and indirectly modifies the shoulders and forelimbs; while all these changes, by altering the animal's centre of gravity, cause compensating changes in the rest of the body. Increased thickness of fur modifies the efficiency of the skin as an excreting organ, and thus reacts upon the lungs, liver, and kidneys. But it is not only in these clearly traceable ways that correlation of growth is manifested. Sometimes the correlations are inexplicable. Thus, to lengthen the beak of a pigeon is to increase the size of his feet, hairless dogs have their teeth imperfect, and white tomcats with blue eyes are almost invariably deaf. In the present state of physiological knowledge we cannot account for such facts; but it is enough for the purposes of the Darwinian theory to know that they exist. For, taken all together, they show that natural selection, operating on even the most, superficial variations, is 
quite competent to work deep-seated changes of structure and function.

When we consider, then, that the circumstances which determine what individuals shall survive are not constant in the long run for any species, though apparently constant for limited periods of time; when we reflect that there is no one of the larger groups of plants and animals - such as orders, or families, or even genera - which have not been subjected again and again to great and complicated changes of environment, it becomes evident that anything like "fixity of species" is utterly out of the question. No such thing is possible or even imaginable, when once the facts of the case have been thoroughly conceived. Looking over the earth's surface to-day, things may seem quiet and stable enough. But if we contemplate the succession of past events, as disclosed by the geologist, what mainly strikes our attention is the secular turmoil. Islands aggregating into continents; continents breaking up into archipelagoes; rivers shifting their beds; coast-lines changing their direction; oceans now separated by impassable isthmus-walls, now mingling their floras and faunas through new-made channels; torrid zones becoming temperate, and temperate zones growing frigid; marshes trans- 
formed into deserts, and glaciated valleys thawing into sunny lakes; high table-lands sinking into ocean-floors, and submarine ledges rearing their heads as Alpine ranges; deep-sea mollusks and crustaceans seeking refuge in shallow waters, while littoral organisms migrate upland to find new food and contend with new enemies; plantseeds carried by vagrant birds to unwonted habitats; peaceful tribes of ruminants decimated by invading carnivores; ceaseless conflict, and redistribution of every possible sort, - these are the things we are called upon to contemplate. Remembering, then, how stability of species is maintained only by the rigorous selection of a few individuals that are best adapted to a given set of exigencies, we see that, as the combinations of exigencies are altered from time to time, the stability of species can in general be but temporary. Now and then we may expect to find very long persistency of type where, in spite of great terrestrial changes, some simple set of conditions most important to the organism remains unaltered; but in the vast majority of cases such persistence is impossible. It is seldom that the life of any species extends over more than one geological epoch; often the duration is much shorter than this. 
Whether, therefore, it is practicable for us today to explain every minute peculiarity of any one particular species by an appeal to natural selection alone is not the main point to be considered in estimating the success of the Darwinian theory. The question has a scientific interest of its own which is very great, but it is not the main question. The main point is that, admitting natural selection to be a vera causa at all (and this no one denies), the stability of species is proved to be but a contingent and temporary affair. The old notion of an absolute fixity of species is overthrown once for all, and with it the only semblance of an argument that could ever have been alleged in behalf of the hypothesis of special creations. For in considering nearly allied forms, like the lion, tiger, and leopard, their actual consanguinity would never have been doubted for a moment but for the inability of naturalists to understand how the type which appears so constant, when viewed through a short period of time and amid unchanging conditions, should after all be variable. Unable to imagine any probable cause or method of variation by which the descendants of a common feline ancestor should have acquired the divergent characters of lions and leopards, the naturalist either gave up the problem as insoluble, 
or else retreated upon the assumption that leopards and lions were separately created. In either case science was equally at fault; for, as above argued, the hypothesis of special creations, as referring a particular group of phenomena to that Divine action which is the equal sonrce of all phenomena, is not entitled to be considered a scientific explanation. But when Mr. Darwin called attention to the working of natural selection, the difficulty was removed, and it at once became highly probable that such allied forms had diverged from a common stock through the accumulation of minute modifications.

Such being the conclusion to which we are led by considering the process of natural selection, it becomes desirable to inquire whether the conclusion is confirmed by the most general phenomena of organic life that have been observed and tabulated. There is no hesitation or ambiguity in the answer. Whether we consider the classificatory relationships of plants and animals, their embryology, their morphology, their geographical distribution, or their geological succession, there is not only abundance of evidence, but the evidence points wholly in one direction. With entire unanimity the phenomena in question testify that species have arisen by descent with modifi- 
cations, and not by disconnected acts of creation. The facts of classification alone are sufficiently decisive. By the older naturalists, who sought to arrange animals and plants in groups according to their resemblances, attempts were often made to construct a linear series in which each group should be intermediate between those which preceded and those which followed it. All such attempts proved futile, and after a half-century of discussion and criticism it became evident that the only possible classification which correctly represents the facts is one in which organisms are arranged in divergent groups and sub-groups, like the branches and twigs of what is aptly termed a family tree. Wherever different orders, families, or genera show points of resemblance to each other, the resemblances nccur always at the bottom, among their lenst highly developed species. Apes, bats, and rabbits are sufficiently distinct in type, but the lowest members of the orders to which these animals respectively belong are strikingly like one another. At the bottom of the mammalian class, the echidna and duck-bill have many points in common with birds and reptiles; while birds and reptiles not only draw together so that it is hard to distinguish their most primitive forms as clearly bird or clearly reptile, but these 
primitive forms remind one in many ways of the batrachians. A batrachian, in tum, is an animal which ends its life as a kind of reptile after having begun it as a lind of imperfectly specialized fish. Again, the lowest known vertebrate, the amphioxus, usually ranked with fishes, though hardly specialized enough to be called a true fish, exhibits marks of actual relationship with the ascidian, which is nothing more than a worm of the order known as tunicata. No two animals could be less like each other than a bee and a nautilus, yet in their lowest members the two sub-kingdoms of articulata and mollusks become barely distinguishable from each other and from the worms with which the vertebrate sub-kingdom also becomes blended. It is on account of this convergence of types as we descend in the scale that naturalists have found it so difficult to classify satisfactorily those lower organisms which $\mathrm{Cu}$ vier roughly grouped together as radiata. Parallel phenomena recur as we reach the confines of the animal and vegetal kingdoms, and meet with numbers of organisms which there is as much reason for assigning to the one kingdom as to the other. All this complicated arrangement of organisms in groups within groups, resembling each other at the bottom of the scale, and differing 
most widely at the top, is just what is presupposed by the Darwinian theory of "descent with modifieation," and on any other theory it appears to be totally inexplicable.

Precisely similar testimony as to gradual divergrnce is found in the facts of embryology and morphology. It is a familiar fact that the germs of all organisms are like each other, and are, moreover, very like'such lowest forms of life as the amoba and protococcus. But as a germ develops it becomes specialized and defined, first as to its sub-kingdom, then as to its class, order, family, genus, species, and variety. The germcell of a mandril is at first indistinguishable from that of a snail or lobster. The fœtal ape arising therefrom is at first definable as a vertebrate, but not as a mammal; on the other hand, it circulates its blood through a system of gills, and its nascent heart is like the beart of a fish. Presently, with the appearance of the allantoidal membrane, the foctus seems to be on the point of becoming a reptile or bird; but after a while it declares itself a mammal. Next it becomes apparent that it is not a rodent or insectivore, but a primate; next, it exhibits characteristics which define it as a true ape, and not a lemur; still later, it is seen to be a catarrhine ape; and finally, it 
is born with the specific attributes of a mandril, which are, however, further intensified as it reaches maturity. Facts like these, which are invariably found in the embryonic development of organisms, tell just the same story as the facts of classification. If they do not mean that the various forms of organic life have arisen by gradual divergence from a common original, one might well be excused for donbting whether the phenomena of nature have any rational meaning whatever. Of like import are many of the more special facts of embryology, such as the useless rudiments of hind limbs in many snikes, the presence of teeth in the beaks of sundry embryonic birds and in the jaws of foetal whales, and the gill-like glinds in the human throat. As if all this were not enough, the study of morpholngy discloses that all the diversified mechanical funetions performed by the various animals comprised in any sub-kingdom are achieved by more or less considerable modifications of a framework that in its typical features is common to all. In embryonic development the fins of the fish correspond with the legs of reptiles and mammils, and with the legs and wings of birds. To enable the bat to fly, no new mechanism is inventerl, but mi embryonal hand develops into a wing by the 
elongation of its fingers and the growth of a weblike skin between them.

If we consider the most general features of the geographical distribution and geological succession of organisms, we find the evidence hardly less complete and convincing. Generally speaking, the contemporary species found in any geographical area most closely resemble the species that inhabited the same area in former ages. Thus in the Miocene age Australia abounded in marsupials, and marsupials specifically different, though nearly allied to these, make up to-day the greater part of the mammalian fauna of Australia. There is no imaginable reason why this should be so, unless the contemporary marsupials are descended from the earlier forms. It cannot be urged that marsupials are better adapted to the conditions of life in Australia than placental mammals; for the placental mammals lately introduced there are already beginning to supplant and exterminate the marsupials. The only possible explanation is that, whereas marsupials once covered the terrestrial globe, and have been supplinted by better adapted forms in thie Oid World and (with the exception of the opossum) in America, on the other land the isolation of Australia has allowed them there to go on repro- 
ducing their kind until the present day. In such an instance as this we have something very nearly like crucial proof of the theory of "descent with modifications." In like manner the extinct edentata of South America are closely allied to the living ant-eaters, sloths, and armadilloes. So, too, the indigenous floras and faunas of islands lying near continents always resemble the floras and faunas of the continents near which they lie. The Galapagos archipelago, distant some five hundred miles from the coast of Ecuador, has a fauna which, though generically distinct from all other's, is yet South American in type, and closely resembles the fauna of Ecuador. Again, among the animals living on the different islands of this group, we find specific diversity along with generic identity. On the Darwiniam theory this is just what might be expected. The long isolation of the archipelago from the continent has given opportunity for the rise of generic divergences between their once homogeneous faunas, while the briefer isolation of the several islands from each other has been attended by slighter, or specific, divergences; and, as if to complete by contrast the force of the eximple, we find that the only animals on the archipelago which are not generically different from their allies on the continent are 
birds, able to fly back and forth over the intervening sea. Unless the Darwinian theory be true, these striking relations not only become meaningless, but it is difficult to see why any discernible relations at all should exist between these neighboring famnas. To cite all the confirmatory facts of this sort would be to write an exhaustive account of the distribution of plants and animals.

In examining the geological record in general, we are struck with its corroboration of the abovecited testimony of classification and embryology. For instance, as we go back in time, we find families and orders dratwing more and more closely together; we find earlier forms less specialized than their successors; and, as we now have embryonic birds with rudimentary teeth in their beaks, so we find that formerly adult birds with such teeth existed. It is one of the most significant truths of palæontolngy that extinct forms are generally intercalary between forms now existing; so that not only genera and families, but even orders, of contemporary animals are every now and then fused together by the discovery of extinct intermediate forms. It is in this way that the Cuvierian orders of pachyderms and ruminants have come to be ranked as a single order, 
the horse and pig being connected by numerous fossil links with the camel and antelope. Until quite lately there has been less success in the attempt to find a perfect series of transitional forms connecting some well-known animal with its generically different ancestor. But the argument heretofore urged against the Darwinian theory, on the ground of this imperfect success, was at best a weak one, as resting merely upon the absence of evidence which further discovery might furnish at any moment. The Darwinian might candidly urge that his failure was due partly to the fragmentary character of the geological record, in which there is no reason for supposing that more than one form out of a luundred has been preserved, and partly to the fact that only a small portion of the earth's surface has been explored by the palieontologist, and that portion but superficially. The justice of such a plea is rendered apparent, while the hostile argument is completely silenced, by the recent discoveries of Professor Marsh as to the palieontological history of the ancestors of the horse. As these discoveries have just been well described in Professor Huxley's admirable lectures in New York, a brief mention here will suffice to show their im. port. 
One of the most striking peculiarities of the equine genus - including the horse, ass, zebra, and quagga - is the modification of the limbs, so that what appears to be the horse's fore-knee is really his wrist, and what in the hind-limb looks like a reversed linee is really his heel, while the lower halyes of the legs are really feet terminating in the middle toe armed with its nail, which we call the hoof. The two adjacent toes are represented only by splint-bones on either side of the midlle metacarpal or metatarsal, and the radius and ulna in the fore-limb, as well as the tibia and fibula in the hind-limb, are almost completely fused together. Now according to the Darwinian theory, such a highly specialized animal as the horse must be descended from a less specialized mammal in which the limbs were like ordinary mammalian limbs, ending in ordinary feet with five separate toes each. The embryology of the horse points to this conclusion, and here, as usual, but with unwonted emphasis, palæontology confirms the inference. Already in Europe had been found the three-toed hipparion, in which the two side toes were like dew-claws, and the older anchitherium, in which all three toes were complete. But the discoveries of Professor Marsh have set before us a much more perfect series. Going 
back in time, as we reach the upper Pliocene, the horse disappears, and we find the pliohippus, very much like him. In the lower Pliocene this creature is replaced by the protohippus, with three toes like the hipparion. In the upper Miocene we have the miohippus, with three well-developed toes like the anchitherium, and with the rudiment of a fore-toe on the fore-foot. In the mesohippus of the lower Miocene this rudiment is a splint-bone, like those which represent the later-disappearing toes in the modern horse. By this time we find the ulna and fibula well developed and distinct from the radius and tibia. Still further back, in the upper Eocene, comes the orohippus, with four complete toes on the forefoot. And finally, in the lower Eocene, we get the eohippus, which shows the rudiment of a fifth toe on the front and a fourth toe on the hind foot. In the structure of the teeth - the other chief point in which the modern horse is notably specialized - we find a similar gradation back to the ordinary mammalian type.

The agreement of observed facts with the requirements of theory is here complete, minute, and specific; and Professor Huxley may well say that the history of the descent of the horse from a five-toed mammal, as thus demonstrated, sup- 
Darwinism and Other Essays.

plies all that was required to complete the proof of the Darwinian theory. The theory not only alleges a vera causa, and is not only confirmed by the unanimous import of the facts of classification, embryology, morphology, distribution, and succession; but it has further succeeded in tracing the actual origination of one generic type from another, through gradual "descent with modifications." And thus, within a score of years from its first announcement, the daring hypothesis of Mr. Darwin may fairly claim to be regarded as one of the established truths of science.

December, 1876. 


\section{II.}

MR. MIVART ON DARWINISM.

IT can hardly be said that in this volume ${ }^{1}$ Mr. Mivart has brought any new contribution to the discussion of evolution and its consequences, though he has succeeded in marshalling together, in a goodly phalanx, the various doubts, objections, and misconceptions with which the question has disturbed the peace of his mind. The book is so polemic as quite to belie its placid and decorous title. The "Lessons from Nature" turn out to be a series of eager assaults upon "Darwinians" and "Agnostics," mingled with jeremiads over the tendency of the times when such perverted thinkers can obtain such extensive following. Though it would be unfair to say that there is no trace of a disposition to interrogate nature calmly and accept the results, yet this disposition is wellnigh paralyzed by a strong mental bias towards considering facts only in their supposed bearing

1 Lessons from Nature, as manifested in Mind und Matter. By St. George Mivart. New York: D. Appleton \& Co. 1876. 
on certain assumed practical needs of theology: An evident struggle between theological predispositions and acquired scientific habits has interfered seriously with the author's balance of mind; and the net result is a book by no means commendable for scientific spirit, though it exhibits praise. worthy industry, and often considerable ingenuity and dialectical skill.

So far is Mr. Mivart from occupying the position of a disinterested student of nature that his numerous misrepresentations can be explained without necessarily charging him with a conscious willingness to be unfair. Sometimes, at least, he appear's to misrepresent scientific thinkers through sheer incapacity to comprehend the motives which guide them. Mr. Darwin's candour, for example, in modifying or retracting hasty inferences implies an attitude of mind which our author seems quite unable to appreciate. The nature of $\mathrm{Mr}$. Darwin's inquiries involves him in the consideration of thousands of exceedingly complex cases of causation, for the unravelling of which a vast experience, the most delicate analytic power, and a prodigious memory for details are absolutely essential. The general sagacity of his conclusions shows that Mr. Darwin possesses these qualities in a degree rarely, if ever, surpassed by any scientific 
inquirer; yet once in a while he makes a slip, forgets or overlooks some inconspicuous but important fact, or sets down an inference without his customary caution. Ordinary writers in such cases too often prefer to stand by what they have written, quietly ignoring criticisms that are hard to dispose of, very much as Mr. Mivart, in reprinting his rejoinder to $\mathrm{Mr}$. Cliauncey Wright, takes care not to inform the reader of the surrejoinder which came from his powerful antagonist. But Mr. Darwin finds it easy to acknowledge himself mistaken. His interest in his personal reputation for infallibility, and his zeal in behalf of the doctrine he is defending, are held in entire subordination to the main purpose of getting the facts presented as fairly and completely as possible. This is the true scientific spirit - the spirit in which to aequire lessons from nature, whether in the world of mind or in the world of matter; and when a writer manifests this spirit so consistently as Mr. Darwin, he is sure to win the respect and confidence of his readers in the highest degree. An occasional error goes for little when weighed in the scales against entire disinterestedness.

To a disinterested critic all this, one would think, should be self-evident. Yet so far is Mr. 
Mivart from recognizing anything of the sort that he cites Mr. Darwin's scrupulous self-corrections as evidence of his utter untrustworthiness! What confidence can we place, he asks, in a thinker who makes so many hasty inferences? - overlooking the fact that, in daily experience, those who are the most rash in forming their opinions are apt to be likewise the most indisposed to reconsider them. If Mr. Mivart had any genuine sympathy with the scientific temper of mind, this particular lind of misrepresentation would never have occurred to him.

Along with this inability to appreciate disinterested thinking, Mr. Mivart has one or two other peculiarities which, taken together, give him a real genius for twisting things. He is characterized by a sort of cantankerousness which prompts him to put a controversial aspect on points which properly require only a judicial estimate of the bearings of circumstances. On the question as to just how much effectiveness is to be allowed to the principle of natural selection, he approaches Mr. Darwin with the air of a lawyer browbeating a witness; and when Mr. Darwin admits that formerly his attention was somewhat too exclusively directed toward this cause of the modification of species, his belligerent critic cries out 
that here is "a change of front in face of the enemy!"

Further twisting is caused by unintelligent study of the subject criticised. Mr. Mivart, for example, attributes to the evolutionists the opinion that "virtue and pleasure are synonymous, for in root and origin they are identical." This misrepresentation arises from imperfect apprehension of the fact that, according to the doctrine of evolution, differences in kind result from the accumulation of differences in degree. One might as well say that evolutionists consider the workings of Newton's genius to be identical with reflex action, since in its root and origin all mental activity was a kind of reflex action. Nay, one might as well say that evolutionists consider a man indistinguishable from a cuttle-fish, since in their root and origin the vertebrate and molluscan types have been proved by Kovalevsky to be identical.

For the rest, Mr. Mivart evinces frequent want of sagacity as to the really vital points of the case in which he appears as an advocate. He takes great pains to show that some savage races have degenerated in civilization, and also that the intellectual difference between the lowest men and the highest apes far exceeds the structural differ- 
ence. But this is, after all, a misconception of the requirements of the argument; for on the one hand the Darwinian theory nowhere requires an uninterrupted progress, but rather implies a complicated backward and forward movement, of which an irregular progress is the differential result. And as to the second point, it is just one of the triumphs of Darwinism, as regards speculative consistency with facts, that it does account for the alteration in the series of effects which occurs as we approach the origin of mankind. For when intelligence has increased pari passu with physical advantages up to a certain point, the variations in intelligence begin to become more valuable than any variations in physical constitution, and consequently become predominantly subject to the operation of natural selection, to the comparative neglect of purely physical variations. A change of this sort, if prolonged for a sufficient length of time, would go far to account for the greatness of the mental difference between men and apes, as contrasted with the smallness of the structural difference.

That Mr. Mivart should fail to appreciate this point, long since suggested by $\mathrm{Mr}$. Wallace, is perhaps not to be wondered at, since he reduces the inquiry to a mere controversy in which he 
holds a brief against the Darwinians. What his own views may be as to the origin of man he nowhere explicitly states. But, in spite of his hostility to Mr. Darwin and his theories, he takes pains to proclaim limself an evolutionist - within such limits as a profound study of Suarez and St. Thomas Aquinas may determine.

December, 1876. 


\section{III.}

\section{DR. BATEMAN ON DARWINISM. ${ }^{1}$}

DR. Bateman's argument against Darwinism is based upon a fallacy which is quite commonly shared by those who have failed to comprehend the doctrine of evolution. ${ }^{2}$ This is the fallacy of supposing that the Darwinian theory can be overthrown simply by insisting upon the obvious fact that the intelligence and acquirements of man are enormously - almost incommensurably - greater than the intelligence and acquirements of the highest apes. As urged in the case of language, Dr. Bateman's argument is not original with him, as he seems to suppose ; it has already been urged by Max Müller, a writer far more distinguished for brilliancy of expression than for profundity of thought. In substance it consists of three propositions:-

I Darwinism Tested by Lanyuage. By Frederic Bateman, M. D. With a Preface by E. M. Goulburn, D. D., Dean of Norwich. London. New York: Scribner and Welford. 1878.

2 On this point see my Oudlines of Cosmic Philosophy, 1874, Part II., chaps. xxi., xxii. 
"1. That articulate speech is a distinctive attribute of man, and that the ape and lower an. imals do not possess a trace of it.

"2. That articulate speech is a universal at. tribute of man; that all races have a language, or the capacity of acquiring it.

"3. The immateriality of the faculty of speech."

It is perhaps hardly correct to call this last point a "proposition," nor is it easy to determine precisely its purport or its relevance. We are told farther on that, although "a certain normal and healthy state of cerebral tissue is necessary for the exterior manifestation of the faculty of speech," it by no means follows that speech is located in a particular portion of the brain, or is the "result of a certain definite molecular condition of the cerebral organ." Of course it does not follow; but the conclusion, however interesting to phrenologists and materialists, is irrelevant to the discussion of the Darwinian theory, or to that of the origin of language. In such inquiries all that any one needs to know is that the fiaculty of speech implies, among other things, the presence of a brain, and whether this "faculty" is to be called "immaterial" or not is quite beside the question.

Our author's argumentation, it will be rightly 
inferred, is more or less rambling in character. Returning to the two propositions which really make up lis argument, it is an obvious criticism that every sensible Darwinian will concede them both without a moment's hesitation. There is not the slightest evidence of the existence of a race of men destitute of articulate speech; and if apes or any other animals do possess the slightest trace of such an acquisition, it may safely be neglected on the principle of de minimis non curat lex. 1 It is only Dr. Bateman's imaginary Darwinian who finds it difficult to admit these plain facts. The actual supporters of this "dangerous heresy" have never gone out of their way to detect an historical substratum for Reynard or Essop, or to hunt from its obscurity the Leibnitzian story of the Latinspeaking dog; there are some of them, we fear, who would even, on general grounds, cast discredit on the story of Balaam. But if this be really the Darwinian state of mind, then $\mathrm{Dr}$. Bateman's work is plainly a case of ignoratio elenchi, or what is otherwise called "barking up the wrong tree."

As regards the process, psychologieal and phys-

1 Neglected, or conceded, by the controversinlist, I mean: to the disinterested student of nature no fact, however small, is really triv. ial. 
iological, by which the faculty of articulate speech was acquired by mankind, no thorough explanation has yet been offered, either upon the Darwinian or upon any other theory. The socalled "borw-wow" or onomatopoetic theory is no doubt correct, so far as it goes, as a description of facts which have attended the acquisition of speech; but it hardly goes to the root of the matter. The power of enunciating sounds so as to communicate ideas and feelings is certainly an art, as much as the later acquired powers of writing or drawing. For the original acquisition of such an art two conditions were requisite - the physiological capacity of the vocal organs for producing articulate sounds, and the psychological capacity of abstraction implied in the conception of a sign or symbol. There must also have been required - as underlying the last-named capacity - the possession of a certain amount of mental flexibility, or inventiveness, or capability of framing new combinations of ideas. This sort of mental flexibility is found among animals in man alone, and in his case it is the accompaniment, and probably the result, of an exceptionally long period of infancy. The significance of infancy, psychologically, is that it is a period during which a great number of all-important nervous combina- 
tions are formed after birth under the influence of outward circumstances which slightly vary from generation to generation. Where there is no infancy, all the most important nervous combinations are established before birth, and under the unmodified influence of the porverful conservative tendency of heredity. Where there is an infancy, many important nervous combinations are not formed until after birth, and the strictly conservative tendency of heredity is liable to be modified by the fact that the experience of the offspring amid environing circumstances is not likely to be precisely the same as that of the parent. The prolongation of infancy, therefore, increases the opportunities for the production of a mental type more plastic than that which is witnessed in the lower animals; it paves the way for inventiveness and for progress. It is, furthermore, the increased variety of experience resulting from this increased mental plasticity that leads to the power of abstraction and generalization the power of marking out and isolating in thought the element that is common to different groups of phenomena.

Now, in the first employment of articulated words by inchoate man, who had hitherto only grunted or howled, the main point to be inter. 
preted psychologically is the inventive turn of mind which could establish an association between a number of vocal sounds and a corresponding number of objects, and which could appreciate the utility of such an association in facilitating concerted action with one's fellowcreatures; though, as to the last point, the utility would be so enormous that the maintenance of the device, when once conceived, could never be in doubt. In the origination of language it is but the first costly step that requires considerdtion; but this step obviously involved no superhuman mystery. It was but an instance - though the greatest of all in its consequences - of that general psychical plasticity which characterizes the only animal which begins life with a considerable proportion of its nervous combinations undetermined.

It is not pretended that such considerations solve the problem of the origin of speech. They nevertheless go far toward putting it into its proper position, and indicating the class. of inquiries with which it must be grouped if it is to be treated in that broad philosophical way which can alone connect its solution with the fortunes of the Darwinian theory. The existence of language is not, as Max Müller's dicto imply, a fact 
in the universe that is isolated or sui generis in being incapable of scientific explanation. Immense as the fabric of human speech has grown to be, it is undoubtedly based on sundry acts of discovery or invention - not necessarily very conspicuous at the outset - among primeval semihuman sivages. The inventive acts which led to the systematic use of vocal sounds for the interchange of ideas, like the inventive acts which resulted in bows and arrows and in cookery, are to be regarded simply as instances of the general increase in psychical plasticity which has been the fundamental fact in the genesis of man intellectually. In other words, the existence of language is a fact no more wonderful than the general superiority of human over simian intelligence; and when it shall have been shown how the rigid mind of an ape might acquire plasticity, the problem of the origin of language, along with many other problems, will have been, ipso facto, more than half solved.

A grent step in this direction was taken by Mr. Wallace, when he pointed out that when variations in intelligence have become, on the whole, more useful to a race of animals than variations in physical constitution, then natural selection must seize upon the former to the rela. 
tive neglect of the latter. This conclusion follows inevitably from the theory of natural selection as conceived by Mr. Darwin; and it further follows, with equal cogency, that when this point is reached an entirely new chapter is opened in the history of the evolution of life. A race which maintains itself by psychical variations can never, by natural selection, give rise to a race specifically different from itself in a zoölogical sense. It may go on adding increments to its intelligence until it evolves Newtons and Beethovens, while its physical structure will undergo but slight and secondary modifications. Obviously, the first beginning of such a race of creatures, though but a slight affair zoölogically, was, in the history of the world, an event quite incomparable in importance with any other instance of specific genesis that ever occurred. It constituted a new departure, so to speak, not inferior in value to the first beginning of organic life. From Mr. Spencer's researches into the organization of correspondences in the nervous system it follows that the general increase of intelligence cannot be carried much farther than it has reached in the average higher mammalia without necessitating the genesis of infancy. The amount of work to be done by the developing nervous system of the offspring, in reproducing the varinus combinations achieved 
by the parental nervous system, becomes so considerable that it cannot all be performed before birth. A considerable and increasing number of combinations have to be adjusted after birth; and thus arise the phenomena of infancy. Among mammalia the point at which this change becomes observable lies between the true monkeys and the man-like apes. The orang-outang is unable to walk until a month old, and its period of babyhood lasts considerably longer.

The establishment of infancy is the most important among the series of events which resulted in the genesis of man. For, on the one hand, the prolongation of this period of immaturity had for its direct effect the liberation of intelligence from the shackles of rigid conservatism by which the unchecked influence of heredity had hitherto confined it. On the other hand, as its indirect effect, the prolongation of the period of helplessness served to inangurate social life by establishing the family, and thus prepared the way for the development of the moral sense. It is by following out this line of inquiry that we shall elucidate the question of the causes of man's enormous intellectual superiority over his nearest zoölogical congeners. Meanwhile, and until further light shall have been thrown upon such incidental questions as the inventiveness displayed in the 
origin of language, the Darwinian is in no wise debarred, by any logical necessity of his position, from fully recognizing the fact of this enormous superiority. Writers like Dr. Bateman argue as if they supposed Darwinians to be in the habit of depicting the human race as a parcel of naked, howling troglodytes. They "point with pride" to Parthenons and Iliads, and ask us to produce from his African forests some gorilla who can perform the like. These worthy critics should first try to grasp the meaning of the contrast, that while zoölogically man presents differences from the higher catarrhine apes that are barely of generic value, on the other hand the psychological difference is so great as, in Mr. Mivart's emphatic language, to transcend the difference between an ape and a blade of grass. After duly reflecting on this, with the aid to be derived from Mr. Wallace's suggestion above cited, they will perhaps be able to comprehend how it is that the Darwinian, without ignoring the immensity of this difference, seeks, nevertheless, by working hypotheses to bring it out of the region of barren mystery into that of scientific interpretation. When they have once got this through their heads, such trash as Dr. Bateman's will no longer get published.

November, 1878. 


\section{IV.}

DR. BƯCHNER ON DARWINISM. ${ }^{1}$

THE words " materialist" and "atheist" have been so long employed as death-dealing epithets in the hands of hard-hitting theological controversialists that it seems hardly kind in us to begin the notice of a somewhat meritorious book by saying that it is the work of a materialist and an atheist. We are reassured, however, by the reflection that these are just the titles which the author himself delights in claiming. Dr. Büchner would regard it as a slur upon his mental fitness for philosophizing if we were to refuse him the title of atheist; and "materialism" is the name of that which is as dear to him as "liberty" was dear to the followers of Danton and Mirabeau. Accordingly, in applying these terms to Dr. Büchner, they become divested of their old opprobriousness, and are enabled to discharge the proper

1 Man in the Past, Present, and Future. A Popular Account of the Results of Recent Scientific Research as regards the Origin, Posi. tion, and Prospects of the Human Race. From the German of Dr. L. Büchmer, by W. S. Dallas, F. L. S. London, 1872. 
function of descriptive epithets by serving as abstract symbols for certain closely allied modes of thinking. Considered in this purely philosophical way, an "atheist" is one to whom the timehonoured notion of Deity has become a meaningless and empty notion; and a "materialist" is one who regards the story of the universe as completely and satisfactorily told when it is wholly told in terms of matter and motion, without reference to any ultimate underlying Existence, of which matter and motion are only the phenomenal manifestations. To Dr. Büchner's mind the criticism of the various historic conceptions of godhood has not only stripped these conceptions of their anthropomorphic vestments, but has left them destitute of any validity or solid content whatever; and in similar wise he is satisfied with describing the operations of nature, alike in the physical and psychical worlds, as merely the redistributions of matter and motion, without seeking to answer the inquiry as to what matter and motion are, or how they can be supposed to exist as such at all, save in reference to the mind by which they are cognized.

Starting, then, upon this twofold basis, - that the notion of God is a figment, and that matter in motion is the only real existence, - Dr. Büchner 
seeks in the present work to interpret the facts disclosed by scientific induction concerning the origin of man, his psychical nature, his history, and his destiny as a denizen of the earth. With reference to these topics Dr. Büchner is a follower of Mr. Darwin, especially of Mr. Darwin as amended by Professor Haeckel. His book, considered on its scientific merits only, and without regard to its philosophic bearings, is a popular exposition of the Darwinian theory as applied to the origin of the human race. Regarded simply as a scientific exposition, conducted on these fundamental principles, there is in the book little which calls for criticism. Dr. Büchner has studied the Darwinian theory very thoroughly, and his statements in illustration of it are for the most part very accurate, showing, so far as this portion of the work is concerned, the evidences of a truly scientific spirit. He is as lucid, moreover, as Taine or Haeckel, and nothing is wanting to one's entire enjoyment of his book, save that modesty in the presence of the limitless workings of nature in which Dr. Büchner is far more deficient than even 'Taine or Haeckel.

But from the scientific point of view it is not necessary for us to discuss Dr. Büchner's book, as it is not an original scientific treatise, but only a 
lucid exposition of the speculations and discoveries of other students of nature. When we have described it as in the main lucid and accurate, we have given it all the praise which as a scientific exposition it can legitimately claim to have earned. When we consider it as a contribution to philosophy, when we ask the question whether it can be of any use to us in solving the great problem of our relations to the universe in which we live and move and have our being, we must set down quite another verdict. As an exposition of Darwinism, the work, though by no means all that could be desired, is still an admirable work. But as a vindication of the atheistic and materialistic way of explaining the universe, it is an utter failure. To suppose that the establishment of the Darwinian theory of man's origin is equivalent to the vindication of materialism and atheism is a mistake of Dr. Büchner's which would be very absurd were it not so very serious. Mr. Darwin's theory only supposes that a certain aggregate of phenomena now existing has had for its antecedent a certain other and different aggregate of phenomena. The entire victory of this theory will only - like the previous victory of Newton's theory over the doctrine of guiding angels, esponsed even by Kepler - assure us that in the entire series of 
phenomenal manifestations of which the world is made up there is no miraculous break, no conjuring, no freak of the magician. And to this conclusion all modern scientific inquiry has long been leading us. It reeded no Dr. Büchner to tell us this.

All this, however, cannot stir us one inch toward the philosophic doctrine of which Dr. Büchner is the advocate. Dr. Büchner shares with the theologians whom he combats the error of supposing that godhood cannot be manifested in a regular series of phenomena, but only in fortuitous miraculous surprises. When he has proved that mankind was originated through the ordinary processes of paternity from some lower form of life, he thinks he has overturned the belief in God, whereas he has really only overturned a crude and barbarous conception of the way in which God acts. And so when it is shown that all the phenomena of the world can be explained in conformity to a doctrine of evolution which originated in the study of material phenomena, our author thinks that the ground-theorem of materialism is forever established; quite forgetting that what we call material phenomena are, after all said and done, nothing but expressions for certain changes occurring in a complicated series of psychical states. 
In short, no matter how far the scientific interpretation of nature may be carried, it can reveal to us only the fact that the workings of the ultimate Existence of which Nature is the phenomenal expression are different from what they were supposed to be by uninstructed thinkers of former times. And no matter how far we may carry the interpretation of natural phenomena in terms of matter and motion, we cannot escape the conchusion that matter and motion, as phenomenal manifestations, can have no genuine existence save as the correlatives of a cognizing mind. To treat of the universe of phenomena without the noumenon God is nonsense; and likewise to treat of matter (a congeries of attributes) without reference to the mind in whose cognizance alone can attributes have any existence is also nonsense. However praiseworthy, therefore, Dr. Büchner's book may be as an exposition of a particular set of scientific doctrines, we think it can have but small value as a contribution to philosophy. Its author is one of those men who see very distinctly what they really see, but who in reality see but a very little way before them

November, 1872. 


\section{V.}

A CRUMB FOR THE "MODERN SYMPOSIUM."

No one to whom the question of man's destiny is a matter of grave speculative concern can have read, without serious and solemn interest, the discussion lately called forth in England by Mr. Frederic Harrison's essay on "The Soul and Future Life." 1 In no way, perhaps, could the darkness of incomprehensibility which enshrouds the problem be more thoroughly demonstrated than by the candid presentation of so many diverse views by ten writers of very different degrees of philosophic profundity, but all of them able and fair-minded, and all of them actuated - each in his own way - by a spirit of religions faith. This last clause will no doubt seem startling, if not paradoxical, to many who have not yet come to realize how true it is that there is often more real faith in honest scepticism than in languid or tim-

1 "A Modern Symposium," The Nineteenth Century, 1877, i. 623, 832: ii. 329, 497. The articles are all reproduced in America, in The Popular Science Monthly Supplement, Nos. 1, 2, 6, and 7, and have been published in book form at Toronto, Canada. 1878. 


\section{A Crumb for the "Modern Symposium." 57}

orous assent to a half-understood creed. But no paradox is intended. I believe that there is as much of the true essence of religion - the spirit of trust in God that has ever borne men triumphantly through the perplexities and woes of the world, and the possession of which, in some degree, by most of its members, is the chief differential attribute of the human race - I believe that there is as much of this spirit exhibited in the remarks of Professor Huxley as in those of Lord Blachford. In the serenity of mood with which the great scientific sceptic awaits the end, whatever it may prove to be; in the unfluching integrity with which his intellect refuses to entertain theories that do not seem properly accredited; in the glorious energy with which, accepting the world as it is, he performs with all his might and main the good work for which he is by nature fitted - in all this I can see the evidence of a trust in God no less real than that which makes it possible for his noble Christian friend to "believe because he is told." I am sure that I understand Professor Huxley's attitude; I think I understand Lord Blachford's, also ; and it seems to me that the difference between the two attitudes, wide as it is, is still a purely intellectual difference. It has its root in differently blended 
capacities of judgment and insight, and in no wise fundamentally affects the religious character.

It will be well for the world when this lesson has been thoroughly learned, so as to leave no furtlier room for misapprehension. That great progress has already been made in learning it we need no other proof than the mere existence of this "Modern Symposium" on the subject of a future life. Three centuries ago it would have been in strict accordance with propriety for the ten disputants to have adjourned their symposium to some ecclesiastical court, preparatory to a final settlement at Smithfield. One century ago there would have been wholesale vituperation, attended with more or less imputation of unworthy motives, and very likely there would have been some Jesuitical paltering with truth. To-day, however, the tremendous question is discussed on all sides - alike by Protestant and Catholic, by transcendentalist, sceptic, and positivist - with evident candour and praiseworthy courtesy; for, in spite of Professor Huxley's keen-edged wit and Mr. Harrison's fervent heat, there is no one so fortunate as to know these gentlemen who does not know that manly tenderness and good feeling are by no means incompatible with the ability 
A Crumb for the "Modern Symposium." 59 to exchange good hard blows in a fair English fight.

It is with some diffidence that I venture to add my voice to a conversation carried on by such accomplished speakers, but the present seems to be a proper occasion for calling attention to some of the misconceptions which ordinarily cluster around the treatment of questions relating to the soul and a future life. In thus entering upon the discussion, I do not feel called upon to defend any particular solution of the main question at issue. Going by the "light of Nature" alone - to use the old-fashioned phrase - it will be generally conceded that the problem of a future life is so abstruse and complicated that one is quite excusable for refraining from a dogmatic treatment of it. Nay, one is not only excusable, one is morally bound not to dogmatize unless one has a firmer basis to stand on than any of us are likely to find for some time to come. We may entertain hypotheses in private, but we are hardly entitled to urge them upon our friends until we feel assured, in the first place, that we have duly fathomed the conditions requisite for a rational treatment of the problem.

It would appear that some of the participators in the "Modern Symposium" have not sufficiently 
heeded this obvious maxim of philosophic cau. tion. Loose talk about "materialism" is apt to imply loose thinking as to the manner in which the metaphysical relations of body and soul are to be apprehended. Perhaps Mr. Harrison, as a positivist, will say that he has nothing to do with apprehending the metaphysical relations between body and soul; but, however that may be, there is some laxity of thought exhibited in charging Professor Huxley with "materialism" because he speaks of "building up a physical theory of moral phenomena." To try to explain conscience, with metaphysical strictness, as a result of the grouping of material molecules, is something which I am sure Professor Huxley would never think of doing; but, unless I am entirely mistaken on this point, there is no ground for $\mathrm{Mr}$. Harrison's charge of materialism.

To see Professor Huxley charged with materialism, and in a reproachful tone withal, by a positivist who does not acknowledge the existence of a soul, save in some extremely Pickwickian sense, is a strange, not to say comical, spectacle. "What next?" one is inclined to ask. Positivists are apt to have, indeed, an ecclesiastical style of expression, and one would almost think, from his manner, that Mr. Harrison was making com- 
A C'rumb for the "Modern Symposium." 61

mon cause with theologians. Into the explanation of this curious phenomenon I cannot here profitably enter. The reasons for it are somewhat recondite, and are subtly linked with the general incapacity, under which positivists seern to labour, of understanding the real import of the doctrine of evolution. However this may be, the impression that the group of opinions represented by Mr. Spencer and Professor Huxley are materialistic is so widely spread that it is worth our while to spend a fer moments in ascertaining what materialism is, and how far it is involved in recent scientific speculations. Is the present drift of scientific thought really setting toward materialism, or is it not?

No epithets are more familiarly used nowadays than " materialism" and "materialist," but their ordinary function is vituperative rather than logical. As vague terms of abuse they are hurled about with a zeal that may be praiseworthy, but with an indiscreetness that is scarcely commendable, being aimed, as often as not, at the heads of writers who doubt or deny the substantial existence of matter altogether! Such blunders show (among other things) how difficult metaphysical studies are, and indicate that a little more care expended upon analysis and definition 
would not be thrown away. It is true that something has already been said upon this point enough, one would think, to obviate the necessity of turning back to slay the resuscitated ghosts of thrice-slaughtered misconceptions. On the character of materialism as a philosophical hypothesis, Mr. Spencer has been tolerably explicit. Professor Huxley has summed up the case with his customary felicity, at the close of that famous Edinburgh lecture which everybody is supposed to have read." In my work on "Cosmic Philosophy," I have devoted a very plain-spoken chapter to the subject. Nevertheless, as Mr. Freeman says, it is not a bad plan, when you have once got hold of a truth, to keep hammering it into people's heads on all occasions, even at the risk of being voted a tedious bore or a viction of crotchets. We live in a hurried and not over-intelligent world, wherein the wariest of us do not always pay due heed to what we are told, and the keenest do not always divine its sense; but, after we have heard it repeated fifty times that Alfred was an Englishman, and Charles the Great was not a Frenchman, we may perhaps succeed in waking up to the historical import of such statements. In this pithy though somewhat cyn-

1 "The Physical Basis of Life," Lay Sermons, p. 160. 
A Crumb for the "Modern Symposium." 63 ical suggestion I shall seek an excuse for recurring here to what I have said more than once already. ${ }^{1}$

From one point of view materialism may be characterized as a system of opinions based on the assumption that matter is the only real existence. On this view the phenomena of conscious intelligence are supposed to be explicable, as momentary results of fleeting collocations of material particles, as when a discharge between two or more cells of grey cerebral tissue is accompanied by what we call a thought. It requires but little effort to see that materialism, as thus defined, does not comport well with the most advanced philosophy of our time. Materialism of this sort has plenty of defenders, no doubt, but not among those who are skilled in philosophy. The untrained thinker, who believes that the group of phenomena constituting the table on which he is writing has an objective existence independent of consciousness, will probably find no difficulty in accepting this sort of materialism. If he is devoted to the study of nervous physiology, be will be very likely to adopt some such crude notion, and to proclaim it as zealously as if it were a very important truth, calculated to promote, in many

1 Outlines of Cosmic Philosophy, ii. 79. 432-451. The Tnseen World, เ1, 53. 
ways, the welfare of mankind. The science of such a writer is very likely to be sound and valuable, and what he tells us about woorara-poison and frogs' legs, and acute mania, will probably be worthy of serious attention. But with his philosophy it is quite otherwise. When he has proceeded as far in subjective analysis as he has in the study of nerves, our materialist will find that it was demonstrated, a century ago, that the group of phenomena constituting the table has no real existence whatever in a philosophical sense. For by "reality" in philosophy is meant "persistence irrespective of particular conditions," and the group of phenomena constituting a table persists only in so far as it is held together in cognition. Take away the cognizing mind, and the colour, form, position, and hardness of the table - all the attributes, in short, that characterize it as matter. - at once disappear. That something remains we may grant, but this something is unknown and unknowable: it is certainly not the group of phenomena constituting the table. Apart from consciousness there are no such things as colour, form, position, or hardness, and there is no such thing as matter. This great truth, established by Berkeley, is the very foundation of modern scientific philosophy; and, though it has been misap- 
A Crumb for the "Modern Symposium." 65 prehended by many, no one has ever refuted it, and it is not likely that any one ever will. Concerning the value of Berkeley's idealism, when taken with all its ontological implications, there is plenty of room for disagreement; but his psychological analysis of the relation of consciousness to the external world is of such fundamental importance that, until one has mastered it, one has no right to speak on philosophical questions. It is not unfair to say that materialists, as a rule, have not mastered the Berkeleian psycholingy, or given much attention to it. In general, their attention has been too much occupied with filaments and ganglia, to the neglect of that close subjective analysis which they unwisely stigmatize as dreamy metaphysic. Hence, on the whole, materialism does not represent anything of primary importance in modern philosophy; it represents rather the crude speculation of that large and increasing number of people who have acquired some knowledge of the truths of physical science, without possessing sufficient subtlety to apprehend their metaphysical bearings. Büchner, the favorite spokesman of this class of people, occupies a position precisely similar to that of Lamettrie in the last century, and will, no doubt, in the days of our grandchildren be as thoroughly 
forgotten as his predecessor, while the same barl'en platitudes will be echoed by some new writer in the scientific phraseology then current.

But there is another way of looking at materialism which makes it for a moment seem important, and which serves to explain, though not to justify, the alarm with which many excellent people contemplate the progress of modern science. A conspicuous characteristic of materialism is the endeavour to interpret mind as a product - as the transient result of a certain specific aggregation of matter. To a person familiar with post-Berkeleian psychology it seems clear that such an endeavour is quite hopeless, and that no such interpretation of mind can ever be made. But a multitude of very respectable readers, who are not so profoundly conversant with metaphysics as Spencer and Huxley, have taken it into their heads that the doctrine of evolution is advancing with rapid strides towards just such an interpretation of mind; and hence it is quite common to allude to Spencer and Huxley as "materialists," which, to my mind, is very much as if one were to allude to Mr. Wendell Phillips as a distinguished pro-slavery orator.

The mistake, however, is not unnatural when we consider its causes. In point of fact the ter. 
A Crumb for the "Modern Symposium." 67 minolngy of science is thoronghly materialistic, though probably not more so than the language of ordinary discourse. It is intensely materialistic for us to speak of the table as if it had some objective existence, independent of a cognizing mind; and yet, in common parlance, we invariably allude to the table in terms which imply or suggest such an independent existence. Just so in theoretical science. In describing the development of life upon the eartli's surface, when we say that consciousness appeared on the scene pari passu with the appearance of nervous systems, it is not strange if we are supposed to mean that consciousness is somehow produced by a peculiar arrangement of nervous tissue - that "spirit" is in some way or" other evolved from " matter."

In reality, however, nothing of the kind is intended. Laxity of speech is mainly responsible for the misapprehension. The evolutionist, in describing the course of life upon the earth, is simply imparting to us, so far as he is able, a piece of historical information. Through various complex and indirect processes of inference, he has become capable of telling us, with some probability, how things would have looked to us in the remote past if we had been there to sce. $\mathrm{He}$ tells us that if we had been on hand in palæozoic 
ages we should not have seen the phenomena of consciousuess manifested in connection with a fragment of porphyry, or a handful of sand, or a tree-fern, any more than we see such things to. day, but only in connection with animals endowed with nerves. In thus extending the results of present experience to the past, the element of sequence in time is introduced in such a way as to suggest the causation of consciousness by nervematter. Nerertheless, the assertion of the evolutionist is purely historical in its import, and includes no hypothesis whatever as to the ultimate origin of consciousness; least of all is it intended to imply that consciousmess was evolved from matter. It is not only inconceivable how mind should have been produced from matter, but it is inconceivable that it should have been produced from matter, unless matter possessed already the attributes of mind in embryo, - an alternative which it is difficult to invest with any real meaning. The problem is altogether too abstruse to be solved with our present resources. But it is curious to héar honest theologians gravely urging against Mr. Spencer that you cannot obtain mind from the "primordial fire-mist" unless the germs of mind were somehow present already. I hope I am not accrediting Mr. Spencer with any opinion 
he does not hold, and I speak subject to correction; but, if my memory serves me, I have more than once heard him in conversation urging this very objection to any materialistic interpretation of evolution. His wonderfully subtle chapter on "The Substance of Mind" 1 contains, as I understand it, the same argument; but it is easy to miss an author's meaning sometimes when the point expounded is so formidably abstract and general.

Be this as it may, we are not helped much by supposing the germs of mind to have been somehow latent in the primeval nebula. The notion is too vague to be of any use. The only point on which we can be clear is that no mere collocation of material atoms could ever have evolved the phenomena of consciousness. Beyond this we cannot go. We are confronted with an insoluble metaphysical problem. Of the origin of mind we can give no scientific account, but only an historical one. We can say when (i. e., in connection with what material circumstances) mind came upon the scene of evolution; but we can neither say whence, nor how, nor why. In just the same

1 Principles of Psycholoyy, second edition, ii. 145-162. [On referring this point to Mr. Spencer, he desires me to add that I am quite correct in my recollection of his conversations and in my interpreta. tion of his position.] 
way we see to-day that mind appears in connection with certain material circumstances, but we cannot see how or why it is so. Least of all can we say that the material circumstances produce mind; on the contrary, we can assert most positively that they do not.

The proof of this rather dogmatic assertion is to be found in the careful study of that very doctrine of the "correlation of forces" which superficial materialists have exultingly claimed as their own, and which their superficial opponents have foolishly conceded to them. We have been wont to hear this doctrine - the crowning achievement of modern science - decried as lending support to materialism. If this were really so, we anti-materialists would have a poor case, for the doctrine in question is established beyond all possibility of refutation. But it is not really so. On the contrary, the final and irretrievable discomfiture of materialism follows as a direct corollary from the discovery of the colrelation of forces.

By the loose phrase, "correlation of forces," what is strictly meant is the transformation of one kind of motion into another lind. What used to be called the "physical forces" - such as light, heat, magnetism, and electricity - are now known to be peculiar kinds of motion among the 
A Crumb for the "Modern Symposium." 71 imperceptible molecules of which perceptible bodies are composed. The discovery of the "correlation of forces" was the discovery of the fact that any one of these kinds of molecular motion is constantly liable to be transformed into any one of the other kinds, or, now and then, into the molar motion of a perceptible body. Heat is all the time being converted into light, or into electricity, or into the peculiar kind of undulatory motion known as "nerve-force" - and vice versa. And the law of the correlation is that, when any one of these species of motion appears, an equivalent amount of some other species disappears in producing it. Throughout the world the sum-total of motion is ever the same, but its distribution into heat-waves, light-waves, nerve-waves, etc., varies from moment to moment.

Let us now apply these principles to the case of an organism such as the human body. All of the "force" - i.e., capacity of motion - present at any moment in the human body is derived from the food that we eat and the air that we breathe. As food is turned into oxygenated blood and assimilated with the various tissues of the body - which themselves represent previously-assimilated food - the molecular movements of the food-material become variously combined intn molecular move. 
ments in tissue - in muscular tissue, in adipose, in cellular, and in nerve tissue, and so on. Every undulation that takes place among the molecules of a nerve represents some simpler form of molecular motion contained in food that has been assimilated; and, for every given quantity of the former kind of motion that appears, an equivalent quantity of the latter kind disappears in producing it. And so we may go on, keeping the account strictly balanced, until we reach the peculiar discharge of undulatory motion between cerebral ganglia that uniformly accompanies a feeling or state of consciousness.

What now occurs? Along with this peculiar form of undulatory motion there occurs a feeling - the primary element of a thought or of an emotion. But does the motion produce the feeling, in the same sense that heat produces light? Does a given quantity of motion disappear, to be replaced by an equivalent quantity of feeling? By no means. The nerve-motion, in disappearing, is simply distributed into other nerve-motions in various parts of the body, and these other nerve-motions, in their turn, become variously metamorphosed into motions of contraction in muscles, motions of secretion in glands, motions of assimilation in tissues generally, or into yet 
other nerve-motions. Nowhere is there such a thing as the metamorphosis of motion into feeling or of feeling into motion.

Of course I do not mean that the circuit, as thus described, has ever been experimentally traced, or that it can be experimentally traced. What I mean is that, if the law of the "correlation of forces" is to be applied at all to the physical processes which go on within the living organism, we are of necessity bound to render our whole account in terms of motion that can be quantitatively measured. Once admit into the circuit of metamorphosis some element - such as feeling - that does not allow of quantitative measurement, and the correlation can no longer be established; we are landed at once in absurdity and contradiction. So far as the correlation of forces has anything to do with it, the entire circle of transmutation, from the lowest physico-chemical motion all the way up to the highest nerve-motion and all the way down again to the lowest physicochemical motion, must be described in physical terms, and no account whatever can be taken of any such thing as feeling or conscimasness.

On such grounds as these I maintain that feeling is not a product of nerre-motion in anything like the sense that light is sometimes a product 
of heat, or that friction-electricity is a product of sensible motion. Instead of entering into the dynamic circuit of correlated physical motions, the phenomena of consciousness stand outside as utterly alien and disparate phenomena. They stand outside, but uniformly parallel to that segment of the circuit which consists of neural undulations. The relation between what goes on in consciousness and what goes on simultaneously in the nervous system may best be described as a relation of uniform concomitance. I agree with Professor Huxley and Mr. Harrison that along with every act of consciousness there goes a molecular change in the substance of the brain, involving a waste of tissue. This is not materialism, nor does it alter a whit the position in which we were left by common sense before nervous physiology was ever heard of. Everybody knows that, so long as we live on the earth, the activity of mind as a whole is accompanied by the activity of brain as a whole. What nervous physiology teaches is simply that each particular mental act is accompanied by a particular cerebral act. In proving this, the two sets of phenomena, mental and physical, are reduced each to its lowest terms, but not a step is taken toward confounding the one set with the other. On the contrary, the 
A Crumb for the "Modern Symposium." 75

keener our analysis, the more clearly does it appear that the two can never be confounded. The relation of concomitance between them remains an ultimate and insoluble mystery.

I believe, therefore, that modern scientific philosophy, as represented by Spencer and Huxley, not only affords no support to materialism, but condemns it utterly, and drives it off the field altogether. I believe it is even clearer to-day than it was in the time of Descartes that no possible analytic legerdemain can ever translate thought into extension, or extension into thought. The antithesis is of God's own making, and no wit of man can undo it.

The bearing of these arguments upon the question of a future life may be very briefly stated. So far as I can judge, I should say that, among highly-educated people, the belief in a continuance of conscious existence after death has visibly weakened during the present century. I infer this as much from the timorousness of conservative thinkers as from the aggressiveness of their radical opponents. In so far as this weakening of belief is due to an imperfect apprehension of the scientific discoveries which our age has witnessed in such bewildering rapidity, a word of caution may not be out of piace. For all that 
physiological psychology has achieved there is no more ground for doubt as to a future life to-day than there was in the time of Descartes: whatever grounds of belief were really valid then are equally valid now. The belief has never been one which could be maintained on scientific grounds. For science is but the codification of experience, and it is helpless without the data which experience furnishes. Now, science may easily demolish materialism and show that mind cannot be regarded as a product of matter, but the belief in a future life requires something more than this for its support. It requires evidence that the phenomena we class as mental can subsist apart from the phenomena we class as material; and such evidence, of course, cannot be furnished by science. It cannot be furnished until we have had some actual experimental knowledge of soul as dissociated from body, and under the conditions of the present life no such knowledge can possibly be obtained.

But this undoubted fact has a twofold import. While on the one hand it shuts us off from all scientific proof of immortality, on the other hand it shows that the absence of scientific proof affords no valid ground for a negative conclusion. If soul can exist when dissociated from body, we have no 
A Crumb for the "Modern Symposium." 77 means of apprehending the fact; and therefore our inability to apprehend it does not entitle us to deny that soul may have some such independent existence. "We camnot allow the materialist even this crumb of consolation, - that, althongh he cannot prove that consciousness ceases with death, nevertheless the presumption is with him and the burden of proof upon his antagonists. Scientifically speaking, there is no presumption either way, and there is no burden of proof on either side. The question is simply one which science cannot touch. In the future, as in the past, I have no doubt it will be provisionally answered in different ways by different minds, on an estimate of what is called "moral probability," just as we see it diversely answered in the "Modern Symposium."

For my own part, I should be much better satisfied with an affirmative answer, ${ }^{1}$ as affording perhaps some unforeseen solution to the general mystery of life. I have no sympathy with those who stigmatize the hope of immortal life as selfish or degrading, and with Mr. Harrison's proffered substitute I confess I have no patience whatever. This travesty of Christianity by Positivism seems

1 For a more complete expression of my view of the case see The Destiny of Man, pp. 108-119. 
to me, as it does to Professor Huxley, a very sorry business. On the other hand, I cannot agree with those who consider a dogmatic belief in another life essential to the proper discharge of our duty in this. Though we may not know what is to come hereafter, we have at any rate all the means of knowledge requisite for making our present lives pure and beautiful. It was Jehovah's cherished servant who declared in Holy Writ that his faith was stronger than death. There is something overwhelming in the thought that all our rich stores of spiritual acquisition may at any moment perish with us. But the wise man will cheerfully order his life, undaunted by the metaphysical snares that beset him; learning and learning afresh, as if all eternity lay before him - battling steadfastly for the right, as if this day were his last. "Disce ut semper victurus, vive ut cras moriturus."

December, 1877. 


\section{VI.}

\section{CHAUNCEY WRIGHT. ${ }^{1}$}

THE sudden and untimely death of Mr. Chauncey Wright, in September, 1875, was an irreparable loss not only to the friends whose privilege it had been to know so wise and amiable a man, but to the interests of sound philosophy in general. To some, perhaps, there may seem to be extravagance in speaking of any such loss to philosophy as irreparable; for in the great work of the world wo are accustomed to see the ranks close up as heroes fall by the way, and when we come to reckon up the sum of actual achievement, in our thankfulness over the calculable results obtained we seldom take heed of those innumerable unrealized possibilities upon which in the nature of things we can place no just estimate. Of course it is right, as it is inevitable, that this should be so. There is, however, a point of view from which

1 Philosophical Discussions. By Chauncey Wright. With a Biographical Sketch of the Author by Charles Eliot Norton. New York: Henry Holt \& Co. 1876. 
it may be fairly urged that the work which rare and original minds fall short of doing because of straitened circumstances or brevity of life does never really get done at all. Something like it gets performed, no doubt, but it gets performed in a different order of causation; and though there may be an appearance of equivalence, the fact remains that, from the sum of human striving, an indefinite amount of rich and fruitful life has been lost. True as this is in the case of exact science, it is still more obviously true in specnlative science or philosophy. For the work of a philosopher, like the work of an artist, is the peculiar product of endless complexities of individual character. His mental tone, his shades of prejudice, his method of thought, are often of as much interest and value to mankind as any of the theories which he may devise; and thus it not seldom happens that personal familiarity with the philosopher is itself a most instructive lesson in philosophy.

In the case of Chauncey Wright, none save the friends who knew the rich treasures of his mind as shown in familiar conversation are likely to realize how great is the loss which philosophy has sustained in his death. For not only was he somewhat deficient in the literary knack of ex. 
pressing his thoughts in language generally intelligible and interesting, but he was also singularly devoid of the literary ambition which leads one to seek to influence the pablic by written exposition. Had he possessed more of this kind of ambition, perhaps the requisite knack would not have been wanting; for Mr. Wright was by no means deficient in clearness of thought or in command of language. The difficulty - or, if we prefer so to call it, the esoteric character - of his writings was due rather to the sheer extent of their richness and originality. His essays and review-articles were pregnant with valuable suggestions, which he was wont to emphasize so slightly that their significance might easily pass unheeded; and such subtle suggestions made so large a part of his philosophical style that, if any of them chanced to be overlooked by the reader, the point and bearing of the entire argument was liable to be misapprehended. His sentences often abounded in terse allusive clauses or epithets which were unintelligible for want of a sufficient clue to the subject-matter of the allusion: in the absence of an exhaustive acquaintance with the contents of the author's mind, the reader could only wonder, and miss the point of the incidental remark. Of such sort of obscure, though preg. 
nant, allusions we have an instance in the use made of the conception of a "spherical intelligence" in the essay on "The Evolution of SelfConsciousness," where the brief reference to the Platonic Timaios is by no means sufficient to relieve the strain upon the reader's attention. It is this too compact suggestiveness which makes this remarkable essay so hard to understand, and the exuberance of which half tempted Mr. Wright to give to the paper the very esoteric title of "The Cognition of Cogito." A writer who kept the public in his mind would not proceed in this way, but would more often give pages luminous with concrete illustrations where Mr. Wright only gave sentences cumbrous with epigrammatic terseness. If Mr. Wright did not keep the public in mind while writing, it was not from the pride of knowledge, for no feeling could have been more foreign to him; and there was something almost touching in the endless patience with which he would strive in conversation to make abstruse matters clear to ordinary minds. It was because, as a writer, he thought in soliloquy, using his pen to note down the course of his reasoning, but failing to realize the difficulty which others might find in apprehending the numerous and far-reaching connotations of phrases to him entirely familiar. 
It was only some such circumstances as these, joined to a kind of mental inertness which made some unusually strong incentive needful to any prolonged attempt at literary self-exposition, that prevented Chauncey Wright from taking rank, in public estimation, among the foremost philosophers of our time. An intellect more powerful from its happy union of acuteness with sobriety has probably not yet been seen in America. In these respects he reminds one of $\mathrm{Mr}$. Mill, whom he so warmly admired. Though immeasurably inferior to Mill in extent of literary acquirement, he was hardly inferior to him in penetrating and fertile ingenuity, while in native soberness or balance of mind it seems to me that Wright was, on the whole, the superior. In reading $\mathrm{Mr}$. Mill's greater works, one is constantly impressed with the admirable thoroughness with which the author's faculties are disciplined. Inflexible intellectual honesty is there accompanied by sleepless vigilance against fallacy or prejudice; and while generous emotion often kindles a warmth of expression, yet the jurisdiction of feeling is seldom allowed to encroach upon that of reason. Nevertheless there are numeroas little signs which give one the impression that this wonderful equipoise of mind did not come by nature altogether, 
but was in great part the result of consummate training, - of unremitting watchfulness over self. Some of his smaller political writings and the "Autobiography" entirely confirm this impression, and show that in Mr. Mill's mind there were not only immense enthusiasms, but even a slight tinge of mysticism. All the more praiseworthy seems his remarkable self-discipline in view of such circumstances.

Mr. Wright, though so nearly in harmony with Mr. Mill in methods and conclusions, was very different in native mental temperament. An illustration of the difference is furnished by the striking remarks in which Mr. Mill acknowledges - in common with his father - a preference for the experience-philosophy on utilitarian grounds: it obliges men to try their beliefs by tests that are perpetually subject to criticism, and thus affords no room for doctrines which, by reason of some presumed sanctity, men may find an excuse for trying to impose on one another. That there is profound truth in this no one can deny; but prejudice and partisanship are liable to grow out of any such practical preference for a given form of philosophy, and one cannot readily imagine Mr. Wright as influenced, even slightly, in his philosophic attitude by such a consideration of 


\section{Chauncey Wright.}

utility. His opinions were determined only by direct evidence, and to this he always accorded a hospitable reception. A mind more placid in its working, more unalloyed by emotional prejudice or less solicited by the various temptations of speculation, I have never known. Judicial candour and rectitude of inference were with him inborn. On many points his judgment might need further enlightenment, but it stood in no need of a rectifying impulse. No craving for speculative consistency, or what Comte would have called "unity" of doctrine, ever hindered him from giving due weight to opposing, or even seemingly incompatible, considerations. For, in view of the largeness and complexity of the universe, he realized how treacherous the most plausible generalizations are liable to prove when a vast area of facts is to be covered, and how great is the value of seemingly incongruous facts in prompting us to revise or amend our first-formed theories.

With these mental characteristics $\mathrm{Mr}$. Wright seems to have been fitted for the work of sceptical criticism, or for the discovery and illustration of specific truths, rather than for the elaboration of a general system of philosophy. As our very sources of mental strength in one direction may 
become sources of mental weakness in another, as we are very likely to have what the French would call "the defects of our excellences," so we may, perhaps, count it as a weakness, or at least a limitation, in Mr. Wright that he was some what over-suspicious of all attempts at constructing ideally coherent and comprehensive systems. That there is colierency throughout the processes of Nature he would certainly have admitted, in so far as belief in the universality of causation is to be construed as such an admission. But that there is any such discernible coherency in the results of causation as would admit of description in a grand series of all-embracing generalizations, I think he would have doubted or denied. Such denial or doubt seems, at least, to be implied in his frequent condemnation of cosmic or synthetic systems of philosophy as metaphysical "anticipations of Nature," incompatible with the true spirit of Baconism. The denial or doubt would have referred, perhaps, not so much to the probable constitution of Nature as to the possibilities of human knowledge. He would have argued that the stupendous group of events which we call the universe consists so largely of unexplored, or even unsuspected, phenomena that the only safe generalizations we can make concerning it must needs 


\section{Chauncey Wright.}

be eminently fragmentiry; and if any one had asked whether, after all, we have not great reason to believe that throughout the length and breadth and duration of the boundless and endless miverse there is an all-pervading coherency of action, such as would be implied in the theorem that all Niture is the manifestation of one Infinite Power, - to any such question he would probably have held that no legitimate answer can be given.

In this general way of looking at things we have the explinnation of Mr. Wright's persistent hostility to the philosophy of Herbert Spencer. This hostility is declared in his earliest essay, entitled "A Physical Theory of the Universe," and it is maintained in the paper on "German Darwinism," published only three days before his death, wherein great pains are taken to show that Mr. Spencer's puilosophy is utterly un-Baconian and unscientific, as resting, not upon inductive inquiry, but upon "undemonstrated beliefs assumed to be axiomatic and irresistible." In the first and last of my many conversations with Mr. Wright - in July, 1862, and in July, 1875 - I found myself charged with the defence of Mr. Spencer's philosophy against what then seemed, and still seems, to me a profound misunderstanding of its true 
character and purpose. As the point is one which goes as far as any other toward illustrating $\mathrm{Mr}$. Wright's philosophic position, and as it has an immediate bearing on the vexed question of science and religion, I will crave the reader's indulgence while I illustrate it briefly here.

Doctors are proverbially known to disagree, whether they be doctors in philosophy or in medicine; but I have often thought that an interesting case might be made out by any one who should endeavour to signalize the half-hidden aspects of agreement rather than the conspicuous aspects of difference among philosophic schools. Certainly, in the controversy which has been waged of late years concerning the sources of knowledge and the criterion of truth, one is inclined to suspect that a greater amount of antagonism has been brought to the surface than is altogether required by the circumstances. In old times, when you were asked why you believed that things would happen in future after much the same general fashion as in the past, there were two replies which you could make. If you were a believer in Locke, you would say that you trusted in the testimony of experience; but here the follower of Leibnitz would declare that you were very unwise, since experience can only tes- 
tify to what has happened already, and, so far as experience goes, you have n't an iota of warrant for your belief that the sun will rise to-morrow morning. Your trust in the constancy of Nature must be derived, therefore, from some principle inherent in the very constitution of your mind, implanted there by the Creator for a wise and beneficent purpose.

Once this transcendentalist argument was thought to have great weight, but of late years it has fallen irredeemably into discredit. For today the empiricist retorts with crushing effect that, precisely because we are wholly dependent on experience, and have no other quarter to go to for rules of belief and conduct, we cannot apply to the future any other rules of probability than those with which our experience of the past has furnished us. If we had any criterion of belief independent of experience, then we might perhaps be able to believe that on the earth a million years hence, or on Mars to-day, a piece of red-hot iron would not burn the hand. Were we not strictly hampered by experience, we might donbt the universality of causation. But being thus strictly hampered, we must either imagine the future under the same rules as those under which we remember the past, or else subside in a kind 
of mental chaos and form no expectations whatever. To this view of the case transcendentalism has as yet made no satisfactory rejoinder.

Our faith in the constancy of Nature results, therefore, from our inability to overcome or "go behind" the certified testimony of experience. Such is the primary psychological fact, about which there is no reason to suppose that $\mathrm{Mr}$. Wright and Mr. Spencer would disagree. But this, like many other facts, has two sides; or at least, there are two possible ways of interpreting it, and here arises the misunderstanding. On the one hand, our belief in the constancy of Nature - may be the result of an immense induction or counting up of the whole series of events which show that Nature is not capricious; or, on the other hand, it may be the generalization of a simple assumption which we make in every act of experience, and without which we could not carry on any thinking whatever. The first alternative is the one defended by Mr. Wright in common with Mr. Mill, while the second is the one more prominently insisted upon by Mr. Spencer. To me it seems that Mr. Spencer"s view is very much the more profound and satisfactory; but I fiil to see that there is necessarily any such practical antagonism between the two as is implied in re. 
cent controversies on the subject. On the other hand, it seems clear to me that the two views are simply two complementary or obverse aspects of the same fundamental truth.

At first siglst it may seem very bold to assert that in every act of our mental lives we make such a grand assumption as that of the constancy of Nature; but it is very certain that, in some form or other, we do keep making this assumption. Every time that the grocer weighs a pound of sugar and exchanges it for a piece of silver, the practical validity of the transaction rests upon the assumption that the same lump of iron will not counterbalance one quantity of sugar to-day and a different quantity to-morrow ; and a similar assumption of constancy in weight and exchangeability is made regarding the silver. The indestructibility of matter and the continuity or persistence of force are taken for granted, though neither the grocer nor his customer may have received enough mental training to understand these axioms when stated in abstract form. Nily, more, though they may be superstitious men, believing in a world full of sprites and goblins; though they may be so ignorant as to suppose that, when wood is burned and water dried up, some portions of matter are annihilated, - yet in each of these 
little practical transactions of life they go upon the same assumption that the philosopher goes upon when, with his wider knowledge and deeper insight, he rules out the goblins and declares that no matter is ever destroyed. Without this assumption in some form we could not carry on the work of life for a single day. The assumption, moreover, is absolutely unconditional; no occurrence ever shakes our reliance upon it. I set my clock to-day, and depend on its testimony to-morrow in starting on a journey: if I miss the train, I may conclude that the clock was not well regulated, or that it has begun to need cleaning; but it never occurs to me that my confidence in the mechanical laws of cog-wheels and pendulunis has been at all misplaced.

This universal and unqualified assumption of the constancy of Nature is, in a certain sense, a net result of experience, inasmuch as we find it tested and verified in every act of our conscious lives. Acting on the principle that "a pound is a pound, all the world around," we find that our mental operations harmonize with outward facts. Doubt it, if we could, and our mental operations would forthwith tumble into chaos. Experience, therefore, - by which is meant our daily intercourse with outward facts, - continually forces 
upon us this assumption. Along with whatever else we are taught about ourselves and the world, there comes as part and parcel the ever-repeated lesson that the order of Nature may be relied on. In this sense the belief may be said to be a net result of all our experience.

But this is by no means an adequate account of the matter. The case has another aspect, to which neither Mr. Mill nor Mr. Wright has done justice. How can the constancy of Nature be said to be proved by experience, when we begin by assuming it in each of the single acts of experience which, taken together, are said to prove it? Does not this look like reasoning in a circle? We are told that the constancy of Nature is proved for us by an unbroken series of experiences, beginning with our birth and ending with our death ; and yet not one of this series of experiences can have any validity, or indeed any existence, unless the constancy of Nature be tacitly assumed to begin with. It is the balance, we are told, which assures us that no particle of matter is ever lost; but in weighing things in a balance we must take it for granted that the earth's gravitative force is uniform, - is not one thing t(s-day and another to-morrow; nay, we must also assume that the present testimony of our senses will continue to 
be consistent in principle with their past testimony. Whatever system of forces we estimate or measure in support of our implicit belief in the constancy of Nature, we must sooner or later appeal to some fundamental unit of measurement which is invariable. Without some such constant unit we cannot prove that the order of Nature is uniform: but we cannot prove the constancy of such a unit without referring it to some other unit, and so on forever; while to assume the constancy of such a unit is simply to assume the whole case.

It would seem, therefore, that our belief in the trustworthiness of Nature is not properly described when it is treiterl simply as a rast induction. It should rather be regarded as a postulate indispensable to the carrying on of rational thought, - a postulate ratified in every act of experience, but without which no act of experience can have any validity or meaning. It is for taking this view of the case that Ml. Spencer is charged with rearing a system of philosephy upon "unclemonstrable beliets assumed to be axiomatic and irresistible." Comsilering that the undemonstrable belief in question is simply the belief in the constancy of Niture, one would be at a loss to see what there is so very heinous in Mr. Spencer's proceeding, 
were it not obrious that we have here struck upon a grave misconception on the part of $\mathrm{Mr}$. Wright. Misled, no doubt, by some ambiguity of expression, Mr. Wright supposed Mr. Spencer to be laying down some everlasting principle of universal objective validity, and quite independent of experience. To do this would undoubtelly be to desert science for metaphysics; but MIr. Spencer has not done anything of the kind. As I said before, there has probably been an excess of controversy on this point. For my own part, without retreating from any position formerly taken, ${ }^{1}$ I should be willing, for all practical purposes, to waive the question altogether. Whether our belief in the uniformity of Nature be a primary datum for rational thinking or a net result of all induction, or whether, with the anthors of the "Unseen Universe," we prefer to call it an expression of trust that the Deity "will not put us to permanent intellectual confusion," - whichever alternative we adopt, our theories of the universe will be pretty much the same in the end, provided we content ourselves with a simple scientific coördination of the phenomena before us. And this is all that has been aimed

I Outlines of Cosmic Philosophy, Part I., chap. iii.: Part II., chaps. i., xvi. 
at in the attempt to construct a synthetic, or cosmic, systein of plilosophy. There has been no further transcending of experience than is implied in the assumption that the order of Nature is the same in the Pleiades and in the Solar System until we learn to the contrary; and it would be difficult to set aside Mr. Spencer's proceedings as un-Baconian without, so drawing the line as to exclucle Nerton's comparison of the falling moon to the falling apple, - the grand achievement which first extended the known dynamic order of Nature from the earth to the heavens.

Our knowledge of the universe is no doubt well-nigh infinitely small, - how small we cannot know. The butterfly sailing on the summer breeze may be no farther from comprehending the secular changes in the earth's orbit than man is from fathoming the real course and direction of cosmic events. Yet if throughout the tiny area which alone we have partially explored we everywhere find coherency of causation, then, just because we are incapable of transcending experience, we cannot avoid attributing further coherency to the regions beyond our ken, so far as such regions can afford occasion for thought at all. The very limitations under which thinking is conducted thus urge us to seek the One in the Many; 


\section{Chauncey Wright.}

yet, if our words are rightly weighed, this does not imply a striving after "systematic omniscience," nor can any theistic conception which confines itself within these limits of inference be properly stigmatized as contrary to the spirit of science.

One of the most marked features of $\mathrm{Mr}$. Wright's style of thinking was his insuperable aversion to all forms of teleology. As an able critic in "The Nation" observes, to Mr. Wright "such ideas as optimism or pessimism were alike irrelevant. Whereas most men's interest in a thought is proportional to its possible relation to human destiny, with him it was almost the reverse." But the antagonism went even deeper than this. Not only did he condemn the shallow teleology of Paley and the Bridgewater Treatises, but any theory which seemed to imply a discernible direction or tendency in the career of the universe became to lim at once an object of suspicion. As he was inclined to doubt or deny any ultimate coherency among cosmical events, he was of course indisposed to admit that such events are working together toward any assignable result whatever. From his peculiar point of view it seemed more appropriate to look upon phenomena as drifting and eddying about in an 
utterly blind and irrational manner, though now and then evolving, as if by accident, temporary combinations which have to us a rational appearance. "Cosmical weather" was the tersely allusive phrase with which he was wont to describe this purposeless play of events, as if to liken the formation and dissipation of worlds to the caprivious changes of the wind. So strong a hold had this notion acquired in his mind that for once it warped his estimate of scientific evidence, and led him to throw asicle the well-grounded nebular hypothesis in favour of the ill-conceiver and unsupported meteoric theory of Mayer. In Mr. Wright's mind it was an insuperable objection to the nebular hypothesis that it seems to take the world from a definable beginning to a definable end, and such dramatic consistency, he argued, is not to be found amid the actual turmoil of Nature's workings. It would be improbable, he thought, that things should happen so prettily as the hypothesis asserts: in point of fact, Nature does so many things to disconcert our ingenious formulas! To the general doctrine of evolution, of which the nebular hypothesis is a part, Mr. Wright urged the same comprehensive objection. The dramatic interest of the doctrine, which gives it its chief attraction to many minds, was to $\mathrm{Mr}$. 


\section{Chauncey Wright.}

Wright prima facie evidence of its unscientific character. The events of the miverse have no orderly progression like the scenes of a well-constructed plot, but in the mamer of their coming and going they constitute simply a "cosmical weather."

Without pausing over the question whether dramatic completeness belongs properly to metaphysical theories only, of may sometimes also be found in doctrines that rightly lay claim to scientific competence, we may call attention to the interesting fact that Mr. Wright's objection reveals a grave misunderstanding of the true import of the doctrine of evolution in general, as well as of the nebular hypothesis in particular. The objection - if it be admitted as an objection - applies only to the crinde popular notion of the doctrine of evolution, that it is all an affair of progress, wherein a better state of things (that is, better from a human point of view) keeps continually supplanting a less excellent state, and so on forever, or at least without definite limit. That Mr. Wright understood the doctrine in this crude way was evident from the manner in which he wis wont to urge lis anti-teleological objection both in his writings and in conversation. In criticizing the nebular hypothesis, for instance, le was sure to 
let fall some expression which showed that in his mind the hypothesis stood for a presumptuous attempt to go back to the beginning of the universe and give some account of its total past career in terms of progress. But the nebular hypothesis, as it is now held by evolutionists, does not make any such attempt at all. The nebular hypothesis traces, from indications in the present structure of the solar system, the eneral history of the process by which the system arose out of a mass of vaporous or nebulous matter. That process has been a species of evolution in so far as it has substituted a determinate and complicated for an indeterminate and simple arrangement; and in so $f a r$ as it has resulted in the production of the earth or whatever other planet may be the abode of conscious intelligence, it has been a kind of progress judged with reference to human ends. But so far from this evolution or progress being set down as a universal or eternal affair, it is most explicitly regarded as local and temporary. Throughout the starry groups analogous changes are supposed to be going on, but at different stages in different systems, just as the varions members of a human society coexist in all stages of youth, maturity, or decline; while here and there are nebulæ in which the first steps of devel- 
opment have not yet become apparent, and circumstances can be pointed out under which one of these masses might now and then fail to produce a system of worlds at all. Not only is there all this scope for irregular variety, but the theory further supposes that in every single instance, but at different times in different systems, the process of evolution will come to an end, the determinate complexity be destroyed, and the dead substince of extinct worlds be scattered broadcast through space, to serve, perhaps, as the raw material for further local and temporary processes of aggregation and evolution. This view is held as scientifically probable by many who have not been helped to it by Mr. Spencer's general arguments; but whoever will duly study the profound considerations on the rhythm of motion, set forth in the rewritten edition of "First Principles," will see that it is just this endlessly irregular alternation of progress and retrogression, of epochs of life with epochs of decay, which the doctrine of evolution asserts as one of its leading theorems. In this respect the accepted name of the doctrine, though perhaps not unfortunate, is but imperfectly descriptive, and is therefore liable to mislead. What the doctrine really maintains is the universal rhythmic alternation of evolution and 
dissolution, only that our attention is pre-pminently attracterl to the former aspect of the twofold process, as that which is at present uppermost in our own portion of the mirerse. In no

- department of Nature, whether in the heavens or on the earth, in the constitution of organic life or in the career of human society, does the doctrine of evolution assert progress as necessary, universal, and perpetual, but always as a contingent, local, and temporary phenomenon.

But what hetter phrase could we desire than "cosmical weather" whereby tersuly to describe the endlessly diversified and apparently capricious course of Nature as it is thus set forth in the doctrine of evolution? As the wind bloweth where it listeth, but we know not whence it came, nol whither it goes, so in the local condensations and rarefactions of cosmical matter which make up the giant careers of stellar systems we can detect neither source nor direction. Net only is there no reference to any end which humanity can recognice as good or evil, but there is not the slightest indication of dramatic progress toward any dénoûment whatever. There is simply the nevelending on ward rush of events, as undiscriminating, as luthless, as irresistible, as the current of Niagara or the blast of the tropical hurricane. 
This is a picture which ought to satisfy the most inexorable opponent of teleology. For my own part, I can see nothing very attractive in it, even from a purely speculative point of view, though it is as striking a statement as can well be made of the meagreness of our knowledge when confronted with the immensity of Nature. The plrase "cosmical weather" happily comports with our enormous ignorance of the real tendency of events. But as terrestrial weather is after all subject to discoverable laws, so to an intelligence sufficiently vast the appearance of fickleness in "cosmical weather" would no loubt cease, and the sequence of events would donbtless begin to disclose a dramatic tenlency, though whether toward any end appreciable by us or not it would be difficult to saly. ${ }^{1}$

In the discussion of such questions, called up by Mr. Spencer's philosophy, Mr. Wright always appeared in the light of a most consistent and unqualified positivist. He hardly could be called a follower of Comte, and I donbt if he even knew the latter's works save by hearsay. But he needed no lessons from Comte. He was born a positivist, and a more complete specimen of the.

1 This point is treated from a far more advanced position in my new book, The Idea of God, as affected by Modern Knouledge. 
positive philosopher has probably never existed. He went as far as it was possible for a human thinker to go toward a philosophy which should take no note of anything beyond the content of observed facts. He always kept the razor of Occam uncased and ready for use, and was especially fond of applying it to such entities as "substance" and "force," the very names of which, he thought, might advantageously be excluded from philosophical terminology. Sometimes he described himself as a positivist, but more often called himself a Lucretian, - the difference between the two designations being, perhaps, not great. As a champion of Lucretius, I remember his once making a sharp attack upon Anaxagoras for introducing creative design into the universe in order to bring coherence out of chaos. What need, he argued, to imagine a supernatural agency in order to get rid of primeval chaos, when we have no reason to believe that the primeval chaos ever had an existence save as a figment of the metaphysician! To assume that the present orderly system of relations among things ever emerged from an antecedent state of disorder is, as he justly maintained, a wholly arbitrary and unwarrantable proceeding. No one could ask for a simplèr or more incisive criticism upon that crude 
species of theism which represents the Deity as a power ontside the universe which coerces it into orderly behaviour.

Althongh, like all consistent positivists, Mr. Wright waged unceasing war against Mr. Spencer's system of philosophy, there was yet one portion of the doctrine of evolution which found in him at most eminent and efficient defender. In spite of his objections to evolution in general, $\mathrm{Mr}$. Wright thoromghly appreciated and warmly espoused the Darwinian theory of the origin of species by "descent with modifications." His most important literary work was done in elucidation and defence of this theory. Of all his writings, by far the clearest and most satisfactory to read is the review of Mr. Mivart's "Genesis of Species," which Mr. Darwin thonght it worth while to reprint and circulate in England. Its acute and original illustrations of the Darwinian theory give it very great value. The essay on phyllotaxy, explaining the origin and uses of the arrangements of leaves in plants, is a contribution of very great importance to the theory of natural selection. So, too, in a different sense, is the paper on the evolution of self-conscionsness, which is the most elaborate of Mr. Wright's productions, but so full of lis worst faults of style that, even 
after much cross-questioning of the author, I never felt quite sure that I grasped his central meaning.

It was in such detached essays or monographs as these that much was to have been expected from Mr. Wright, especially in the application of Darwinian conceptions to the study of psychology. Could he have been induced to undertake an elaborate treatise, we should have seen the philosophy of Mill and Bain carried to its furthest development and illustrated with Darwinian suggestions by a writer not in sympathy with the general doctrine of erolution, - an interesting and instructive spectacle. But I doubt if Mr. Wright would ever have undertaken an extensive work. To sit down and map out a subject for systematic exploration would have been a proceeding wholly foreign to his habits. Once launched out on a shoreless sea of speculation, he would brood and ponder for weeks, while bright determining thoughts would occur to him at seeming haphazard, like the rational combinations of phenomena in his theory of "cosmic weather." To his suggestive and stimulating conversation this unsystematic habit gave additional charm. An evening's talk with Mr. Wright always seemed to me one of the richest of intellectual entertain. 
ments, but there was no telling how or where it would end. At two o'clock in the morning he would perhaps take his hat and saunter homeward with me by way of finishing the subject; but on reaching my gate a new suggestion would turn us back, - and so we would alternately escort each other home perhaps a dozen times, until tired Nature asserted her rights, and the newly opening vistas of discussion were regretfully left unexplored.

I never knew an educated man who set so little store by mere reading, except Mr. Herbert Spencer ; but, like Mr. Spencer, whom he resembled in little else, Mr. Wright had an incomprehensible way of absorbing all sorts of knowledge, great and small, until the number of diverse subjects on which he could instruct even trained specialists was quite surprising. There were but fer topics on which he had not some acute suggestion to offer: and with regard to matters of which he was absolutely ignorant - such as music - his general good sense and his lack of impulsiveness prevented his ever talking foolishly.

This lack of impulsiveness, a kind of physical and intellectual inertness, counted for a great deal both in his excellences and in his shortcomings. His movements were slow and ponderous, his 
mild blue eye never lighted with any other expression than placid good humour, and his voice never varied its gentle monotony. His absolute freedom from egotism made him slow to take offence, and among the many accidents of controversy there was none which could avail to ruffle him. The patient deference with which he would answer the silly remarks of stupid or conceited people was as extraordinary as the untiring interest with which he would seek to make things plain to the least cultivated intelligence. This kind of patient interest, joined with his sweetness of disposition and wimning simplicity of manner, made him a great favourite with children. He would amuse and instruct them by the hour together with games and stories and conjurer's tricks, in which he had acquired no mean proficiency.

Along with this absence of emotional excitability, Mr. Wright was characterized by the absence of asthetic impulses or needs. He was utterly insensible to music, and but slightly affected by artistic beauty of any sort. Excepting his own Sokratic presence, there never was anything attractive about his room, or indeed anything to give it an individual character. In romance, too, he was equally deficient: after his 
first and only journey to Europe, I observed that he recalled sundry historic streets of London and Paris only as spots where some happy generalization had occurred to hin.

But rnmantic sentiment, resthetic sensitiveness, and passionate emotion, - these are among the things which hinder most of us from resting content with a philosophy which applies the law of parsimony so rigorously as to cut away everything except the actuality of observed phenomena. In his freedom from all such kinds of extra-rational solicitation Mr. Wright most completely realized the ideal of the positive philosopher. His positivism was an affair of temperament as much as of conviction; and he illustrates afresh the profound truth of Goethe's remark that a man's philosophy is but the expression of his personality. In his simplicity of life, serenity of mood, and freedom from mental or material wants, he well exemplified the principles and practice of Epikuros; and he died as peacefully as he had lived, - on a summer's night, sitting at his desk with his papers before him.

It is a bitter thing to lose a thinker of this mould, just in the prime vigour of life, and at a time when the growing habit of writing seemed to be making authorship easier and pleasanter, so 
that in years to come we were likely to have had even richer and brighter thoughts from the pen that must now forever lie idle. The general flavour of Mr. Wright's philosophy - unsystematic, but fruitful in hints - may be gathered well enough from the paper's which $\mathrm{Mr}$. Norton has carefully collected in this memorial volume. But the best that can now be done in the way of editing will give but an inadequate impression of Chauncey Wright to those who have not listened to his wise and pleasant talk. To lave known such a man is an experience one cannot forget or outlive. To have had him pass away, leaving so scanty a record of what he had it in him to utter, is nothing less than a public calamity.

December, 1876. 


\section{VII.}

\section{WHAT IS INSPIRATION?}

THE word "inspiration" furnishes an excellent example of the way in which a whole theory of the universe may be imbedded in an etymology. In its origin the word means a "breathing in," or suggestion from some external source, of thoughts not natural to the writer or speaker. The nonnaturalness of the thought is an essential part of the definition, since, if the thought be such as would naturally arise, through ordinary logical or emotional sequence, in the mind of the writer or speaker, there is no reason for referring it to any external source. That thoughts often do come into the mind unbidden, and apparently without any assignable immediate antecedent, is a matter of the commonest experience. From the purposeless succession of phantasms in idle reverie up to the orderly visions of Milton, the melodious themes of Beethoven, or even the wonderful flashes of insight of Newton or Faraday, we have instances of visual or anditory images, or appre. 
hensions of physical truths, entering and occupying the foreground of consciousness suddenly and without warning. Tine more valuable and siriking instances of this sort are, in modern parlance, described as cases of inspiration, though by this phrase no more is now mant than to designate some rare or admirable kind of normal mental action. The modern student has learned that consciousness has a background as well as a foreground, - that a number of mental processes go on within us, of which we cannot always render a full and satisfactory account. Many a link of association is buried beneath the surface, and the coveted flash of memory, of judgment, or of fancy does not always come at our bidding. 'To account for this group of phenomena, modern psychologists have propounded various theories of "latent mental action" or "unconscious cerebration;" but no one now resorts to the hypothesis that such phenomena are due to the operation of some outside spirit or intelligence acting upon the mind. Hypotheses of this sort do not harmonize with the accumulated experience of modern times, and they have become utterly and hopelessly discredited.

In ancient times, however, the case was entirely different. In one of the most enlightened and 
sceptical communities of antiquity we find one of the most enlightened and sceptical minds habitually explaining the suggestions of its own supreme common sense by ascribing them to the dictation of an indescribable external agency. 'The daimonion, or familiar warning spirit, of Sokrates shows how consonant with the general theories of the ancients was the conception of inspiration in its full and literal sense. In the stage of culture thus exemplified every briglit stroke of genius was interpreted as the result of inspiration, though it was naturally in cases of supreme practical importance that the interpretation was most forcibly felt and most thoroughly believed. The poet's invocation to the Muse was at first no doubt much more than a faded metaphor; but it is beyond question that men like Isaiah and Mohammed believed themselves to be mere mouth-pieces of the living word of God.

The belief in inspiration, as thus generally "cherished in ancient times, seems to have grown out of a more primitive belief in possession, which is found everywhere current among savage and barbarous tribes, and which, until within a few generations, has maintained itself even in the Christian world. The subject has been treated in an elaborate and masterly manner by Mr. Ty- 
lor in the second volume of his great work on "Primitive Culture." In the lower stages of culture, the morbid phenomena of hysteria, epilepsy, and mania are explained by the hypothesis of a foreign spirit, which is supposed to have taken temporary possession of the body or earthly tabernacle of the patient. In Christian cases of exorcism, this foreign spirit was naturally supposed to be of diabolical character; but in the cruder theory of the barbarian no such uncanny suspicion is attached to it. On the contrary, the possessed person is usually regarded as an exceptionally valuable source of information concerning the supernatural world to which the possessing spirit belongs. Alike in the medicine-man of the American Indian, and in the Pythian priestess of Delphi, may be seen the close theoretical connection between disease-possession and oracle-possession. The Zulu diviners ascribe their hysterical symptoms to possession by "amatongo," or ancestral spirits; and the Siberian shamans select epileptic children to be educated for the priesthood, which is thus "apt to become hereditary along with the epileptic tendencies it belongs to." In the primitive theory, the diviner or prophet can give information from the supernatural world because his own personality is for the time being sup- 
planted by the personality of the foreign spirit which has come to dwell in his borly. This is the theory of oracle-possession, and from this to the theory of inspiration, as generally current in antiquity, it is evidently but a short step. Instead of supplanting the personality of the prophet, the foreign spirit has but to be conceived as swaying or influencing the prophet's mind from without, and this step is taken; instead of possession we have inspiration.

Thus in its origin the word "inspiration" is implicated with a whole theory of the universe, or, to speak more appropriately, with a general way of looking at natural phenomena. In the lower stages of culture men know nothing of a universe, but they contemplate natural phenomena as under the capricious direction of innumerable ghostly beings similar to men. In most cases, indeed, these demons or deities are supposed to be the ghosts of ancestral chieftains. The philosophy which interprets Nature in this way is extremely crude, but it is quite intelligible and consistent with itself ; and, when a barbarian speaks of his prophet as "inspired" by the tutelary deity of the tribe, we know exactly what he means. He means that the words are whispered or other'wise suggested to the prophet by the ghost of 
some old clief of the tribe; and, when he himself has thoughts, waking or sleeping, which he cannot readily account for, he thinks that these are similarly suggested to him by some ghostly demon or deity. The daimonion of Sokrates was a specimen of just this sort of barbaric psychology.

Now, in modern times and among Christian peoples, this primitive plilosophy of Nature is pretty thoroughly superseded. The tendency of modern thought is strongly towards a very strict monotheism. An imperfect monotheism had long ago driven out the general notion of innumerable ghost-deities; but Christianity arose at a time when the primitive plilosophy was still very strong, and so Christianity has always been more or less incrusted with heathen conceptions. In recent times. however, the prolonged study of physical science has begun to tell powerfully upon all our habits of thought; and one effect of this is that we have at last really begun to grasp the conception of the unity of God, in the only sense in which such a conception can have any validity. We have begun to conceive of Divine action as uniform, incessant, and general, throughout each and every region of the universe, however vast or however tiny, so that the infinite whole is animated forever by one immutable principle of 
life; and this conception we call, in common parlance, the conception of a government of law, and not of caprice. So strong has this habit become that we look with distrust upon any hypothesis which implies a conception of Divine action as in any sense local, or special, or transitory.

The hypothesis of inspiration has been retained by modern Protestant Christianity, chiefly as a means of accounting for the assumed infallibility or supernatural excellence of the literature gathered together in the canonical Scriptures. It is supposed that the writers of these works were in some way instructed by Divine action, so that their works are either entirely true in every statement, or at least may claim to be examined in accordance with different canons of criticism from those which we feel bound to apply to all other works. Now, this hypothesis most certainly implies a conception of Divine action as local, special, and transitory; and, in so far as it does this, it bears the marks of that heathen mode of philosophizing which was current when Christian monotheism arose, and which has incrusted Christianity with many of its conceptions. It is obvionsly not an hypothesis in accord with the very strict monotheism towards which modern thonght is so manifestly tending, and it is not likely long to survive 
unless upheld by very weighty evidence. Such evidence might be forthcoming if the various books of the Bible had been found able to withstand every test of scientific and literary criticism that could be brought to bear upon them, and come out unscathed in every statement. Such a phenomenon would at least have been very remarkable, but in point of fact the outcome of Biblical criticism has been very different from this. A century of intense study and searching controversy has superabundantly proved that the Bible not only contains much that conflicts both with modern knowledge and with modern morality, but that the various parts of it often hopelessly contradict each other in matters of fact, and sometimes present irreconcilable divergences in matters of doctrine, while minor errors of historical or philological interpretation abound in it throughout. In view of such a conclusion there would seem to be no need for any hypothesis of special Divine action in the composition of the Bible. On the contrary, the belief in the peculiar inspiration of this collection of books should probably be regarded as one of the incumbrances with which Christianity has been loaded by the old heathen way of looking at things.

A sad incumbrance it certainly is to any one 


\section{What is Inspiration?}

who truly loves and reveres the Bible. To make a fetish of the best of books does not, after all, seem to be the most reverent way of treating it. Take away the discredited hypothesis of infallibility, and the errors of statement and crudities of doctrine at once become of no cons quence, and cease to occupy our attention. It no longer seems worth while to write puerile essays to show that the Elohist was versed in all the conclusions of modern geology, or that the books of Kings and Chronicles tell the same story. The spiritual import of this wonderful collection of writings becomes its most prominent aspect; and, freed from the exigencies of a crude philosophy and an inane criticism, the Bible becomes once more the Book of mankind.

August, 1878. 


\section{VIII.}

\section{MODERN WITCHCRAFT. ${ }^{1}$}

Or this most dismal of subjects Dr. Hammond has given us a book that is both sensible and entertaining. His survey of so-called "spiritualistic" phenomena is extensive, and with a large and important part of them his intimate acquaintance with abnormal states of the nervous system has enabled him to deal very successfully. The results of a physician's experience are, moreover, very happily supplemented by historical research. One of the excellent points about Dr. Hammond's book is its frequent comparison of contemporary dehusions with those of earlier times. He makes such wholesome use of the amnals of witcheraft and the biographies of medieval saints, mystics, and charlatans, as fairly entitles his book to a prominent place on the Index Expurgatorius. The marvels countenanced from time to time by

1 Spiritualism and Allierl Causes and Conditions of Nervous Derangement. By W. A. Hammond, M. D. New York: G. P. Putnam and Sons. 1876. 
the Roman Church fare no better in his hands than the wonderful deeds of the Homes and the Davenports, and of these it is left doubtful whether the most marvellous part is the audacity of the performers or the gullibility of the spectators.

According to Dr. Hammond, spiritualism is for the most part barefaced imposture, the remainder being innocent delusion. By many persons who adopt this view on the whole, yet are unable to realize how great is the capacity of the human mind for being deceived, a reservation is made in behalf of divers phenomena which are alleged to take place in conformity to some undiscovered "natural law," or to require for their explanation some species of "force" other than those with which scientific men are familiar. Dr. Hammond is not inclined to admit any snch reservation as this, which, even if it were allowed, would be of small use to the spiritnalists. Even if an event were admitted to be inexplicable save by an appeal to some "force" other than those that have hitherto been studied, we should still have no sort of reason for assuming any connection between this unknown "force" and the "spirits" of dereased persons. Such an assumption couk find no warrant whatever, save in a general a priori 
hypothesis, handed down to us from barbarous times, which has been uniformly discredited wherever there has been an opportunity for testing it. Even to describe such a "force" as "psychic" is to beg the whole question; for until we have subjected it to a long course of experimentation, like that which has built up our scientific knowledge of heat and light, we can have no means of knowing whether it is "psychic" or not.

It is, however, very unphilosophical at the outset to appeal to any new or unknown force until we have thoroughly exlausted all means of explanation furnishable by forces that have already been defined; and by the advocates of spiritualism no such preliminary inquiry has ever been made or even attempted. When, therefore, Mr. Crookes finds himself unable to explain the way in which Mr. Home causes the index of a spring-balance to descend without exerting any apparent pressure on the lever, it is a very violent stretch of inference to call in an imaginary "psychic force" by way of simplifying the matter. This is appealing from the known to the unknown, and it is in no such way that discoveries are made in those plyysical sciences which Mr. Crookes has so carefully studied. Dr. Hammond may well say that "there are so many ways in which known 
forces manifest themselves, and so little is known of the laws which govern them, that Mr. Crookes might, for the present, with safety and propriety, have held his opinion in abeyance." As Mr. Crookes's experiment is the only one cited in which the spiritualists seem to have been able to work in broad daylight, and to dispense with the grosser forms of jugglery, a brief description of it may prove instructive.

-In order to test Mr. Home's pretensions to a power of altering the weights of bodies by "spiritual agency," Mr. Crookes constructed a simple and ingenious apparatus "consisting of a mahogany board thirty-six inches long by nine and a half inches wide and one inch thick. At one end a strip of mahogany was screwed on, forming a foot, the length of which equalled the width of the board. This end of the board rested on [ the edge of] a table, while the other end was supported by a spring-balance" pendent from a tripod stand. Obviously, now, when Mr. Home placed the tips of his fingers lightly on the end of the board which was resting on the foot or fulcrum, the pointer of the balance ought to have remained perfectly stationary; even a heavy pressure directly over the fulcrum could not alter the position of the lever. But, as a matter of fact, 
the pointer descended, showing that the weight or dorwnward pull at the end of the lever supported by the balance had been increased by from three to six pounds. In order still further to guard against the possibility of $\mathrm{Mr}$. Home's exerting any muscular action on the board, Mr. Crookes placed a glass vessel full of water over the centre of the fulcrum, "and by means of an iron stand, quite detached from all the rest of the apparatus, a vessel of copper was held so that it dipped juto the water witlout touching the sides of the glass vessel, the bottom of the copper vessel being perforated with holes, in consequence of which it was partially filled with water. . . When Mr. Home placed his hands inside the copper vessel, any force passing through his hands had to traverse the water hence no muscular action of his could have any effect upon the springbalance. With the apparatus thus arranged, the lever oscillated as in his previous experiment, the average strain registered being three or four pounds."

Such were the phenomena to explain which Mr. Crookes invoked the assistance of an unknown something which it pleased his fancy to call "psychic force," while his companion, Dr, Huggins, more wisely declined to express any 
opinion. In connection with these phenomena, Dr. Hammond calls attention to an experiment of Professor Tyndall's, in which an egg is placed in an egg-cup and a long lath balanced upon the egg : if a dry stick of sealing-wax, which laas been well rubbed with a piece of woollen cloth, be held over one end of the lath, the latter, no matter how heavy, will rise to meet it. In dry weather many persons can make the finger serve the same purpose as the sealing-wax, by first shuffling their feet for a few moments over the carpet. Taking these things into consideration, Dr. Hammond arranged an apparatus like that of $\mathrm{Mr}$. Crookes, and, applying the stick of sealing-wax just over the fulcrum, where Mr. Home's finger-tips had rested, the pointer of the balance at once descended. The same result was immediately afterwards obtained when, after shuffling over a thick rug, Dr. Hammond rested his finger on the same place. So fir, therefore, the strain on the balance would seem to be due neither to ghosts of departed men nor to "psychic force," but to some peculiar manifestation of that commonplace agent, friction electricity. How far Dr. Hammond's experiments may be conclusive, it is not in our power to say. What it concerns us to notice is that his method of going to work, by 
searching for some analogous case within the region of experience, is the method of science and common sense, whereas Mr. Crookes's method, of deserting the region of experience in quest of some "psychic force," is the method which characterizes alike the barbaric myth-maker and the ill-trained thinker in a civilized community. So long as scientific men are capable of doing such unscientific things, it is not to be wondered at that primitive superstitions still survive.

Some of Mr. Home's other tricks are suggestive in another way. The feat of making a small table so heavy that the credulous bystander cannot stir it from the floor shows what curious results may be obtained from highly impressionable people by riveting their attention. Dr. Hammond lias himself performed this trick with entire success. Taking a small Japanese table, weighing less than two pounds, he informed a young man that he was going to make it too heavy to be raised from the floor. For a quarter of an hour he held the tips of his fingers on it, until the young man's attention became riveted, when he removed his hands and challenged the young man to lift the table. It proved immovable, and "I saw," says our author, "that so far from endeavouring to lift it, as he supposed he was 
doing, he was in reality pressing it with all his might towards the floor." But as soon as Dr. Hammond had waved his hand over the table and declared that it might now be lifted, the young man lifted it with ease. Scientifically viewed, such phenomena are very interesting; they seem closely akin to the phenomena of hypnotism in men and animals, so strikingly illustrated in the experiments of Kircher and Czermak. Hens and pigeons can easily be put into a cataleptic state by holding a cork or a bit of chalk before their eyes so as to attract their attention; and in a similar way a frog's attention may be so absorbed that his belly may be cut open without his seeming to notice it. Mr. Braid has similarly hypnotized men; and Dr. Hammond produced complete anæsthesia in a lady by causing her to look for a few moments at a cork fastened upon her forehead while her back was cauterized with a red-hot iron.

As for Mr. Home's tricks of putting live coals into his waistcoat pocket and on other people's bald heads with impunity, such things have so long been commonplaces with second-rate conjurers that it is astonishing to find intelligent men like Mr. Wallace quoting them as instances of ghostly agency. Nothing could be easier for a 
clever jugghler like Mr. Home than to exchange real coals for false ones, or to protect his own pockets and the heads of his dupes with asbestos cloth, without attracting notice. Such a proceeding would require far less skill than those of professional magicians, like Hermann or Houdin, in comparison with whose truly wonderful achievements the best performances of spiritualists are not for a moment worthy to be named.

Still keeping to Mr. Home, his famous trick of "levitation," or appearing to float through the air ont of one third-story window into another, seems partly to illustrate the effects of intense expectation in producing hallucination, partly to show us for the thousandth time low little unsifted human testimony is worth; for on one occusion, while two "respectable witnesses" were sure that they saw the great "medium" come sailing feet foremost through the window, their less gullible companion was equally positive that the levitating grentleman was sitting quietly in his arm-chair all the while! Nothing is more common than for us to be told what people of undoubted veracity have seen. For my own part, if I were to answer frankly in such cases, I should take my cue from a cele. brated naturalist whose friend was recounting to him a miraculous shower of frogs from the sky. 
"It is fortunate," said he, "that you have seen it, for now I can believe it. If I had seen it myself, I should not have believed it!" The commonest acts of perception are so liable to be warped by hypothesis (a fact which conjurers like Houdin consummately understand) that it is quite useless to conjecture what our witnesses may really liave seen, unless we know much more than they are likely to tell us of the physical and mental conditions under which their seeing was done. At a meeting of spiritualists in Boston, Mr. Robert Dale Owen once saw what he took to be an "apparition in shining raiment," keing quite clear in his mind that no deception or illusion was possible under the circumstances. But Dr. Hammond, making a diagram of the rooms from dita contained in Mr. Owen's account, shows that, with the greatest ease, a "woman in white" might have been brought into the room and illuminated by means of a dark lantern without awakening suspicion. The case of Angélique Cottin, the famous "electric girl," is equally instructive. After tipping tables, repelling books, brushes, and other small objects, and disturbing magnetic needles before numerous "intelligent audiences," her alleged powers were carefully investigated by a committee of the 
Academy of Sciences, consisting of Arago, Becquerel, Geoffroy St. Hilaire, and others. Tables, books, brushes, and magnetic needles, all kept most provokingly quiet, and the "electric girl" subsided into oblivion. So, numbers of people who watched the "Welsh fasting-girl" were quite sure that she subsisted without food; but, when really competent watchers were introduced, . the poor creature died of starvation, destroyed by her own obstinacy and the criminal acquiescence of her parents.

We have touched upon but few of the topics treated in Dr. Hammond's book. Into his elaborate discussion of the painful and often disgusting phenomena of hysteria, ecstasy, and stigmatization, we have not space to follow him. His subject is one which leads the inquirer into some of the darkest and most loathsome corners of the human mind; but the inquiry has, nevertheless, its uses.

July, 1876. 


\section{IX.}

COMTE'S POSITIVE PHILOSOPHY. ${ }^{1}$

IT is now nearly a quarter of a century since, by the publication of the last volume of the "Cours de Philosophie Positive," Auguste Comte completed his great task of organizing into a coherent system the doctrines held and the methods of investigation pursued by scientific men. His work was not long in obtaining the recognition of advanced thinkers; and during the period which has elapsed since its completion, its leading views — noticed with more or less approval by Mr. Mill, Mr. Grote, and Sir G. C. Lewis, explained and defended by Mr. Lewes and M. Littré, partially adopted by Mr. Buckle, adversely criticised by Mr. Spencer, and violently attacked by the entire a priori school of philosophers and theologians have seriously occupied the attention of a large part of the thinking public. The term "positivism" has won for itself a place in the vocabulary

1 The Positive Philosophy of Auguste Comte. By John Stuart Mill. Boston: William V. Spencer. 1866. 12mo, pp. 182. 
of philosophy beside the older names "idealism" and "scepticism," as indicating a distinct and important phase in the development of speculative thought. But its more recent introdnction into philusophic language has not availed to protect it from those ambiguities of interpretation which envelop, as with a halo, the latter time-honoured appellations. On the contrary, so far are most persons from having a distinct idea of what they mean when they speak of positivism that it is not uncommon to hear classed as positivists men like Professors Tyndall and Huxley, the peculiar tendency of whose opinions has been but slightly, if at all, detemined by the speculations of M. Comte. To call these men positivists is to necessitate such an extension of the term as to include all truly scientific investigators of phenomena, from the days of Galileo and Newton downwards. This vagueness results naturally from the circumstance that many of M. Comte's most prominent doctrines did not originate with himself, but were held by him in common with many thinkers, both of the present and of past ages. Not only as a discoverer of new truths, but as an organizer of those alleady discovered, did he announce himself to the world.

At the present time, when such a general inter. 
est is felt in the philosophy of $\mathrm{M}$ : Comte, and such a wide-spread curiosity is manifested to know in what that philosophy really consists, a work like the one now before us is most welcome. $\mathrm{Mr}$. Mill is admirably qualified to furnish us with a clear and trustworthy exposition of the Positive Philosophy. His own researches have led him over the same paths which were traversed by M. Comte, and the results of his meditations on the proper methods to be pursued in scientific exploration were laid before the world nearly a generation ago, in his "System of Logic," - a work which in our opinion is as important a contribution to human knowledge as the "Philosophie Positive" itself. And while, on the one hand, the number of opinions held in common by the two, to say nothing of Mr. Mill's well-known candour, is a sufficient guaranty for the fair treatment of the subject, on the other hand, Mr. Mill's eminence as an original thinker prevents him from ever abdicating the position of a critic for that of a disciple.

In common with the majority of scientific thinkers, M. Comte asserts the universality and invariability of natural laws; and he coincides in the opinion, held by one great school of psychologists since Locke, that all knowledge is derived from 
experience. But his emphatic and determined rejection of the methods of subjective psychology leaves him so destitute of the means for establishing this doctrine that it can hardly be regarded as a coherent, though doubtless an indispensable, portion of his system. Allied to this theorem is that of the relativity of all knowledge, which also is not peculiar to the Positive Philosophy. It has been held with more or less consistency by a vast number of thinkers from Protagoras downward, including in the list of its adherents many whose antagonism on most other points has been unqualified, - men such as A ristotle and Bruno, Averroes and Bacon, Hume and Kant. In relation to this dogma, M. Comte is the natural successor of Brown. As Mr. Mill truly remarks, "the doctrine and spirit of Brown's philosophy are entirely positivist, and no better introduction to positivism than the early part of his Lectures has yet been produced." While, curiously enough, Brown's most redoubtable opponent, Sir William Hamilton, has also verbally adopted this positive theorem, although his simultaneous assertion of the principles of Natural Dualism sufficiently shows that he never really understood it. Hume was probably its first consistent supporter, though he often pushes scepticism to the point of denial, 
apparently maintaining the relativity not only of all knowledge, but of all existence likewise. Not so M. Comte, who ever implicitly recognizes the existence of noumena, while insisting upon their eternal banishment to the realm of the Lnknowable. We should strive, therefore, not to ascertain the causes of phenomena, either primary or final, but only to formulate the laws of their coexistence and sequence. With the study of phenomena as causes, $i . e$. as invariable antecedents of other phenomena, M. Comte has never, as it has been foolishly asserted, found fault. His philosophy is entirely concerned with the investigation of these, in distinction from noumenal causes, the origin of phenomena, and the end for which they exist. Of this bridge of 'Time, which man and Nature alike are traversing, he forbids us to strain our vision in vain efforts to discern the beginning and the end, immersed as they botb are in the utter darkness of eternity.

But though M. Comte did not originate the doctrine of the relativity of all knowledge, and though while ignoring psychologic research he can in no wise prove it, he has yet, as Mr. Mill observes, made it in a great measure his own doctrine by his method of treating it. The first distinctive feature of his philosophy is the assertion 
that, in its investigation of nature, the human mind has passed through three essentially different stages. These are, first, the Theological stage, in which all phenomena are viewed as resulting from the volitions of supernatural agents; second, the Metaphysical stage, in which phenomena are supposed to be determined by the existence of inherent occult causes; and, third, the Positive stage, in which, the search for causes being abandoned, the mind rests content with grouping phenomena according to their relations of coexistence and succession. The exposition of this law of intellectual development occupies a considerable portion of Mr. Mill's volume, and is, we think, both lucid and profound. But we cannot go so far as Mr. Mill in accepting the theorem as a true and adequate statement of the course which the human mind has pursued. As such a statement, we believe it to be imperfect and superficial, though containing a sufficient amount of truth to have made its application to the study of history result in sundry minor generalizations of the highest value. The "positive" method of contemplating phenomena is doubtless becoming exclusively prevalent with scientific explorers; and for this reason, the name "positivism," after losing its more special comnotations, is perhaps destined to 
become the designation of scientific thought in general. The naturalistic tendencies observable in Sokrates and Aristotle, organized by Bacon and Descartes, and represented by subsequent discoverers, might thus withont inaccuracy be considered "positive."

The second distinctive feature of M. Comte's philosophy is its arrangement of the sciences in such an order that those which deal with the most general and least complex relations are studied prior to those which treat of relations more special and involved. M. Comte distinguishes between the abstract sciences, "which have to do with the laws which govern the elementary facts of nature," and the concrete sciences, which "concern themselves only with the particular combinations of phenomena which are found in existence." Thus Physics and Chemistry are the abstract sciences corresponding to the concrete science Mineralogy, while Zoölogy and Botany deal with concrete examples of the abstract laws enunciated by Physiology. Leaving the concrete sciences out of consideration, M. Comte arranges the abstract sciences as follows: I. Mathematics; II. Astronomy; III. Physics (comprising the sciences of Weight, Heat, Sound, Light, and Electricity); IV. Chemistry; V. Biology; and VI. 
Sociology. In the arrangement of the subdivisions of each science, he attempts to apply the same principle of advancing from the general to the special: thus, in Mathematics, the laws of number are to be studied before those of magnitude, and these again before those of equilibrium. In the arrangement of the different branches of Physics, however, this principle evidently fails; it being impossible to assert that the phenomena of weight and pressure are less general than those of heat, or perhaps even those of light. The omission of a science of Psychology from the above scheme will be deemed by most persons a grave defect. Nor can M. Comte be said to have at all mended the matter by offering us in its stead (we blush to tell it) the wretched substitute Phrenology. In spite of these defects, the advantages of studying the sciences in this order will be disputed by no one; it being manifest that each science furnishes almost indispensable aid to the study of its successors, while throwing comparatively little light on the subjects treated by its predecessors. Each science, too, has methods of investigation peculiar to itself; and it is the elaborate statement of these methods that we consider the most permanently valuable of $M$. Comte's contributions to philosophy. But we do 
not agree with the statement that this admirable arrangement of the sciences represents the true order of their historic development; and that, while each science has experienced successively the application of the theological, the metaphysical, and the positive methods, the order in which they have attained the positive stage conforms to the order in which they are here placed. We do not believe that any serial arrangement can represent either the true relations of the sciences to each other, or the comparative rapidity with which they have advanced toward perfection. The simplicity of the phenomena with which they deal is far from being the only condition which has determined their evolution. And we therefore differ from Mr. Mill in thinking that Mr. Spencer has entirely destroyed the pretensions of M. Comte's classification to be considered as founded in the nature of things, however valuable it may be as a help to study.

It is on his contributions to our knowledge of the laws of social evolution that M. Comte chiefly prides himself. He claims the right to be called the founder and legislator of the science of society. We are not among the number of those who are disposed to grant him this lofty title. We do not even think that the science of society, as a 
systematic whole, can yet be said to exist. MIuch has indeed been done to prepare the way for such a science. Some subordinate discoveries of ines timable value have been made, and it has been conclusively shown that social phenomena are proper objects of scientific treatment. Among the pioneers of this new science, M. Comte will always hold an honourable place. His treatment of history is eminently original and suggestive; and his views, even when not wholly true, are rarely without a large amount of truth. His catholic spirit, and his hearty admiration for whatever is great and good in the past, are moral qualities beyond all praise.

It is impossible, in our limited space, to do more than allude to the subjects which are so admirably elucidated and commented on in Mr. Mill's volume. To M. Comte's later speculations we do not wish to refer, further than to express our opinion that they are a tissue of the wildest and most extravagant vagaries ever conceived outside of Bedlam; or, remembering all that the world owes M. Comte, we might less harshly and not less truly call them the most mournful exhibition furnished by the annals of philosophy of a great mind utterly shattered and ruined. It is a spectacle to which we cannot refuse our pitying 
sympathy, even while we are unable to repress our contempt. We have no criticism to make on Mr. Mill's treatment of the subject, which is in the main sober and just. But we are surprised at the remark with which he concludes the book, that M. Comte should be considered as great a thinker as either Descartes or Leibnitz; and hardly more extravagant than they. M. Comte's achievements have indeed been great. But neither in the amount of mental effort implied by them, nor in the magnificence of their consequences, can they ever be compared to Descartes's application of algebra to genmetry, or to Leibnitz's discovery of the differential calculus. Our surprise is all the greater since, in his recent work on Sir IVilliam Hamilton, Mr. Mill has shown himself quite capable both of appreciating the transcendent merits of Descartes, and of sympathizing with the state of mind which led to the eccentricities of Leibnitz. M. Comte might in some respects be more justly compared to Bacon; and the rejection of the Copernican system, which has so often been alleged as a proof of the narrowness of the latter, seems after all a trifling blemish, when we remember how persistently M. Comte ignores all that has been achieved in the department of Psychology. The above is one of the rare cases in 
which Mr. Mill must be accused of haste and partiality. And we deem it not inconsistent with the respect due to his noble qualities to say that, while his aim is ever to present in the most favouraole light opinions from which he differs, he does not always succeed in maintaining the inpartial attifude so indispensable in a critic, and of wrich Bayle has given us perhaps the finest example.

Octooem 1865. 


\section{$\mathbf{X}$.}

MR. BUCKLE'S FALLACIES. ${ }^{1}$

IT has always been a favourite illusion that social changes do not, like physical changes, conform to fixed and ascertainable laws. Not only is it that philosophers of a certain class have, from the earliest times, explained historical events as instances of the continued interposition of an arbitrary power, exterior to and independent of the material universe; not only is it that thinkers of an opposite school have referred the actions of men to a no less arbitrary power, operative in each individual as an ulti-

2 As this review of Mr. Buckle's History of Civilisation was written and published when I was only nineteen years old, I must not now be held responsible for all the opinions expressed in it. The apparently favourable estimate of Positivism which runs through it will best be understood from the preceding article, which was written only four years later, when my view of Comte was essentially the same. It will be seen that I have never been, in any legitimate sense of the word, a positivist. I have reproduced this article without altering a single word; and have appended to it a "Postscript," written fifteen years later, as an illustration of the change which Mr. Buckle's reputation has undergone. 
mate inexplicable agent; but it is that the mass of men have ever been accustomed to look upon the phenomena of society as upon isolated facts, incapable of any scientific explanation whatever. And this is what might be expected from the great abstruseness and complexity of the subject. Since the science of human actions is the most difficult of all, and since it depends on the simpler physical sciences, it was not until these in the course of their development had been purified from the dreamy obscurities of metaphysics that the conception of a universal and undeviating regularity in the succession of historic events was rendered possible. Accordingly, when physical science was yet in its infancy, as in ancient times, there could be no social science. The speculations of Plato upon this subject were but profitless reveries; and even the admirable " Politics" of Aristotle disclosed " no sense of the progressive tendencies of humanity, nor the slightest glimpse of the natural laws of civilization." 1 Coming down even to modern times, we find in the seventeenth century nothing better on the philosophy of history than the puerile "Discourse" of Bossuet. The profound remarks of Pascal and Leibnitz, in regard to the progress of

1 Conte, Philosophie Positive, tome iv. p. 240. 
society, are to be deemed rather presentiments of the truth than the results of deliberate investigation. Machiavelli was one of the first to subject social phenomena to a careful study; but he arrived at no broad generalizations, and "he suffered, moreover, from the serious deficiency of being too much occupied with the practical utility of his subject." 1 The "Scienza Nuova" of Vico contained many new and startling views of history, and the writings of Montesquieu presented a daring attempt to constitute a social science; but both these great thinkers were crippled by a lack of materials, owing to the imperfect condition of physical knowledge at the time when they wrote. Condorcet, proceeding from the suggestions of his friend Turgot, arrived at the law that the whole human race is in a course of evolution, from the less perfect to the more perfect; but his writings are encumbered with metaphysical notions, and he had no idea of the true nature of human development. For above all his predecessors stands Voltaire, whose "Essai sur les Mœurs" was an immortal attempt to apply the principles of scientific investigation to the entire history of our race. Nothing more was done in this direction until the unprecedented develop-

1 Buckle, vol. i. p. 751, note 131. 
ment of physical knowledge which ushered in the present century was followed by the appearance of the "Philosophie Positive" of Auguste Comte. In this noble work, social as well as physical changes are shown to conform to invariable laws. Comte thus founded social science, and opened a path for future discoverers. But he did not perceive, any more than previous inquirers, the fundamental law of human evolution. It was reserved for Herbert Spencer to discover this allcomprehensive law, which is found to explain alike all the phenomena of man's history and all those of external nature. This sublime discovery, - that the Universe is in a continuous process of evolution from the homogeneous to the heterogeneous, - with which only Newton's discovery of the law of gravitation is at all worthy to be compared, underlies not only physics, but also history. It reveals the law to which social changes conform.

This preliminary glance is necessary, in order to comprehend the relation of Mr. Buckle's work to the treatises on social science which have preceded it. Mr. Buckle is one of that series of philosophers who, from Plato downwards, have studied human affairs. The Introduction to his "History of Civilization in England" is similar 
to the works we have just mentioned, in attempting to discover the laws which regulate the progress of society; and in many respects it surpasses them all. Mr. Buckle, it is true, gives us no new method of research, like Comte; nor does he, as we shall see, discover any universal law, like Spencer. Yet, in the boldness and com. prehensiveness of his views, and in the fearless candour with which they are stated; in the wealth of his erudition, and in the honesty with which he applies his facts; in the noble love of liberty which pervades his work, and in the eloquence which invests all parts of it with an undying charm, he has had fer equals in any age. Feeling that it is but just to pronounce our opinion at the outset, we say this with the more readiness, both because in the course of this criticism we shall be compelled to differ from him on many points of vital importance, and especially because Mr. Buckle's work has been received with a bitter and contemptuous hostility on the part of many reviewers, which cannot have failed to excite much groundless prejudice against the author and his doctrines. Not only is it that the merits of the work have been lnst sight of, while its defects have been exaggerated to an enormous 
extent; ${ }^{1}$ not only is it that its tendencies have been perversely misrepresented, and that it has been accused of aiming to subvert the principles of morality and religion: but it is that some of the most obvious facts upon which its arguments are based have been disputed; it is that the author has been charged with inaccuracies and errors which would disgrace the composition of a school-boy. Without repeating or taking further notice of such accusations, which savour no less of ignorance than of a spirit of unfair depreciation, we propose to examine Mr. Buckle's leading propositions, in the hope of ascertaining how far they explain the phenomena of society.

Proceeding on the method of investigation pointed out by Comte, Mr. Buckle claims to have established, in the volumes now before us, four great laws, which " are to be deemed the basis of the history of civilization." 2

The first of these fundamental laws is "that the progress of mankind depends on the success with which the laws of phenomena are investigated, and on the extent to which a knowledge of those laws is diffused." In laying down this prop-

1 [I had reference to the absurd article in the Quarterly Review, July, 1857.]

2 Buckle, vol. ii. p. 1. 
osition, Mr. Buckle can, of course, make no claims to originality. It is simply a clear and precise statement of the position taken by all the foremost thinkers of the age. For example, $\mathrm{Mr}$. Lewes says, "The evolutions of Humanity correspond with the evolutions of Thought." 1 Mr. Mill says, "We are justified in concluding that the order of human progression in all respects will mainly depend on the order of progression in the intellectual convictions of mankind; that is, on the law of the successive transformations of human opinions." 2 The same is implied in Mr. Spencer's law of evolution, ${ }^{3}$ and in the law of the three stages of civilization announced by Comte. ${ }^{4}$ With respect to the proposition as it stands, we have no criticisms to offer. It is substantiated, not only by the numerous facts brought up in the course of Mr. Buckle's work, but by all those furnished by the history of mankind in all ages and countries. The annals of our race are but an illustration of the law that "the evolutions of Humanity correspond with the evolutions of Thought."

I Philosophy of the Sciences, p. 23.

2 System of Loyic, vol. ii. p. 517, 4th edition.

3 Social Statics, pp. 409-456. Essays, pp. 1-54. First Principles pp. 1t6-218.

4 Philosophie Positive, tome i.pp. 3-20. 
Thus far Mr. Buckle proceeds on safe ground: but when he attempts, in his second fundamental law, to go still further, and to determine how much of our civilization is due to intellectual, and how much to moral, progress, - when he attempts ${ }^{1}$ to prove that the intellectual element in our nature is advancing, while the moral element is not, and that knowledge is the cause of progress, while good intentions are not, - he gets at once into complicated difficulties; and his argument, when stripped of its dazzling rhetoric, is so vague, confused, and unsatisfactory that we cannot help suspecting that the author has but an imperfect comprehension of what he is arguing for. At the outset, he makes an assertion directly contradictory to the proposition which he is to prove. $\mathrm{He}$ says, "There can be no doubt that a people are not really advancing, if, on the one hand, their increasing ability is accompanied by increasing vice, or if, on the other hand, while they are becoming more virtuous they likewise become more ignorant. This double movement, moral and intellectual, is essential to the very idea of civilization, and includes the entire theory of mental progress." 2 Having thus unequivocally expressed what we shall presently perceive to be in all prob-

1 Vol. i. chap. iv. 2 Vol.i. p. 159. 
ability the true state of the case, he proceeds to contradict himself, by setting to work to show that a people advance in civilization according as they advance in knowledge, leaving the moral element entirely out of the question. As this is one of the most important points in his whole work, and one which has excited hot discussion, we shall proceed to examine it at some length, taking up in succession the several steps of the argument.

Amid much that is obscurely stated, and much that is irrelevant to the subject, we trace the following line of propositions : -

I. The native faculties of men do not improve, so that we must look for progress only in their acquisitions.

II. They acquire but few " moral truths," which "remain stationary;" but they acquire many " intellectual truths," which are "continually advancing."

III. Because civilization cannot be regulated by the "stationary agent," it must be regulated solely by intellectual progress.

Let us see whether these statements will bear a critical examination. ${ }^{1}$

1 [This argument of "Intellect $v$. Morals" was regarded by Mr. Buckle as the fundamental position of his book. See Stuart-Glennie's Pilgrim Memories, p. 196.] 
I. Mr. Buckle begins by denying that the natural faculties of man are in a course of development. "Here, then, lies the gist of the whole matter. The progress is one, not of internal power, but of external advantage. The child born in a civilized land is not likely, as such, to be superior to one born among barbarians, and the difference which ensues between the acts of the two children will be caused, so far as we know, solely by the pressure of external circumstances; by which I mean the surrounding opinions, knowledge, associations, - in a word, the entire mental atmosphere in which the two children are respectively nurtured." 1

This is only bringing up again the old dispute about "the innate" and "the acquired," which has raged for centuries among metaphysical thinkers, but which we thought had been satisfactorily settled by the physiologists some time before Mr. Buckle penned the above passige. After it had been proved that every organism is constantly advancing in the vigour and complexity of its functions in relation to the conditions which surround it, nothing more was needed. But Mr. Buckle appears to have forgotten this. He not only ignores some of the late results of physiolog*

1 Vol. i. p. 162. 
ical investigation, but, still worse, in the passage just quoted, he flatly contradicts a theory which he elsewhere upholds. We refer to the doctrine, held by many naturalists, which supposes all the varieties of organic life, present and past, to have arisen from one or two primitive forms, by successive modifications of structure and function. With the evidence which might be brought forward in favour of this theory, we have, at present, no concern. It is enough to know that $\mathrm{Mr}$. Buckle is himself one of its supporters, as appear's from several passages in his work. ${ }^{1}$

Now, this theory supposes that all organic beings are continually advancing, not only in complexity of structure and variety of function, but also in the activity and vigour of their faculties. This may be illustrated by comparing the extremes of the animal kingdom. The hydra, or fresh-water polyp, is little more than a mere bag. In common with all the acrita, he possesses nervous substance, diffused in a cellular state throughout his body. ${ }^{2}$ Moreover, if you turn him inside

1 Vol. i. p. 806, note 130 , and p. 822 . The same is implied on p. 641. Ie also accepts the kindred doctrine of the unity of the organic and inorganic worlds. (See vol. ii. pp. 529-533.)

2 Or, more accurately speaking, he possesses a sensitive substance which, in more elevated beings, is specialized into nerrous tissue. (See Lewes' Seaside Studies, p. 390.) 
out, his skin will digest, and his interior membrane will respire; he will apparently suffer no discomposure from this reversed state of affairs. ${ }^{1}$ Again, if you put him into a vessel of water, he will invariably seek that part of it least exposed to the light, thus manifesting a rudimentary sensibility, which in its more developed state, in higher organisms, we call vision.2 The lower polyps exhibit also contractility over their whole body; and it has been supposed that they also possess, in a diffused condition, the germs of smell, taste, and even hearing. ${ }^{3}$ When now we ascend to the vertebrata, we find digestion specialized in the stomach, respiration in the lungs, contractility in the muscles, sensibility in the nerves; taste, smell, hearing, and vision, in the mouth, nose, ears, and eyes. This difference coexists with a great increase of power in the several functions. The faculties of the mammal are, as every one knows, far superior to those of the polyp. No one would think of comparing the rudimentary scent of the zoophyte with the developed scent of the dog, or the rudimentary sight of the acaleph with the developed sight of the Bosjesman. Vast, indeed, is the

1 Draper's Human Physiology, p. 501.

2 Spencer's Psychology, p. 401.

8 Ibid.pp. 394-408. 
difference between the hydra, whose body is but one organ, feebly performing several functions, and the elephant, whose body is a community of organs, each powerfully performing its own peculiar function: so vast, that many persons, even after allowing for the accumulated influence of causes which have been in operation for countless ages, are unable to believe that the higher organism could have come from the lower, throngh myriads of intermediate forms. Yet, if we are to believe this, - if we are to accept it as true, that this continuous perfecting of all the physical and mental faculties has been going on among the lower tribes ever since life first appeared on the earth, - why are we to suppose that it has not taken place in man? Is it that, when man came upon the stage, one of the most comprehensive laws of nature was, by some miracle, suspended forever in his case? Is it that in the most perfect of organized beings, exhibiting both in structure and function the completest instance of the evolutional process, that process could no longer be carried on? If we are to accept the development theory at all, we must accept it without limitations. We might as well say that the human race forms an exception to the operation of the laws of gravitation or chemical affinity as to 
say that it forms an exception in the case of the law of evolution, provided that law be once established.

We shall find our conclusion inductively confirmed, on observing that the development theory explains the differences between the races of mankind, as well as those between the animal tribes. Premising the fact, well known to every anatomist, that change in structure is invariably accompanied by change in function, we notice that the lower races, such as the Alfurus, resemble the quadrumana in having very small legs, protruding jaws, receding foreheads, thick lips, eyes wide apart and curved upwards; that as we proceed in turn to the red Indians, the Turanians, and the Semites, this resemblance becomes much less marked, and at last scarcely perceptible; and that, on reaching the Europeans, it can no longer be traced, except in infants. The legs have become much longer and more massive than the arms, which have diminished in length; the jaws have retired; the forehead has advanced; the lips have become comparatively thin: the eyes have approached each other, and lost their upward curvature. These facts, so familiar to every one that it is almost needless to cite them, show that, in respect to structure, we find a marked progress 
in the human species, no less than in the animal tribes. Even though the European is born with the structural peculiarities of the savage, he loses them almost immediately after birth; and his possessing them at birth no more proves that his matured faculties are on the same level with those of the savage than his possessing the characteristics of a fish some months before birth proves that his matured faculties are on the same level with those of a fish. Unless, therefore, $\mathrm{Mr}$. Buckle is prepared to deny that development in structure is necessarily attended by development in function, he cannot logically aroid the conclusion that the human species is in a course of evolution from the less perfect to the more perfect, or, to use his own expressions, that the progress of mankind is one of "internal power," as well as of "external advantage."

We have seen that Mr. Buckle accepts the law of development; that it is illogical to assert that man forms an exception to such a universal law; that this law, moreover, explains the facts of human variation, as well as those of animal variation; and that, consequently, Mr. Buckle's assertion that human faculties do not develop is totally inconsistent with the very theory held by himself respecting organic development in general. We 
have now to show that his assertion is in itself unfounded. But, preliminary to this, we must call attention to another point.

How it is that Mr. Buckle, who holds fast to the law of development, can reject the law of hereditary transmission, we are unable to imagine. Nevertheless, reject it he does, in the following passage, which, as Mr. Lewes remarks, must excite the astonishment of the physiologist:-

We often hear of hereditary talents, hereditary vices, and hereditary virtues; but whoever will critically examine the evidence will find that we have no proof of their existence. The way in which they are commonly proved is in the highest degree illogical; the usual course being for writers to collect instances of some mental peculiarity found in a parent and in his child, and then to infer that the peculiarity was bequeathed. By this mode of reasoning, we might demonstrate any proposition; since, in all large fields of inquiry there are a sufficient number of empirical coincidences to make a plausible case in favour of whatever view a man chooses to advocate. But this is not the way in which truth is discovered; and we ought to inquire, not only how many instances there are of hereditary talents, etc., but how many instances there are of such qualities not being hereditary. Until something of this sort is attempted, we can know nothing about the matter inductively; while, until physiology and 
chemistry are much more advanced, we can know nothing about it deductively. These considerations ought to prevent us from receiving statements which positively affirm the existence of hereditary madness and hereditary suicide; and the same remark applies to hereditary disease, and with still greater force does it apply to hereditary vices and hereditary virtues; inasmuch as ethical phenomena have not been registered as carefully as physiological ones, and therefore our conclusions respecting them are even more precarious. ${ }^{1}$

All this sounds very fine; but we do not think that our ignorance of this subject is so hopeless as Mr. Buckle supposes. Although we are at present unable to explain all the phenomena of the case, and account for all the apparent exceptions that arise, we do, nevertheless, all of us know that oaks always produce oaks, oysters oysters, sharks sharks, dogs dogs, and men men. We should probably deem it somewhat out of the usual course of things if a cow were to give birth to a leopard. We are not accustomed to think of a greyhound as having had for his sire an Arabian steed. We do not expect, on planting a nursery of acorns, to come back and find an orchard of apple-trees. And even the most unexcitable of as would open his eyes at the sight of a barn-door

1 Vol. i. p. 161, note 12. 
hen strutting about as the mother of a brood of eaglets. And yet, if there is no such thing as the transmission of qualities from parent to offspring, we see no reason ${ }^{1}$ why these liypothetical cases should not exist as realities. "Unless parents transmitted to offspring their organizations, their peculiarities and excellences, there would be no such thing as a breed or a race. The cur would run the same chance as the, best bred dog, of turning out valuable. The greyhound might point, and the cart-horse win the Derby. Daily experience tell us that this is impossible. Science tells us that there is no such thing as chance. Physiology tells us that the offspring always, and necessarily, inherits its organization from its parents; and if the organization is inherited, then with it must be inherited its tendencies and aptitudes." 2 This, from one profoundly versed in physiology, expresses what any one, not labouring to establish some preconceived theory, will at once recognize

1 Lest it should be thought that we do injustice to Mr. Buckle, in giving such a broad significance to his rejection of the law of liereditary transnission, we give a definition of that law, taken from one of the greatest thinkers of our time: "Understood in its entirety, the law is that each plant or animal produces others of like kind with itself; the likeness of kind consisting not so much in the repetition of individual traits as in the assumption of the same generic structure." - Spencer's Essriys, p. 203.

${ }^{2}$ Lewes' Physiology of Common Life, vol. ii. p. 377. 
as the real state of the case. And, indeed, since structure and function are inseparably connected; since diversity of structure necessarily supposes diversity of function, and similarity of structure similarity of function, it follows that, as like produces like in the case of structural forms, so also must like produce like in the case of functional peculiarities; and as the nervous system is but a part of the organism, and must come under the same generalization as the whole, so also does the same hold true of the functions of the nervous system, that is, of thought, feeling, and the like. In other words, there must be cases not only of hereditary madness and hereditary disease, but also of hereditary vices and hereditary virtues, so long as disease and madness, virtue and vice, coexist with peculiar structural states. And, as before, unless Mr. Buckle is prepared to deny the inseparable connection of structure and function, he cannot escape this conclusion.

As we have already observed, it is passing strange that Mr. Buckle, while embracing the law of development, should spurn that of hereditary transmission, to which it is so intimately related, and on which it, in some degree, depends for its proofs. But Mr. Buckle has a theory of his own to maintain. He wishes to show that 
the faculties of men do not improve. It is in order to do this that he rejects the law of transmission. But it has been shown that his rejection of it is illogical, and that the law of transmission is as universal as any other, since, were it not so, there could be no such thing as a species at all. With the help of this law, it is easy to demonstrate that, in the very nature of things, the faculties of men must improve.

Among that "highest class of biological truths," which apply to all organisms whatever, is the law that, "other things equal, development varies as function;" I that is, the growth of any organ depends upon its activity. We are everywhere met by instances of this: not only in the gymnast, who surprises us by the great size and power of his muscles; not only in the sailor, who sees a ship in the distant offing, when the passenger can descry but a speck; not only in the musician, who recognizes as different two sounds which to unpractised ears are alike; but also in the man of science, who unravels with ease problems which to common apprehensions are insoluble. "On this law are based all maxims and methods of right education, intellectual, moral, and physical."2 Expressed in the form, "Practice makes perfect," 
it is an axiom in every one's mouth. By exercising an organ, we increase its size and power. By neglecting to exercise it, we cause it to become diminutive, weak, inefficient.

It is evident, then, that when an individual has grown to maturity in the constant exercise of any faculty, the organ answering to that faculty will be correspondingly developed; and that, in the natural course of things, he will transmit to his offspring that faculty in its state of increased power. Thus it is that a Philip becomes the father of an Alexander; that the son of a Bernardo Tasso gives to the world a deathless poem; and that a family of three hundred musical geniuses at last counts among its members Johann Sebastian Bach. In individual cases, however, the operation of this law is obscured and often hindered by a concurrence of unfavourable circumstances. It is in the case of large collections of individuals, where the disturbing causes are averaged, that we find it most strikingly exemplified. Thus we see red Indians so swift of foot; "the telescopic-eyed Bushmen;" and Peruvians with sense of smell so acute that, according to Humboldt, they can distinguish by it, in the middle of the night, to what race a man belongs. ${ }^{1}$ Ex-

1 Dunglison's Human Physiology, vol. i. p. 729. 
tending our view from separate nations to the whole race, we perceive the law in still greater g'nerality. While some nations have been developing in some faculties, others have been developing in others, and the total movement has been ever onward. Each generation has inherited the faculties of the preceding, still further improved by constant employment. Phœnicians have thus spread commerce through unknown seas; Greeks have educated the world; Romans have legislated for it; Hindus, Jerrs, and Arabs have given it religions; Germans have deluged it with systems of philosophy; Frenchmen and Englishmen have given it positive knowledge; Americans have, by inventive genius, furnished material comforts; Italians have added the glorious embodiments of beauty, grace, and charm; and the consensus of the whole is civilization. Retrogression nowhere meets us; progress meets us everywhere; and, from the considerations above adduced, we are obliged to conclude that this advance has been one as well of "internal power" as of "external advantage." Mr. Buckle's assertion is, therefore, seen to be not only inconsistent, but also unfounded.

II. Having now proved, as he thinks, that we must look for progress in "external advantage" 
only, and not in "internal power," our author goes on to show the "superiority of intellectual acquisitions over moral feelings;" and first he asserts that all our acquisitions are either " moral truths" or "intellectual truths," and that the former are "stationary," while the latter are continually advancing. It is noticeable that he here deplores the difficulties which arise "from the loose and careless manner in which ordinary language is employed on subjects that require the greatest nicety and precision." 1 After giving us this caution, one would naturally expect to find our author very clear and accurate in the choice of terms, and in the statement of propositions; but, on the contrary, the loose and careless manner in which he himself employs ordinary language throughout the discussion is quite amazing. In the first place, he makes a verbally unintelligible distinction between "intellectual truths" and "moral truths." Scientifically speaking, there can be no such thing as a "moral truth;" for every truth is a proposition, consisting of subject, predicate, and copula; and is uttered and recognized by the intellect, not by the "moral instinct," which belongs to the emotional part of our nature. It is the province of intellect to

\footnotetext{
1 Vol, i. p. 159.
} 
think, of emotion to feel. Mr. Buckle falls into exactly the same error in a singular passage in his second volume, where he says :-

'The emotions are as much a part of us as the understanding: they are as truthful; they are as likely to be right. Though their view is different, it is not capricious. They obey fixed laws; they follow an orderly and uniform course; they run in sequences; they have their logic and method of inference. ${ }^{1}$

All this is either strained metaphor or downright nonsense. If it were true, what would be the use of making any distinction at all between intellect and feeling? If to feel is to judge, and to experience an emotion is to lay down a proposition, why not include both under one name? Mr. Buckle is misled by the fact that, in all our mental operations, feeling and thinking are closely united. Our wishes colour our judgments. We are all led, in many cases, to believe that to be true which we wish to be true. Thus emotional states give rise to intellectual states. On the other hand, Mr. Bain has shown that belief, when active, always leads to volition ; ${ }^{2}$ and as volition is the final stage of emotion, we perceive that intellectual states likewise occasion emotional states.

1 Vol. ii. p. 502.

2 Bain, The Emotions and the Will, pp. 568-598. 
But this intimate comnection of the two should not lead us to confound the one with the other; and we fall into a grave error whenever we do so. Once more we repent, it is the province of emotion to feel, of the intellect to think and form propositions. Scientifically speaking, therefore, all truths are intellectual; and there can be no such thing as a "moral truth."

But there is another sense in which the expression "moral truths" may be taken. It may mean "truths relative to morality." Mr. Buckle generally uses it in this sense, but he so often confounds "moral truths" with "moral feelings" that the foregoing remarks were rendered necessary to a right understanding of lis argument.

Our author then declares that the truths which we possess relating to morality have not changed for thousands of years. No, they have not. Neither have "intellectnal truths." A truth, once established, never changes, cannot change; otherwise it would be no truth, but a falsehood. Take, for example, the law of gravitation: "All bodies in the universe attract each other with forces directly proportional to their masses, and inversely proportional to the squares of their distances apart." We have had no oscasion to alter this statement since the time of Newton. It is a 
demonstrated truth, and will never be susceptible of the slightest change. The sime is the case with the truth, "It is wrong to kill." Once recognized, this truth can experience no change, for the very reason that it is a truth, and not a falsehood. In a word, when a proposition has been once shown to be true it will forever remain so, whether it relates to our moral obligations, or to anything else whatever. There is no ground for Mr. Buckle's distinction.

Nor would our author be one whit the more justified in saying, as he might say, that the interpretation put upon " moral truths" is unchanging as compared with that put upon "intellectual truths." On the contrary, it appears to us that the reverse is the case. When a truth relating to some of the simpler subjects of investigation is once received, its interpretation usually admits of little change. To employ the same example as before, the law of gravitation is received in the same acceptation now as when it was first discovered. Advancing to the more abstruse sciences, such as physiology, we find that the interpretation put upon generally received truths suffers marked variations. The law of organic development has been held by the most eminent scientific thinkers since the beginning of the present cen. 
tury; but, since the embryological discoveries of the Germans, it is held in a form different from that in which it was held before. The followers of Spencer, Lewes, and Darwin do not put the same interpretation upon the law of development that the followers of Lamarck did, forty years ago. Coming now to the very complex subject of morality, we find, unfortunately for Mr. Buckle, that the acceptation in which its propositions are held varies with every phase of civilization. Among the American Indians, so noted for their revengeful dispositions, the obligation not to take life, if recognized, was not so construed as to include the miserable object of the fell passion. Among the ancient Jews, the command "Thou shalt not kill " meant "Thou shalt not kill Jews;" and, from the story of Saul and Agag, we may suppose that the murder of Gentiles was considered rather a meritorious act than otherwise. And in general, where the same "moral truths", have been received, it has been in as many different ways as there were different kinds of people to receive them. This fact, that the way in which generally received truths are understood varies as the complexity of the sciences to which they belong, results from the obvious circumstance that the more complex a science is, the less we know 
about it. As we know less about moral science than about any other, our opinions, even about those "moral truths" which are universally admitted, are more liable to change than our opinions about similarly received truths in other matters. Mr. Buckle could have, therefore, no ground for asserting that the interpretation put upon "moral truths" is unchanging as compared with that put upon "intellectual truths."

Our author says, somewhat incousistently, that "moral truths" receive no additions, and again that they receive fewer additions than "intellectual truths." We shall speedily show that the first of these statements is at variance with fact, and that the second has no logical value, and will not help his argument in the lenst.

It is not true that "moral truths" have received no additions. It is not true, as Mr. Buckle says, that "the sole essentials of morals have been known for thousands of years, and not one jot or tittle has been added to them by all the sermons, homilies, and text-books which moralists have been able to produce." It is not true, as Sir James Mackintosh says, that "morality admits of no discoveries." It is not true, as Condorcet says, that "la morale de toutes les nations a été la même." It is not true, as Kant says, that 
"in der Moralphilosophie sind wir nicht weiter gekommen als die Alten." For what is Moral Philosophy but the science which is to determine the laws to which our conduct should conform? And if this is the case, we need only to look into Mr. Buckle's work itself, to find a system of morality containing truths which only two centuries ago were not even dreamed of. Take, for example, the moral law that governments shall not interfere with trade. This is as much a moral law as that which forbids stealing: but we find Mr. Buckle reckoning it among the merits of Voltaire, that he was one of the first to perceive the justice of a free system of trade. ${ }^{1}$ Its justice is even now denied by opponents of reform. This, then, is a case of a "moral truth" which has not been known for thousands of years.

Mr. Buckle may say, however, that he does not use the term "morality" in so wide a sense, that he means by it merely a collection of general rules and precepts, serving as rough guides for daily conduct. Of course, if Mr. Buckle chooses to define his terms to suit himself, he can prove anything. If he defines morality so as to make it include nothing but the precepts known three thousand years ago, and then says that all moral

1 Vol. i. p. 741. 
truths now known were known then, he merely asserts that what was known then was known then; a statement which probably few will be hardy enough to dispute, but which unfortunately leaves the argument just where it was before.

But supposing we accept this narrow definition of morality, what will become of our author's statement, even then? He himself quotes, from several authors, passages which show that there was a time when some nations did not acknowledge the moral law forbidding murder. "Among some Macedonian tribes, the man who had never slain an enemy was marked by a degrading badge." I And at the present day, among barbarous tribes, as the Dyaks of Borneo, "a man cannot marry until he has procured a human head; and he that has several may be distinguished by his proud and lofty bearing, for it constitutes his patent of nobility." 2 By calling up these facts, Mr. Buckle destroys his own statement that "moral truths" receive no additions.

As for his other assertion, - that " moral truths" receive fewer additions than "intellectual

1 Grote's History of Greece, vol. xi. p. 397, quoted in Buckle, vol. i. p. 176 , note 29 .

2 Journal of Asiatic Society, vol. iv. p. 181. 
truths," - it means simply that fewer discoveries are made in moral science than in all the other sciences put together. It is as if he should say that "optical truths" receive ferver additions than "physical truths." As we have shown, he is not justified in using the expression "intellectual truths," so as to exclude from it truths relating to morality, which are recognized by the intellect as much as any others. His statement, therefore, merely compares a part with all the other parts of the whole to which it belongs.

We are quite willing to admit that moral science has not been enriched by as many discoveries as any one of the other sciences. This results from the circumstance that it is far more difficult and complicated than the rest. Our knowledge of morality is less complete than our knowledge of chemistry, for the same reason that our acquaintance with chemistry is less perfect than our acquaintance with astronomy. The laws expressing the relations of men to one another are the most recondite of all, and the most liable to apparent exceptions. We are accordingly longer in ascertaining them.

To sum up: we have seen that the distinction made by Mr. Buckle between "intellectual" and "moral" truths is a vague and popular" one, and 
will not bear a critical analysis. We have throughout, however, used the expression "moral truths" as equivalent to "truths relating to moral subjects," and the expression "intellectual truths" as equivalent to "truths relating to all other subjects:" and this is admissible, because it gives the meaning intended by the author. We have then shown: first, that intellectual truths are as fixed and unchangeable as moral truths; secondly, that the interpretation put upon moral truths is even less constant than that put upon intellectual truths; thirdly, that moral truths receive additions, no less than intellectual truths; fourthly, that the fact that moral truths receive fewer additions than intellectual truths is of no logical value, because it compares one class of truths with several ; and fifthly, that the circumstance that moral science advances with a slower pace than the other sciences shows only that it is more complex than they are, but does not warrant us in assuming that it is radically different from them. Reviewing our conclusions in this compact form, we see that moral truths come under the same category as intellectual truths, throughout. This confirms what we said at the outset, that there is no such difference between them as Mr. Buckle supposes, and that 
both should be spoken of together as truths or judgments in distinction from feelings. $\mathrm{Mr}$. Buckle's argument, then, when laid bare, is as follows: that some truths are constant, while others are not, - which is false; and that one set of truths receives additions, while another does not, - which is also false.

But this is not all. Our author's argument is not only untenable, but it is irrelevant to the subject in debate. Even if he could establish his point, he would be none the more forward. Startling as this assertion may seem, it is nevertheless indisputable. For if his reasoning hitherto were valid, it would prove merely this that our knowledge of some subjects advances, while our knowledge of others does not. But Mr. Buckle's professed object is to show that feeling as compared with knowledge is of no account as a civilizing force. To what end, then, does he go so far out of his way in giving us this jumble of ill-digested argument to show the "superiority" of some intellectual acquisitions over others? This singular aberration results from his confounding truth with feeling, the intellectual with the emotional part of our nature. He seems to forget the distinction between knowing in what duty consists and having the intention to perform it. But 
it is altogether one thing to wish to do right, and another thing to know what it is right to do, as many a luckless wight finds out to his cost. Farther on Mr. Buckle recognizes the distinction clearly enough.

It would, however, be rather unfortunate than otherwise for Mr. Buckle's main argument if he could succeed in showing that " the sole essentials of morality have been known for thousands of years." For if it were true that men knew what was right - that they were acquainted with all the laws to which our conduct ought to conform - in ancient times as well as at the present day, and that they have nevertheless advanced in the practice of morality, we should be obliged to conclude that, as the knowledge has remained stationary, it must have been the development of moral feeling and the increase of good intentions alone which could have occasioned the progress. The contrast is really between moral truths and moral feelings. So that, if Mr. Buckle had succeeded in proving that " moral knowledge" does not advance, and should at the same time succeed in his attempt to prove that " moral feeling" does not improve, he would, if consistent, arrive at the singular result that there has been no improvement at all in the actions of men. 
It is quite a relief, on emerging from this labyrinth of baseless assertion and ill-directed argument, to find that our author at last seems to remember his original object, as he sets himself to work really to show the "superiority" of knowledge over feeling as a civilizing agent. His reasoning is here very plausible, and his illustrations drawn from the history of war and religious persecution are well chosen, and appear at first quite convincing. He tells us that good intentions were of no avail in stopping persecution, becanse persecutors themselves have generally had the best intentions. The heathen emperors of Rome, who tortured Catholics, the Catholic Inquisitors of Spain, who tortured Protestants, all meant well enough, he argnes, - they were very often men of the purest character; but they did not know that it was wrong for them to interfere with the religious convictions of others. So Mr. Buckle does perceive, after all, that our knowledge of our moral obligations has increased somewhat! We are no better, he says, than the Inquisitors of old, but we know that religions persecution is wrong, wicked, harmful; while they, in their mistaken zeal, thought it to be right, holy, beneficial. This point he argues admirably, but he does not succeed in absolving religious persecutors from all 
charge of selfish passion. Indeed, he elsewhere expresses it as his own opinion that the clergy have been strongly influenced, in their vindictive attempts to destroy or injure those dissenting from their views, by motives of ambitious policy. We have no doubt that such motives have always been of immense power among this class of men, as well as among other classes. But we will not urge this or any similar objection against $\mathrm{Mr}$. Buckle's grand argument. We will merely call attention to the circumstance that a man's "moral feeling," his "moral instinct," his "conscience," or whatever any one chooses to call it, is a natural faculty. In other words, ethical emotions, being functions of the nervous system, are natural faculties. And we have already shown that the natural faculties of mankind develop. The refutation of Mr. Buckle's first grand argument carries with it the refutation of the second.

III. It carries with it, likewise, the refutation of the third. For the proposition that civilization is regulated, not by the "stationary agent," but by intellectual acquirement, can have no value, unless it be proved that moral feeling is the "stationary agrent." But this cannot be proved. On the contrary, it has been shown that our powers, both moral and intellectual, are continually devel. 
oping, and that our acquisitions, both moral and intellectual, are constantly increasing. The moral element is, then, no more stationary than the intellectual; and thus Mr. Buckle's third grand argument falls to the ground, and with it falls his fundamental law, which is shown to be utterly destitute of any truth whatever.

It may be well to remark, before proceeding further, that rejection of Mr. Buckle's second law is perfectly compatible with acceptance of his first. There is no inconsistency in saying, on the one hand, that moral feeling is a civilizing agency, and, on the other hand, that the progress of civilization conforms to the successive transformations of opinion. For the ethical as well as all the other emotions enter largely.into every opinion-forming process. Though our emotions do not combine into propositions the ideas which are constituent parts of our beliefs, they do none the less, as Mr. Bain has clearly proved, ${ }^{1}$ sway the intellect as it performs this operation. The emotions accordingly enter into every act of belief, and there can be no complete theory of human opinion which leaves them out of account. Thus our acceptance of Mr. Buckle's first law confirms

1 See the whole of his admirable work on The Emotions and the Will. 
our rejection of his second, and we see, more clearly than ever, that "the double movement, moral and intellectual, is essential to the very idea of civilization," and that, without including both elements, there can be no complete theory of progress.

It may likewise be well to remark that a discussion of this sort has no immediate bearing on the subject of Christianity. It has been supposed by some persons that Mr. Buckle's entire argument is nothing but a sinister attack upon the Christian religion. We see nothing of the kind in it. Christianity is a system of belief, in which both intellectual and moril forces must co-operate; and a person, while denying the civilizing agency of the moral element, may with perfect consistency maintain the civilizing agency of that set of opinions in the formation of which the moral element has had but a partial share. Our author's argument, therefore, is not to be construed into an assault upon Christianity, nor is our owl argument to be construed into a defence of it. Confusion necessarily results from mixing questions which should be kept separate.

We come now to Mr. Buckle's third ${ }^{1}$ law -

I On the first page of his second volume, Mr. Buckle places this law second in order, and the law just considered third. But as it is 
that scepticism "has in every department of thought been the invariable preliminary to all the intellectual revolutions through which the human mind has passed," and that "without it there could be no progress, no change, no civilization." 1 In examining this proposition, it is needful, at the outset, to have a clear idea of the nature of scepticism, as understood by Mr. Buckle. The word itself has been variously interpreted; sometimes in a more general sense, as meaning the absolute denial of all dogmas, theories, and beliefs whatever; sometimes in a more special sense, as signifying disbelief in the peculiar doctrines of Christianity. It is in neither of these senses that Mr. Buckle uses the word. He defines scepticism as suspension of judgment, or hesitation in forming or receiving an opinion. A true sceptic, then, would neither believe nor disbelieve anything at all. He would doubt even his own doubts. History presents but few instances of a consistent and thorough-going sceptic. Pyrrho and Hume will, however, serve sufficiently well as examples. Scepticism is not to be confounded with that philosophy which, not content with

.unvenient to examine this law in connection with the fourth, we have taken the liberty to alter Mr. Buckle's arrangement.

Vol. i. p. 328. 
doubting, absolutely denies. This might be called negative philosophy, or negativism, in broad distinction from positive philosophy, which aims at establishing from incontrovertible data a system of results comprising all that it is in the power of the human mind to know. Negativism and positivism, then, constitute two opposite phases of human thought. As examples of negative thinkers, "we have Hobbes, Voltaire, Lessing, and Ronsseau; while as instances of positive thinkers we may cite Bacon, Leibnitz, Newton, and Spencer. Scepticism is identical with neither of these philosophies, though it has some points in common with both. Scepticism, indeed, is not a philosophy at all; it is a no-philosophy, - a transition state where, robbed of its belief, the mind rests not, but stays unresting, in dreary incertitude and distressful vacillation, until it finds refuge in belief again.

Bearing in mind this meaning of the word, we can safely proceed to examine the proposition before us. We do not think it altogether probable that Mr. Buckle would, on mature reflection, lay down this law about scepticism as a universal one, operative alike in all stages of progress; but, as he makes no limitations to it in the course of his work, we must discuss it here in relation 
to the three stages of mental evolution, and see whether or not it is alike applicable to all.

We shall find, to begin with, that it is not applicable to the theological state. When man first looked upon the wonders of Nature, his untaught imagination gave birth to weird, fantistic shapes innumerable, peopling the air, the streams, the forest, and the mountain-chasm. Just awakened, as it were, to self-consciousness, and feeling his own life thrilling within him, he ascribed that life to everything around him. He looked upon the wide, dark surface of the "many-sounding sea," and saw there a mighty, restless, earth-upheaving Power, which refinement afterwards personified, and called Poseidon. Gazing above him on the blue expanse which seemed to encompass the "plain of the earth," he came to recognize there a Divinity of light and warmth, a Devas, a paternal Zeus. When the bright clouds flitted along the sky, it was Hermes driving the celestial cattle to the milking; when the north-wind arose, cold and blustering, it was Boreas storming in his wrath; when the stars came out at night, there were countless deities to whom this primitive man made sacred the days of the week. The changes of the seasons, the ceaselessly recurring death and resurrection of Nature, were typified in wild 
legends of Jemshid and Zohâk, of Osiris and Thammuz, of Hylas and Orpheus. The whole universe was thinking, feeling, and willing. Nothing was dead or inert; all things were endowed with life and activity. From this came sacrifices, shrines and temples, oracles, and sacerdotal orders. It would be difficult to find any traces of scepticism in all this. Belief then reigned alone in the human mind, and doubt found no place there. As long as the phenomenal was as yet harder to comprehend and more difficult to control than the unseen and unexplored world that lay beyond it, scepticism was impossible. Not only was it impossible, but it would have been harmful. For the primitive man was barbarous, treacherous, revengeful. ${ }^{1}$ His selfish instincts were as yet all in all. His sympathetic and sosial feelings were as yet undeveloped. In such a rude condition it was only the bond of a firmly rooted and wide-spread belief - it was only the ascendency of a priestly and governmental order, thus secured - which could keep society from being disorganized. Had scepticism been once let in, religious and political organization would have been weakened, sects and parties would have sprung up prematurely, and the

1 Spencer's Social Statıcs, pp. 409-413. 
strong check needful to curb the undisciplined passions of men would have been destroyed, civilization would have stopped, and society could no longer have existed. It was only after centuries of theocratic and monarchic rule - after the primeval nomadic mode of life had been long abandoned, and agriculture and commerce had in course of time, by mingling men with each other in peaceful relations, called forth social virtues that scepticism could safely arise. And then it did arise. We find it first showing itself in the states of Greece, where popular despots arose and were overthrown, as at Korinth, Sikyon, and Megara; and where philosophers began to speculate about the first principles of things, as Thales, Xenophanes, and Herakleitos. Thenceforward scepticism increased, until it reached for a time its culmination in the universal doubts of Pyrrho. But it is not in ancient times at all that we are to look for any very prominent manifestation of scepticism. The spirit of doubting and hesitating inquiry was of slow growth, and did not attain to its maturity until monotheism had been established in Europe for more than a thousand years. Not only, therefore, has scepticism not always been essential to progress; not only have some important changes in human opinion - as 
the change from fetishism to polytheism - been accomplished without it; but also, in the first of the three great periods of civilization it did not arise at all until very late, and was then but a secondary force in the minds of men.

It is in the metaphysical or revolutionary period of modern society, extending from the twelfth century to the present time, that we see the sceptical spirit in full operation. To this stage of human evolution Mr. Buckle's proposition is applicable without any limitations. The application he has himself given us, with great fullness and detail, in the case of England, France, Spain, and Scotland. In the brief space to which we are here restricted, it would be vain to attempt to add to the profuse and happily chosen illustrations contained in those instructive chapters which our author has principally devoted to this portion of his subject. Nowhere else has the revolutionary period of history been so admirably portiayed. Nowhere else can we find a truer, a juster, a profounder appreciation of the workings of the sceptical spirit. Here we discover no inconsistencies, no errors of statement, vitiating the whole argument. Here Mr. Buckle reveals his wonderful power. Here he draws sure conclusions from well-ascertained data. For there can be no 
shadow of doubt that in the twelfth century the sceptical spirit had begun greatly to increase its power and extend its influence; that in the sixteenth it had become a mighty civilizing force; and that in the eighteenth it had penetrated all departments of thought. It was this sceptical spirit which gave rise to the conceptualism of A belard, the infidelity of Vanini, and the heresy of Wyclif. It became, as Mr. Buckle remarks, "in physics, the precursor of science; in politics, of liberty; and in theology, of toleration." But for the scepticism in his own mind; Luther could not have become the founder of Protestantism; and but for the scepticism already rife in the minds of others, he could have found no followers. We find scepticism dictating the metaphysics of Descartes and the diplomacy of Richelieu. We find it inciting the English to rebellion against the despotism of the Stuarts, and striving, though vainly, in the wars of the Fronde, to establish political liberty in France. It lay at the foundation of the sensationalism of Locke and the idealism of Berkeley, and was itself at laste organized into an independent system by Hume. It was the opening phase of that negative philosophy which, first receiving definite shape in the deism of Herbert and Bolingbroke, ended in the atheism of 
Diderot and Helvetius. It was the parent of the transcendentalism of Kant and Fichte, the physiophilosophic vagaries of Schelling and Carus, the absolutism of Hegel, and the pantheism of Feuerbach. Carried into science, it paved the way for the immortal discoveries of Lavoisier and Bichat. Wielded by Voltaire, it broke down ecclesiastical power in France; and in the hands of Rousseau swept away the vilest of despotisms by the most fearful of revolutions. It roused the Dutch to cast off the yoke of Spain, sent the Puritans to Massachusetts, inspired the Americans in their "Declaration of Independence," and shaped the fabric of their democratic government. What need of further examples? It is the sceptical spirit, advocating liberty in politics and toleration in religion, which has been at the bottom of every change through which humanity has passed in modern times. Mr. Buckle's law is entirely applicable to the metaphysical period of civilization, and is the key to the explanation of its phenomena.

But the metaphysical state is not a permanent one. It constitutes a transition from that primitive belief which was the offspring of man's early endeavours to compass and explain the Infinite about him, to that new belief which is founded 
on a long and thorough investigation into the laws of the natural world. Giving up as hopeless all search for the undiscoverable, all striving to know the unknowable, science contents itself with finding out that which lies within our reach. But it was not in the power of man, on first perceiving the inadequacy and incongruity of his old belief, to pass at once to the new. No one can reject an old system of opinions, which has shaped his thoughts and guided his actions in the past, and then take up a new system, to shape his thoughts and guide his actions in the future, without going through an intermediate state of painful and wearisome doubt. As with the individual, so with the race. The sceptical period could not but intervene. It was only after countless attempts to explore the dark and dangerous region of the Infinite had all proved futile - it was only after successive theories had all been weighed in the balance, and found wanting - that man could come at last to repose in the calm spirit and sure methods of scientific inquiry. Before this must necessarily have come that tumultuous season of doubt and denial, of discord and revolution, in which the sceptical spirit reigned supreme. The rottenness of old institutions, forms and dogmas, had to be exposed before they could 
be given up. Then the barrenness of doubt had to make itself felt before it could be supplanted by knowledge. It was not until Hume, by carrying scepticism to its uttermost extent, had shown its unsatisfactory character and vain results, that the germs of scientific method, implanted by Bacon and Descartes, could develop and bear fruit in the positive philosophy of Comte.

As the metaphysical period is but a transition from the theological to the positive, it only remains to show that scepticism is peculiar to it, being a transition from belief to knowledge. We have here very few facts to guide us to an inductive investigation, since the positive era is only now commencing. But, if we consider the state of human thought at the present day on the various subjects of scientific research, we shall find that in the most advanced departments scepticism no longer finds a place. Astronomers long ago gave over doubting and asking questions of each other about the fact of the earth's motion. It was the scepticism of Copernicus and Galileo that overthrew the old notion of its fixity; but that scepticism speedily issued in positive certainty. Whether a man believes or disbelieves in the motion of the earth is now a mere matter of knowledge or ignorance. There is no place for doubt, 
no room for difference of opinion. So with all demonstrated facts and laws. A truth once established remains forever a truth. We cannot choose but accept it. And science, as a body of established truths, cannot admit of scepticism.

The past history of science confirms, and its future progress must also confirm, this conclusion, which might be drawn at once from the very nature of thonght. When we know as much about the most complex subjects as we now know about the most simple ones, there can be no such thing as doubt at all. "The mystic drama will be sunny clear, and all Nature's processes will be visible to man, as a divine Effluence and Life." 1

We have seen that in the theological stage of human development scepticism did not exist; that in the metaphysical stage it arose and extended its sway over every department of thought; but that in the positive stage it is destined to decrease, until it exercises no perceptible influ-

* ence. Corresponding to these three stages of evolution are the three predominant mental states of belief, doubt, and knowledge. The three great periods into which Comte has divided the history of civilization might be named with perfect accu racy the period of credulity, the period of scep-

1 Lewes' Seaside Studies, p. 219. 
ticism $_{y}$ and the period of science. Mr. Buckle's law has this much of truth in it, that the sceptical age is the necessary forerunner of the scientific; that in the race, no less than in the individual, doubt must intervene between belief and knowledge.

We shall now briefly consider Mr. Buckle's fourth fundamental law, - that " the great enemy of civilization is the protective spirit;" or in other words, "the notion that society cannot prosper, unless the affairs of life are watched over and protected, at nearly every turn, by the state and the church, - the state teaching men what they are to do, and the church teaching them what they are to believe." 1 Here, as in the foregoing case, Mr. Buckle errs only in stating his law without any limitations, as if it were a universal one. It cannot be questioned that for several centuries the protective spirit has been extremely prejudicial to progress. The notion that government ought to control the actions and beliefs of men has, when carried into politics, furnished a plea for despotism, and when carried into theology it has been productive of intolerance and persecution. Mr. Buckle devotes a large portion of his work to the establishment and elucidation of this fact. $\mathrm{He}$ 1 Vol. ii. p. 1. 
shows that government and legislation are incompetent to direct the affairs of men. He shows that politicians have injured trade by interfering with it; that legislators have caused smuggling, with its attendant crimes; that they have also increased hypocrisy and perjury; and that, by their laws against usury, they have but heightened the evil they sought to prevent. He shows that the protection of literature by Augustus, by Leo X., and by Louis XIV. caused literature to decline. In each case "there was much apparent splendour, immediately succeeded by sudden ruin." 1 The system of protecting literature was carried to its fullest extent by Louis XIV., and nowhere can we see more clearly the baneful effects of such a course. For the scientific progress which had been so marked in the reign of Louis XIII. stopped forthwith. Descartes and Pascal, Fermat, Gassendi, Riolan, Joubert, and Paré died, and left no successors. Nothing was done in astronomy, in chemistry, in physiology, or in botany. Of mechanical inventions there were none. Even the fine arts soon began to decline; and intellectual decay, the natural consequence of patronage, was seen in every department of thought So in many other cases we see the damage en1 Vol. i. p. 647. 
tailed by the interference of government. Laws fixing a minimum of wages have caused thousands of labourers to be turned out of employment. ${ }^{1}$ Laws regulating marriage have ended in increasing the number of illegitimate births. ${ }^{2}$ Laws for the establishment of sanitary supervision have spread disease, and lengthened ont the mortality returns. ${ }^{3}$ Laws for the support of colonial government have given rise to the most barbarous tyranny. ${ }^{4}$ Trade-union projects, economic experiments, poor - laws, education - laws, church - laws, currency-laws, have all turned ont to be failures, and in many cases have inflicted upon society positive misery, instead of conferring upon it positive benefit. Paradoxical as all this may at first seem, it is but a statement of historic facts. ${ }^{5}$ Modern history is filled with similar examples, all showing the utter incompetence of government to regulate the affairs of men. The duty of government is to insure the fulfilment of the first prineiple of morality, - that no man shall infringe

\footnotetext{
1 As in the case of the Spitalfields weavers in 1773.

2 As in Bararia.

3 As in England, some years ago, during the cholera pestilence.

4 As in the case of the East India Company, and of the American
} Colonies before the Revolution.

5 See the evidence in Spencer's Social Statics, pp. 195-406, and in Mr. Buckle's volumes. 
upon another's sphere of action. If it but performs its duty, it will do well. But when it goes to making plans for securing the "greatest happiness to the greatest number," it usually contrives to end up by securing the least happiness to every one, having failed in its projects, and neglected its proper function mean while.

But on looking back and contemplating society in its primitive state, we shall arrive at very different conclusions. We shall perceive that the protective spirit, far from being prejudicial to progress, was one of its most essential conditions. Indeed, on calling to mind all those centuries of primeval history, when there was nothing to counteract the workings of the protective spirit, and when all things conspired to strengthen its power, one might reasonably ask at the outset why it was that under such circumstances the human race made such sure and unceasing progress; why it was that it progressed at all; why it was that it did not even retrograde. If the protective spirit is of necessity in every age the enemy of civilization, how did it happen that we ever emerged from a state of barbarism? How comes it that we have not remained uncivilized, mere nomads, or at best diggers of earth, living from hand to mouth, little better, on the whole, 
than a race of chimpanzees? For Mr. Buckle's own facts show that the protective spirit has never been so strong as in the early ages of history. "In India, slavery, abject, eternal slavery, was the natural state of the great body of the people." 1 The "vast social system" of Egypt was "based on despotism" and "upheld by cruelty." 2 In Mexico and Peru, "there was the same utter absence of anything approaching to the democratic spirit: there was the same despotic power on the part of the upper classes, and the same contemptible subservience on the part of the lower." 3 Again, in Babylonia, Assyria, and Persia, despotism was the only form of govermment ever experienced or thought of. 4 We have evidence of the same in the case of China and Japan. We find, moreover, that in barbarous countries, like Ashantee, despotism universally prevails. Going still lower, still farther back, we see nomadic tribes always in subjection to the will of the strong man. Now, for many thousands of years ${ }^{5}$ civilization was advanc-
1 Vol. i. p. 73.
2 Ibid. p. 83.

3 Ibid. p. 101. In Peru, according to Mr. Prescott, the people could not even change their dress without a license from their rulers!

4 The passage in Herodotus, b. iii. c. 80-83, is well known to have Do historical value; see the remarks of Rawlinson, vol. ii. p. 393.

5 Bunsen's Egypt, passim. Darwin, Origin of Species, p. 23. 
ing in Egypt; Babylonia, Persia, and many of the other nations above-mentioned made considerable progress; India even arrived at a high state of refinement, as is witnessed by her extensive and magnificent literature. All this shows that in early times progress did co-exist with the strongest possible manifestation of the protective spirit; and when we consider that there was nothing then to counterbalance the workings of the protective spirit, that all physical causes contributed to favour its development, ${ }^{1}$ and that scepticism, the only thing that could have weakened it, did not exist, we may suspect that the protective spirit could not have been so detrimental to the interests of civilization as Mr. Buckle supposes.

On looking at the matter deductively, it will even appear that without the protective spirit there could have been no civilization. For what but the most absolute despotism and the profoundest awe of the ruling power could ever have kept together the communities of the primitive men, with their cannibalism, their bloodthirstiness, their dishonesty and treachery? As long as men could not live together peaceably, as long as they neither knew nor practised the first principles of morality, there must have been some

1 Buckle, vol. i. chap. 2. 
power sufficient to keep society from falling to pieces, or there could have been no progress at all; and the only such power conceivable was that total subjection of the many to the few which constitutes the protective system of government. As long as Persians mutilated each other, and Carthaginians burned their children, and Chinamen beat to death their wives; as long as Hindus practised thuggee, and Spartans practised stealing, and Ionians practised piracy, there must have been "Drakonian statutes written in blood," there must have been absolute despotism. Without this, society would have become a parcel of units. Imagine a republic of Tatars, a constitutional democracy of Vandals, and develop the consequences!

Thus in the primitive stage of civilization the protective spirit played the same part as universal credulity in preserving society from disintegration. Thus it becomes more evident than before that scepticism would have been harmful at that early period. It would have weakened the protective spirit and destroyed allegiance, besides causing religious dissension. Nothing of the kind was then admissible. The selfish and brutal feelings of men had to be restrained, and their social and humane feelings called forth, before the sceptical 
spirit could safely commence its inroads upon the spirit of universal belief and universal submission. The protective spirit was therefore in early times the great safeguard of civilization and the allessential condition of progress; and this very important restriction must be placed upon Mro Buckle's law.

On looking at the subject in its broadest and most general aspect, we shall arrive at the conclusion that all systems of belief and all great institutions are beneficial when they first spring up. Each has its functions to perform, and the more carefully we study history the more deeply shall we be convinced that it performs it in the best possible manner. But after these beliefs and institutions bave done their work and are no longer needed, after they have been stereotyped in lifeless forms, then it is that they become productive of evil and are prejudicial to the interests of mankind.

With the help of these considerations, we can more completely understand Mr. Buckle's two propositions. With the restrictions here placed upon them, they might be stated thus: in the revolutionany period of modern society, scepticism has been uniformly essential to progress, and the protective spirit has been uniformly detrimental 
to it. This is strictly true, and needs no qualification.

In his second volume our author develops another fundamental law, which we have not time to consider here. It may be stated thus: in a country where the deductive method of investigation prevails, there will be a much greater difference in the intellectual and social condition of the upper and lower classes than in a country where the inductive method is the prevalent one. This may be illustrated by comparing Greece, Germany, and Scotland, on the one hand, with England and the United States on the other. The application of this law in the case of Germany and America is to be contained in the third volume.

In conclusion, we must say a few words in regard to Mr. Buckle's application of his four great laws. The application of the first runs through the whole work. In every chapter we are met by numberless illustrations of the law that the progress of humanity conforms to the progress of opinion. It is different, however, in the case of the second law which we have discussed. Mr. Buckle appears entirely to forget his theoretical neglect of the moral element in our nature, and to take it practically into account as much as any 
one else. In his delineations of wars, civil revolutions, and especially of religious persecutions, he seems to believe in spite of himself that "moral feelings" do exercise as much power over men as "intellectual acquisitions;" and that the effects produced by the former are quite as lasting as those produced by the latter. He repeatedly recognizes the fact that our desires and impulses influence us strongly in the acceptance and defence of opinions. In speaking of the Scotch clergy, he attributes their tyrannical enforcement of superstitious notions to an inordinate desire for power, not to a mistaken interest in the welfare of others. After noticing the profound reverence of the Scotch people for their clergy, he observes: "It is not surprising that the clergy, who at no period and in no nation have been remarkable for their meekness, or for a want of confidence in themselves, should, under circumstances so eminently favourable to their pretensions, have been somewhat elated, and should have claimed an authority even greater than that which was conceded to them. . . . It was generally believed that whoever gainsaid the clergy would be visited, not only with temporal penalties, but also with spiritual ones. For such a crime, there was punishment here, and there was punishment hereafter. 
The preachers willingly fostered a delusion by which they benefited. . . . They did not scruple to affirm that, by their censures, they could open and shut the kingdom of heaven. . . The clergy, intoxicated by the possession of power, reached to such a pitch of arrogance that they did not scruple to declare that whoever respected Christ was bound, on that very account, to respect them. ... Such was their conceit, and so greedy were they after applause, that they would not allow even a stranger to remain in their parish, unless he, too, came to listen to what they chose to say. ... How they laboured to corrupt the national intellect, and how successful they were in that base vocation, has been hitherto known to no modern reader." $1 \mathrm{He}$ also tells us that the Scotch clergy used "means of intimidation," because, being " perfect masters of their own art," they well knew that " by increasing the apprehensions to which the ignorance and timidity of men make them too liable" they would also "increase their eagerness to fly for support to their spiritual advisers." 2

All this is very significant. It shows that Mr. Buckle is unable to escape from recognizing the

1 Vol. ii. pp. 344, 347, 348, 357, 365.

2 Ibid. pp. 366, 384. 
enormous influence of feeling in leading to belief and action. After labouring to show that persecutors are actuated only by mistaken benevolence, he here declares that the tyrannical and intolerant acts of the Scotch clergy were dictated by cunning selfishness and long-sighted craft. We think that he here commits almost as great an error as before, though in the opposite direction, by attributing too much to the selfish desires of these men, and by taking too little account of their good, but mistaken, intentions. There is glaring inconsistency in this: but when a man lays down a "law" so incredibly absurd as the one in question, we must expect to find him inconsistent in its application.

But Mr. Buckle devotes by far the largest portion of his work, thus far, to the illustration of his third and fourth laws. As he treats only of the revolutionary period, his illustrations are all appropriate and forcible. We lack words to express our admiration of these profound and instructive chapters. The inquiry into the history of the intellect in England, France, Spain, and Scotland shows an extent of learning and a depth of thought unsurpassed, so far as we know, in historical literature. Our author traces the rise of scepticism and the decline of the royal power in England, 
the workings of the protective spirit in England and France, the causes, remote and proximate, of the French Revolution, all with the most consummate skill. In the case of Spain, he sets before us in vivid colours the utter impotence of government to direct social progress. He describes in bold outlines the course of philosophic investigation among the Scotch, and the influence of their habits of thought upon their general condition. Everywhere, in this part of the work, we see the touches of a master; everywhere we find something to instruct and entertain. Had Mr. Buckle written nothing more, these chapters alone would suffice to make his name immortal. Considered merely as historic pictures they rival anything in Gibbon or Grote.

We have not criticized at length Mr. Buckle's first law, because we have no restrictions to place upon it, and because it may be found demonstrated, as completely as possible, in Mr. Buckle's own work. As the result of our examination into his other laws, we have found that the second contains no truth whatever, being supported by a tangled chain of soplisms, every link in which is unsound; but that the third and fourth are strictly true, if limited to the period of which Mr. Buckle treats. The first law did not originate with him, 
and the second he has fuiled to establish; but the third and fourth may take their places as important additions to our knowledge of human history. 'This is the lasting service which Mr. Buckle has already rendered to science.

With respect to the tendency of Mr. Buckle's work, an unprejudiced mind can have but one opinion. It is calculated to awaken independent thought, and to diffuse a spirit of scientific inquiry. Written in an easy and elegant style, it will be read with pleasure by many who would not otherwise have the patience to go through with the subjects of which it treats. Thus, grand and startling in its views, impressive and charming in its eloquence, it cannot fail to arouse many a slumbering mind to intellectual effort. Such has its tendency already been, and such it will continue to be. Indeed, with Mr. Buckle's diligence, his honesty, his freedum of thought, his bold outspokenness, his hearty admiration for whatever is good and great in man, the tendency of his work could not well be otherwise. All these are qualities which will be remembered when his inaccuracies and errors, however great, shall be forgotten. And whatever may be thought about the correctness or incorrectness of $\mathrm{Mr}$. 
206 Darwinism and Other Essays.

Buckle's opinions, the world cannot be long in coming to the conclusion that his "History of Civilization in England" is a great and noble book, written by a great and noble man.

September, 1861. 


\section{XI.}

POSTSCRIPT ON MR. BUCKLE.1

THE pilgrimage of an "infidel" to Mount Sinai and the tomb of Christ affords a suggestive theme for meditation. It is with no disparaging intent that we use the vague epithet "infidel," for $\mathrm{Mr}$. Stuart-Glennie is himself most explicit in assuring us that neither with Christianity nor with what he calls "Christianism" does he acknowledge any fellowship or alliance. By Christianity he means "that great historical system which culminated in the philosophy of Scholasticism, the religion of Catholicism, and the polity of Feudalism;" and by Christianism he means "that historical theory which represents Jesus of Nazareth as a supernatural being, who came on earth for the good of mankind, was put to death, and rose again to sit on the right hand of God." The historical system Mr. Stuart-Glennie perceives to

1 Pilgrin Memories; or, Travel and Discussion in the BirthCountries of Christianity with the late Henry Thomas Buckle. By John S. Stuart-Glennie, M. A. New York: D. Appleton and Co. 1875. 
have come to an end, and the historical theory he has learned to regard as antiquated and unsound, and he therefore frankly declares himself an opponent of Christianity, and stigmatizes as dishonest all description of the Christian religion as a morality, or sentiment, or ethical impulse. With the same frankness he expresses himself about beliefs which "Christianism" has always held dear, in language, and still more in a tone, calculated to exasperate the Christian world to the last degree, so that a leading orthodox reviewer has been led to recognize in lim the "fool" described by the Psalmist who has "said in his heart that there is no God." This is, however, inaccurate, for Mr. Stuart-Glennie is certainly no atheist. It is the very purity and sensitiveness of his theistic instinct that leads him, like Theodore Parker, to condemn as degrading much that still finds a place in popular theology. One might, indeed, even plausibly question the propriety of Mr. Stuart-Glennie classifying himself as an anti-Christian, were it not that he is so explicit in defining what he rejects as Christianity. But, in truth, such questions of nomenclature are rdle, for "Christian" is a word of such wide and vague connotations that, however well adapted nt may be for various religious uses, it possesses 
hardly more defining value than such a word as "philosophical;" and whether a given set of opinions can be grouped under such rubric or not has become a point hardly worth arguing.

While mainly a personal narrative, this book of "Pilgrim Memories" keeps certain ulterior ends in view. The author has projected, and in part executed, an extensive series of works to be entitled "The Modern Revolution," in which nothing less is aimed at than the establishment of a new law of history, a new speculative basis for religion, and a new point of departure for dradmatic art. The new law of history and the new speculative basis for religion we are to seek in the conception of historic development as "a certain Change, and Process of Change, in men's notions of the Causes of Change." One object of the present volume is to show how this conception took shape in the author's mind in the course of his journeyings and discussions with $\mathrm{Mr}$. Buckle. By the Gulf of Ezion-Gebir, "walking or riding along a shell- and coral-covered strand: on our right the sea, red with the coralline forests of its depths, and with a margin so bright and clear that, as we rode, we saw all its gemlike pavement; on our left sandstone precipices of the most magnificently-varied hues," - amid 
this strangely beautiful scene we enter upon quite a Platonic dialogue, in which the author seeks to expound his new conception of causation, while Mr. Buckle occasionally interposes with "I do not follow you, I confess," or "That seems philosophical enough," quite after the manner of the

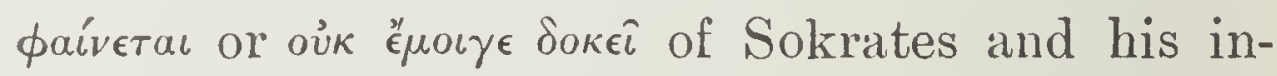
terlocutors. This long conversation, or series of conversations, is perhaps the most interesting portion of the book. Yet Mr. Buckle evidently does not get a thorough hold of what Mr. Stuart-Glennie means by defining causation as involving "not merely the conception of Uniformity of Sequence," but also that of "Mutuality of Coexistence, or Mutual Determination;" and we must confess that to us also his meaning seems by no means distinctly set forth or adequately elucidated. It is to be hoped that in future volumes this point will be thoroughly cleared up, for we are told that the "Change in our conceptions of the Causes of Change," which the author has discovered to be the "Ultimate Law of History," is neither more nor less than "an advance from the conception of One-sided Determination to that of Mutual Determination." That this statement is fraught with meaning for Mr. Stuart-Glennie there can be no doubt; he recurs to it again and again, as if 
it were a sort of talismanic formula for the solution of all manner of problems, psychological and historical. But it is just one of those formulas, like Mr. Spencer's famous law of the change from incoherent homogeneity to colierent heterogeneity, that needs to be charged with significance by means of copious preliminary explanation in order to convey any sense at all to the mind of the reader.

To the many readers who, some twenty years since, were interested in what then bid fair to be the "biggest of big books," the most attractive pages in Mr. Stuart-Glennie's volume will be those which give us glimpses of the personal peculiarities of Mr. Buckle. The sad story of Mr. Buckle's fruitless journey in quest of health, the rapid decay of his strength, and his untimely death at Dimascus has long been generally known, but it acquires fresh interest from the fuller account now given by his fellow-pilgrim. Few would now rate the value of Mr. Buckle's work, or the loss to science from his premature end, so lighly as they were commonly rated at the time. Yet, as a fresh instance of how life is short while art is long, of how the world passes away from us while yet we are stammering over the alphabet of its mysteries, there is something infinitely 
pathetic in the cry which went up from the exhausted and fever-stricken traveller: "My book, my book! I shall never finish my book!" The pathos is not diminished, but perhaps rather deepened, by the reflection that the book possessed no such transcendent value as its author ascribed to it, and that in all probability the strange irony of fate, had it granted to Mr. Buckle the long life of a Carlyle or a Humboldt, would only have permitted him to survive his own reputation as a leader in the world of thought. It is seldom that so brilliant a success as Mr. Buckle's has been even temporarily achieved by such superficial thinking and such slender scholarship. The immense array of authors cited in his book bears witness to the extent of his reading, but the loose, indiscriminate way in which they are cited shows equally how uncritical and desultory his reading was. One may ascribe this looseness to the native impatience of temperament illustrated in his disposing of Gibbon and Hallam in ten days; but certainly his solitary education and solitary habits of study conld do little towards curing the fault. One reason why the scholarship of universitybred men is in the main so far superior to that of men who have been taught at home is that the former are regularly forced, by continual contact 
and rivalry with fellow-students, into habits of self-restraint and self-criticism in reaching conclusions which only the rarest innate virtues of intellect can enable the latter now and then, in spite of their solitude, to acquire. It is but once or twice in an age that the home-tanght student can receive the stimulus to patient sagacity that was afforded in the cases of Grote and Mill. The kind of unceasing criticism which university-life affords the best means of securing is in most cases indispensable. Less effective, because less direct and constant, but still very valuable, is the discipline that is gained by early and frequent authorship, where a writer is so constituted as to be able to profit alike by fair and unfair public criticism. That there may be men of genius with such marked native qualities of cantion and vigilance as to enable them partially to dispense with such educational aids we do not deny; but Mr. Buckle was not one of these. He begin life with his full share of the "original sin" of hasty generalization; and nothing in his circumstances tended to check or control this disposition until, at an age when one's mental habits are usually pretty well ingrained, he appeared before the world with the first instalment of his able and stimulating but crude and hastily-wrought book. 
Not only did Mr. Buckle's impatient and uncritical habit prevent his vast reading from resulting in sound scholarship, but his lack of subtlety and precision were so marked as to stamp all his thinking with the character of shallowness. He seized readily upon the broader and vaguer distinctions among things, the force of which the ordinary reader feels most strongly and with least mental effort, and of such raw material, without further analysis, and without suspecting the need for further analysis, he constructed his historical theories. To this mode of proceeding, aided by his warmth of temperament and the lavish profusion of his illustrations, he undoubtedly owed the great though eplemeral success which his book attained. The average reader is much sooner stimulated by generalizations that are broad and indistinct than by such as are subtle and precise; and if we stop to consider why Mr. Buckle's name has been sometimes associated with those of men so far beyond his calibre as Mill and Darwin, we may see the reason in the fact that Mr. Buckle could be entirely grasped by many of those very admirers of the latter writers who least appreciate or fathom their finest and deepest mental qualities. But this essentially superficial character of Mr. Buckle's thought is shown not only in his ob- 
tuseness to subtle distinctions, but even more conspicuonsly in his utter failure to seize upon any deeply significant but previously hidden relations among facts, in the work which he put forth as the "Novum Organum" of historical science.

If we contrast his book with some of the really great books which were contemporary with it, such as Mr. Darwin's "Origin of Species," Mr. Spencer's "Principles of Psychology," or Sir Henry Maine's "Ancient Law," the difference is striking enough. Each of these works set forth old facts in new and hitherto unsuspected connections, and in so doing enunciated thoughts which have quite changed the aspect of the questions with which they deal. There is not a naturalist in either continent to-day whose most specific inquiries do not bear some more or less conscious reference to what is known as "the Darwinian theory." The time-honoured contest represented by Locke and Leibnitz, or by Hume and Kant, is beginning to take a new point of departure, owing to Mr. Spencer's suggestion of the acquirement of mental faculties through inheritance and slow variation; and Sir Henry Maine's lucid exposition of early ideas regarding contract, property, and family relationship obliges us to look at all the phenomena of society from an altered 
standpoint. But, in marked contrast with works of this kind, we find in Mr. Buckle's book sundry commonplace reflections of quite limited value or applicability, such as the statements that scepticism is favourable to progress, or that over-legislition is detrimental to society. No doubt such commonplaces might be so treated as to acquire the practical value of new contributions to history. But to treat them so requires subtle analysis of the facts generalized, and all that $\mathrm{Mr}$. Buckle did was to collect miscellaneous evidences for the statements in their rough, ready-made form. Of generalizations that go below the surface of things, such as Comte's suggestive though indefensible "Law of the Three Stages," we find none in Mr. Buckle. The only attempt at such an analytic theory is the generalization concerning the mo:al and intellectual factors in social progress, wherein Mr. Buckle's looseness and futile vagueness of thought is shown perhaps more forcibly than anywhere else in his writings. It is not of such stuff as this that a science of historic phenomena can be wrought.

In Mr. Stuart-Glennie's reminiscences, which seem to be most carefully and honestly reported, these characteristics of Mr. Buckle - his warm, impatient temperament and his lack of mental 
subtlety or deep penetration - are continually brought to our notice; and all the more forcibly because of the absence of any such intent on the part of the fellow-pilgrim to whom we owe these interesting notes of discussion. To examine the details of these conversations would carry us beyond our limits, and would hardly be justified by their intrinsic importance. One little point we must note as characteristic, with regard to $\mathrm{Mr}$. Buckle's temperament as a historian. While Mr. Stuart-Glennie seems to have his whole soul stirred within him by the historic associations clustering about the places visited, and is moved to reflections always interesting and often suggestive, $\mathrm{Mr}$. Buckle, on the other hand, though sufficiently alive to the beauties of nature, seems quite oblivious to historic memories. At the sepulchre of Christ his thoughts were mainly on political economy, "the state of society and the habits of the people." In such trivial details some light is thrown, perhaps, on that lack of intellectual sympathy with the past which was one of Mr. Buckle's most notable defects as a historian.

But with all this intellectual narrowness and looseness of texture, the narrative gives one a very pleasant impression of $\mathrm{Mr}$. Buckle person. ally, and, furthermore, enables one to comprehend 
how, with such slight qualifications, he should have become so interesting to the world. One leaves Mr. Stuart-Glennie's book with the regret experienced on parting with intelligent and kindly companions. As we close it and lay it aside, we feel that yet another charming moment of our reading-life has gone to be numbered with the things of the past.

March, 1876. 


\section{XII.}

THE RACES OF THE DANUBE.

IN the famous Eastern Question, which so long has disturbed the peace of Europe, may be noted two aspects of a process which, under great variety of conditions, has been going on over European territory ever since the dawn of authentic history. The formation of a nationality - that is, of a community of men sufficiently connected in interests and disciplined in social habits to live together peacefully under laws of their own making - has been the leading aspect of this process, in which the work of civilization has hitherto largely consisted. But along with this, as a correlative aspect, has gone the pressure exerted against the community by an external mass of undisciplined barbarism, ever on the alert to break over the fluctuating barrier that has warded it off from the growing civilization, ever threatening to undo the costly work which this has accoplished. Though the enemy has at times appeared in the shape of unmitigated tribal bar- 
barism, - as in the invasion of Huns in the fifth century and of Mongols in the thirteenth, - and at other times in the shape of an inferior type of civilization, as exemplified by the Arabs and Turks, the principle involved has always been the same. In every case the stake has been the continuance of the higher civilization, though the amount of risk has greatly varied, and in recent centuries has come to be very slight. At the present day the military strength of mankind is almost entirely monopolized by the higher civilization, and it is no longer in danger of being overwhelmed by external violence. But when the Greeks confronted a social organization of inferior type at Marathon and at Salamis, the danger was considerable; and in pre-historic times it may well have happened more than once that some germ of a progressive polity has been swept away in a torrent of conquering barbarism.

Until the rise of the Roman porwer the chief military business of the cultivated community had been to drive off the barbarian, to slanghter him, or reduce him to slavery; but the more profound policy of Rome transformed him, whenever it was possible, into a citizen, and enlisted his fighting power on the side of progress. From the corrquest of Spain by Scipio to the subjugation of Central 
Germany by Charles the Great, this is the most conspicuous feature of Roman history. The area of stable nationality in Europe was continually enlarged, and the frontier to be defended against wild tribes was gradually shortened and pushed eastward to the Lower Danube. In the time of Marius, the Ganl and the German were enemies who might possibly undo all the good work that had been begun. But the Gaul very quickly became a thorough Roman in his habits and interests, forgetting even his native language; and the German tribes, as they acquired a foothold, one after another, within the limits of the Empire, became so far assimilated that the transformation of the Roman structure effected by them was in no respect, not even in a political sense, an overthrow.

In the turbulent period of the fifth century, when the debatable frontier was still at the Rhine and Upper Danube, a terrible foe appeared in Attila, with his horde of savage Huns; and it was then mainly by the prowess of Gauls and Germans, in the memorable battle of Châlons, that the security of European civilization was decisively guaranteed. So formidable a danger has perhaps never since menaced Christendom, though Gibbon reckoned the teaching of the 
Koran in Oxford as one of the consequences that might have ensued had Charles the Hammer been overthrown at Tours by the Arabs. Under the grandson of this doughty hero - Charles the Great - the entire strength of Germany became enlisted in the service of the Christianized Empire, and among the results of this were the conversion of the newly-arriving Magyars, Poles, and Bohemians, and the conquest of Prussia by the Teutonic knights. By the thirteenth century the fabric of European civilization had become so solid that a barbaric power not inferior to Attila's was hardly able to make any impression upon it. Batu, with his fifteen hundred thousand Mongols, gained a victory at Liegnitz in 1241, such as Attila had fought for in vain at Châlons; but it came some centuries too late, for the contest between stable nationality and nomadic barbarism was by this time settled forever. The most the greasy Mongol could accomplish was to check for a few generations the growth of a national life among the Slavic tribes of Russia.

But though Châlons and Tours demonstrated that Christian civilization could hold its own, whether against the barbarian or the infidel, the latter nevertheless twice succeeded in marking serious encroachments on Roman territory. 
The first great wave of Mohammedan invasion not only swept away the provinces south of the Mediterranean, but overwhelmed the greater part of Spain, and cut it away from the Empire for several centuries. The disastrous effect of this long isolation upon the future history of Spain has been often remarked, and if thoroughly treated would make an interesting study. Yet the contributions of the Mohammedan conquerors to the work of human culture, which were by no means insignificant, may perhaps be thought to have afforded some compensation for the harm done. Spain is the only instance of a country once thoroughly infused with Roman civilization which has been actually severed from the Empire; and even here the severance, though of long duration, was but partial and temporary. After a struggle of nearly eight centuries, the higher form of social organization triumphed over the lower, and the usurping race was expelled.

Contemporaneously with this final rescue of Spanish territory, the second great wave of Mohammedan invasion overflowed the remnants of the Byzantine Empire, and seemed for a while to threaten the security of Europe. In this second invasion, conducted by Turks, there was much more of barbarism than in the older invasion of 
the Arabs, and after allowing for all possible mito igating considerations, it seems, difficult to regard the conquest of Constantinople and the territory south of the Danube as anything but a great calamity. How much or how little capacity for renovation, under the influence of modern ideas, may have been latent in the Byzantine Empire, we now shall never know. But, far as it had sunk, politically and socially, toward the Asiatic type of a community, its regeneration could hardly have been as hopeless an affair as is that of its Ottoman successor. In such a society as that of the Turks there is, indeed, nothing to regenerate, but the work of civilization in the European sense, if it is to be done at all, must be begun from the beginning. The very germs of constitutionalism, of legality, of government by discussion, are wanting there as they have never been wanting in any European community in the worst of times. This has been the essential vice of all the Mussulman civilizations. Their theocratic type of constitution crushes out all flexibility of mind or individuality of character, and quenches all desire of change. For this reason they have invariably failed, in the long run, when brought into competition with the more mobile societies of Europe; and for this reason, in spite of the ro. 
mantic splendour and the scientific achievements which immortalize the memory of Bagdad and Cordova, we must be glad that they have failed.

There has been neither high romance nor useful performance of any sort to reconcile one to the unrighteous dominion which a tribe of Mus. sulman 'Tatar's has exercised for four centuries over some of the fairest provinces of Europe. The history of that dominion has been a monotonous display of brute force without any noble ulterior purpose which might redeem its vulgarity. It is the history of a race politically unteachable and intellectually incurious, which has contributed absolutely nothing to the common weal of mankind, while by its position it has been able to check the normal development of a more worthy community.

The provinces which Muhamad II. wrested from the Empire had at no time been very thoroughly Romanized, and such civilization as they had acquired in antiquity had fared but ill amid the everlasting turmoil to which their frontier position had subjected them. Invading swarms from the northeast, when unable to penetrate farther into Europe, halted here and wrangled for supremacy, and the ceaseless but ineffectual warfare of Avars, Bulgarians, Croats, Serbs, and Mag. 
yars makes a dreary and unprofitable history. On a superficial view this whole region seems politically a Bedlam, as it is linguistically a Babel. But - as was hinted at the beginning of this paper - the complication of disorder on the lower Danube is perhaps no greater than has existed, at one time or another, in those parts of Europe that are now most thoroughly civilized. All over Spain, Gaul, and Britain, and even Italy, the conflicts of races have been fierce and their intermixtures extremely intricate. But under the organizing impulse of Rome, directed alike by Empire and Church, the populations of these countries long ago became so far consolidated in general interests and assimilated in manners and speech that in each country the old racial differences are but occasionally traceable in rural customs and patois, and even when plainly traceable have little or no political importance. It is a long time since the Iberian, the Gaul, the Roman, the Visigoth, the Burgundian, the Frank, the Walloon, and the Norman disappeared politically in the Frenchman; and the Scot, whose slogan for ages was "Death to the Sassenach!" is to-day the most loyal of Britons. Over three fourths of western Europe the adoption of Roman speech has obliterated old lines of demarcation until it 
has even become possible to talk about a "Latin race"! In like manner the Prussian of Königsberg, his Lettic mother-tongue forgotten for six generations, makes common cheer with the Suevi of Stuttgart and the Alemanni of Munich. In the border-land of the Damube, on the other hand, whatever chance there might have been for any such assimilation of races and dialects was cut off by perpetual incursions of Tataric tribes preventing the growth of anything like nationality. Under some circumstances the pressure exerted by a totally alien enemy might serve as a stimulus to national consolidation. But here the various races were too recently brought together, and the pressure of barbaric attack was so great as to keep society disorganized. The races of the Danube are accordingly still so heterogeneous that it is worth while to point out their various affinities and give some brief account of their past career.

In order to get a comprehensive view of the subject, it is desirable to go back to the beginning and recall the principal features of the settlement of Europe by the people who now possess it. According to the most probable opinion, the present population of Europe is the result of the pre-historic mixture, in varying degrees, of two 
very different races. The first or Iberian race may be regarded as aboriginal in Europe, in the sense that we cannot tell how it got there. It was a black-haired and dark-skinned race, if we may judge from the remnant of it which still preserves its primitive language in the isolated corner of Spain between the Pyrenees and the Bay of Biscay. The second or Aryan race seems to have been fair-haired and blue-eyed, and it overran Europe in successive swarms, coming from the highlands of central Asia, where divers tribes of Tatars have since taken its place. The Aryans crowded the Iberians westward, and everywhere overcame them (save in the corner of Spain just mentioned), and intermingled with them, forcing upon them their own speech and customs. Thus the language of Europe to-day is Aryan, and its legal and social structure is Aryan, but its population is a mixture of Aryan and Iberian. In the extremities of Europe as looked at from Asia - in the three southern peninsulas, in Gaul, and in western and northern Britain - the dark aboriginal type predominates; while in Scandinavia, northern Germany, and northern Russia the blonde type of the invaders remains in the ascendant. It is owing to this mixture of strongly contrasted races that the 
peoples of Europe present such marked varieties of complexion.

So much, at least, is probable, though more or less hypothetical. In following the successive stages of Aryan invasion, we gradually emerge from this twilight of plausible hypothesis into the clearness of authentic history. The Aryans came, as just observed, in successive swarms. The first series of swarms got naturally the most mixed up with the Iberian aborigines, and the result of their gradual settlement was the formation of the Keltic, Italic, and Hellenic peoples. In Spain the aborigines held their own most successfully, and hence the mixture was recent enough to be recognized by Roman historians, who called the Spaniards Kelt-Iberians; but elsewhere it was accomplished so early as to be forgotten before people began to write history. It has been fashionable to sneer at zealous Irish writers for their propensity to find traces of the Kelts everywhere. But there is no doubt whatever that the Kelts were once a very widely diffused people. They have left names for rivers and mountains in almost every part of Europe. The name of the river Don in Russia, for example, is one of the common Keltic names for water, and so we find a river Don in Yorkshire, a Dean in Nottingham- 
shire, a Dane in Cheshire, and a Dun in Lincolnshire. The same name appears in the Rho-danus, or Rhone, in Gaul; the Eri-dan-us, or Po, in Italy; as well as in the $D n$-ieper, $D n$-iester, and Dan-ube; and even in the Are-don in the Caucasus. This is one example out of hundreds by which we trace the former ubiquity of the Kelts, who as late as the Christian era were present in large numbers as far east as Bohemia.

The second series of invading Aryan swarms consisted of Germans, who began by pushing the Kelts westward, and ended by overrunning a great part of their territory and mixing with them to a considerable extent. There is some German blood in Spain, and a good deal in France and northern Italy; and the modern English, while Keltic at bottom, are probably half Teutonic in blood, as they are predominantly Teutonic in language and manners. The Vandals, Goths, Alemanni, Suevi, Burgundians, Lombards, Franks, Saxons, and Normans, who invaded and reconstructed the Roman Empire between the fifth and eleventh centuries, were all Germans, and there is no reason to suppose that they differed except in their tribal names. From the fifth century onward these Germans encroached upon the territory of the Empire, mainly because they were pushed 
forward by Aryan Slavs and Tataric Huns who attacked them from the east. Throughout the classic period of antiquity, and until the fifth century after Christ, the Teutonic family appears far to the eastward of its present position. In the time of Herodotos, and down to the age of Constantine, the inhabitants of Thrace - now the centre of European Turkey - were blueeyed Goths, called Getre by the classic historians. Pretty much the whole of Turkey and southern Russia were German in those dirys; and, as Donaldson conjectured, it is possible that the people known to the ancients as Skythians may have been no other than Goths.

Thus, as if to illustrate how completely all Aryan Europe is made up out of the same raceelements, we find that the lower Danube, for at least a thousand years, was German territory; and, except on the very improbable supposition that its old population has been entirely exterminated or transferred westward, we have every reason to believe that there is much German blood there at the present day.

While this region was still in the hands of the Germans, at the beginning of the second century after Christ, the legions of the Emperor Trajan passed beyond the Danube, and, conquering the 
country then known as Dacia, formed a permanent settlement there. In 271 the Emperor Aurelian, finding the province difficult to defend, surrendered it to the Goths, in whose hands it remained for a long time a bulwark against the incursions of wild tribes from the northeast. The Latin language was firmly established over' this territory, and is spoken to-day, in a modernized form, by six millions of "Rumans" in Wallachia, Moldavia, and Transylvania. Of this population, the Transylvanian Rumans have long formed part of the kingdom of Hungary; the rest, under the nominal suzerainty of the Porte, are ruled by a German prince of the house of Hohenzollern; and the racial basis of the whole is, no doubt, mainly Teutonic, with a considerable Roman and still greater Slavic admixture.

The Slavs make up the third and last division of the Aryan conquerors of Europe. Their speech has in many respects departed less widely from the forms of the common Aryan mother-tongue than the speech of the earlier invaders. In physical characteristics they resemble most closely the northern Germans, in whom, with the central Russians and Letts, we see perhaps the purest specimens of the Aryan race; but in the south they have been more or less modified by inter. 
mixture with various strains of Tataric blood. Napoleon's witticism, however, that you need only scratch a Russian to get at the Tatar underneath, contained little more wisdom than is usually to be found in such smart sayings based on hasty generalization from inadequate and half-understood data. On the whole, the principal intermixture of the Slavs has been with their nearest congeners and neighbours, the Teutons. Slavonic tribes, pushing their way far into the centre of Europe, still hold Bohemia, Moravia, and Silesia, while further south, in Carinthia and Istria, the Slav country comes up close to the Tyrol and to Venice.

In the Middle Ages, this border region, from the head of the Adriatic to the mountains of Bohemia, was the seat of everlasting war; and such immense numbers of the eastern invaders were captured from time to time and sold into slavery in all parts of Germany that their national name became the common appellative for wretches doomed to involuntary servitude. Such seems to have been the origin of our English word "slave." Until lately it was supposed that the vernacular meaning of the national name was "the glorious," as slava is a common word for "glory" in must of the Slavonic languages; and frequent comment 
was made on the curious fate whereby the proud name of a noble race of warriors became perverted into a common noun to describe the most abject condition of humanity. It is very doubtful, however, whether the striking contrast really exists to supply a fit subject for moralizing. It is fal more probable that the name Slav is connected with slovo, "a word," and means the "distinctlyspeaking people" as contrasted with the Njemetch, or "talkers of gibberish," by which polite epithet the Slavic laces have always distinguished the Germans. This naive assumption, that it is ourselves alone who talk intelligibly, while foreigners babble a meaningless jargon, has been a very common one with uninstructed people, and "Njemetch" is not the only national appellative that bears witness to its prevalence. The epithet "Welsh," which the Germans apply to the Italians, the Dutch to the Belgians, and the English to the Kymry of western Britain, has precisely the same meaning; and so had the word "barbarian," by which the ancient inhabitant of Hellas described indiscriminately all people who did not speak Greek. ${ }^{1}$

It was about the middle of the fifth century

1 The name "Wallach," by which the Germans designate the in. habitants of Rumania, is the same word as "Welsh." 
that the Slavonic race began to play a part in European history. Advancing from what is now southern Russia, in the rear of the Tataric hordes of Attila, various Slavic tribes overran the provinces of Mœsia, Thrace, Illyricum, and Macedonia. Overcoming, and, to some extent, crowding out, the Gothic inhabitants, they were within a century firmly established throughout the area between the Black Sea and the Adriatic, which they have ever since continued to occupy. But, far from attempting to set themselves up as an independent political power in this territory, they were readily brought to acknowledge the sovereignty of the Empire. They no more thought of overthrowing the dominion of Rome than the Germans did: what they were after was a good share of its material advantages. To have set up a rival imperium would have been quite beyond their slender political capacity, and their imagination did not reach so far as to conceive the idea. So long as they were allowed to retain their forcibly-acquired possessions of land and cattle, they were quite ready. to help to defend the Empire against Tataric Avars and other marauders. The relations thus knit between the Slavs and the government at Constantinople were similar to those established between the Germans and the 
imperial authorities in the West. Slavonic troops came to form a large and redoubtable element in the eastern armies, and to the infusion of new life thus received we may no doubt partly attribute the prolonged maintenance of the Byzantine Empire. It is, perhaps, not generally remembered that the greatest warrior and one of the most illustrious emperors of this part of the Roman world were of Slavic origin. The vernacular name of which Justinian is the Latin translation was Upravda, or "the Upright;" and his invincible general Belisarius was a Dardanian Slav named Beli-czar, or "the White Prince." Within less than a century after this white prince had driven the Goths from Italy, the able Emperor Heraclius, contending on the one hand against the Persians while menaced on the other by the barbaric Avars, invited two Slavic tribes from beyond the Danube to aid in expelling the latter invaders. These tribes were the Croats and Serbs, and they have remained ever since in the lands which were then granted them in reward of their military services.

One reason, and perhaps the chief one, why the invading Germans and Slavs so readily became subjects of the Roman Empire is to be found in the fact that they were settled agricultural races, 
and not wandering nomads. It may seem odd to speak of races as "settled" who moved about so extensively over the face of Europe within the short period of two centuries. But if they wandered, it was only because they were driven by enemies in the rear too strong or too numerous for them to overcome, not because their mode of life obliged them to roam over vast areas in quest of the means of subsistence. The profound philology of the present day has shown that the Aryans, while still in their primitive Asiatic bome, and long before they had become distinguishable as Kelts, Grreco-Italians, Teutons, Slavs, or Indo-Persians, had advanced beyond the hunting and exclusively pastoral stages of barbarism, and acquired a subsistence partly by tilling the soil and partly by the rearing of domestic cattle. They possessed even houses and inclosed towns, and the rudiments of what Mr. Bagehot calls "government by discussion" were not wholly unknown to them. The picture of society with which we are familiar in the Germania of Tacitus and in the Homeric poems represents a condition of things in many respects similar to that which obtained among the primitive Aryans. In these respects they differed widely from the savage Tataric hordes which molested them on the east, 
and to whose attacks, as well as to the unman. ageable increase in their own numbers, we must probably ascribe their gradual and long-continued migrations into southern Asia and into Europe. When after many centuries those less civilized Aryans known as Germans and Slavs were driven into collision with their more civilized brethren of the Roman Empire, their invasion was in an allimportant respect very different from the invasions of Huns or Avars. The followers of Alaric, Hengist, and Chlodwig came to colonize, whereas the followers of Attila came but to riot and destroy. The vandalism of the former was incidental, while that of the latter was fundamental.

The Teutonic and Slavic invaders, once over the first intoxication of victory, began, as by natural instinct, to found rural estates and cultivate the soil; and thus becoming property-holders, although their title rested on violence, it became their interest to assist in preserving the political system so far as practicuble. The date 476 , which the old historians made to mark the political fall of the Roman Empire, in reality marked nothing at all at the time except a paltry intrigue by which the German Odoacer, having got rid of a fainéant emperor who was too near at hand, continued to administer the affairs of Italy under 
commission from the government at Constantinople. In reality the identity of interests between the Tentonic settlers and the imperial system became more and more manifest during the three following centuries, until it was definitely declared in 800 in the coronation of Charles the Great, whereby the headship of the western world was restorea to Rome, while the connection with the East was finally severed.

If we consider the eastern half of the Empire at this time - or, at least, so much of it as was comprised in Europe, the remainder having been mostly torn away by the Saracens - we find it undergoing a gradual process of Slavonization quite analiggous to the Teutonic reconstruction which was just culminating in the West. Pretty much the whole of what is now European Turkey had become filled with a Slavic population. For the most part this population had been converted to the Greek or so-called Orthodox form of Christianity, though in remote parts of Serbia paganism lingered till the thirteenth century. There was probably some sense, though slight, of a community of race throughout the peninsula. The interests of the Slavs, on the whole, were concerned in the protection of the imperial system against external attack, although the various 
chiefs made war on each other and mismanaged their own affairs with as little sense of allegiance to the Byzantine suzerain as the rulers of Brittany or Aquitaine felt for their degenerate Carlovingian overlords. Thus on a superficial view the conditions of order and turbulence, so to speak, might have seemed very similar here to what they were in the West; and all that was needed for the growtl of a new national life might seem to be the rise of a dominant tribe - after the likeness of the Franks - which in due course of time should seize the falling Byzantine sceptre and assert unquestioned sway over the whole peninsula. Could something like this have happened, the Eastern Question would probably never have come up to perturb the politics of modern Europe, and the entire careers of Russia and Austria must have been essentially modified. But for the Hungarians, Crim Tatars, and Turks, something of this sort might very likely have happened. As it was, however, no sooner did one Slavonic community begin to rise to pre-eninence than some fatal combination of invaders proceeded to cripple its power, and this state of things continued until the turbaned infidel made an easy prey of the whole region.

In the ninth century the chronic agitation of 
eastern Europe was raised to terrible fever-heat by the approach of the Hungarians, - a non-Aryan race from central Asia which has bad a very different career from that of the other non-Aryan invaders of Europe. Of all such invaders these alone have established a securely permanent foothold, unless we count the cognate Finns, who were established in the far North in pre-historic times. To keep in his mind a succinct view of these ethnological facts, the reader will do well to remember that all the languages now spoken in Europe are Aryan languages descended from a common Aryan mother-tongue, with just four exceptions. The first of these is the Bask of northwestern Spain, sole remnant of the aboriginal Iberian speech. The second is the group of Finnic dialects spoken by a Tataric people which has lived from time immemorial on the eastern shores of the Baltic. The third is the Hungarian, and the fourth is the Turkish. These languages have absolutely nothing in common with the Aryan, either in grammar or vocabulary. The Bask, too, has nothing in common with the three other alien tongues. But Finnish, Hungarim, and Turkish are quite nearly related to each other, and there is also blood-relationship between the peoples who speak these languages. Like the Turks, the Hun- 
garians are a Tatar race; and there cannot be a more striking commentary on the fallaciousness of explaining all national peculiarities by a cheap reference to "blood" than is furnished by these two peoples, the one being as highly endowed with political good sense as the other is hopelessly destitute of it. This is not the place to attempt to explain the difference in detail as due to the different circumstances amid which the two peoples have been placed; but there is no doubt that their careers have been sufficiently different. In the ninth century the Hungarians were as great a terror to Christendom as the Turks were in the fifteenth ; but the Magyars, after failing to break through the bulwark of Christianized Germans, which the genius of Charles the Great had prepared for such emergencies, settled down quietly in Pannonia - to which they have given the name of Hungary - and became converted to the Roman form of Christianity. But in the course of this settlement the Magyars interfered seriously with the integrity of the Slavonic communities on the Danube. They tore away a considerable portion of Croatia and Serbia, and subjected so many Slavic tribes that at the present day the Slavs outnumber the Magyars, even within the limits of Hungary itself. ${ }^{1}$

1 In 1850 the population of Hungary was thus divided: Magyars 
In calling the Magyars the only non-Aryan invaders who have secured a permanent foothold in European territory, I had forgotten, for the moment, the Bulgars who conquered lower Moesia in the beginning of the sixth century. These Bulgars were a Tatar race, known also as Ugrians, a name of which the "ogre" of our nursery stories is supposed to be a corruption. But the achievements of the Bulgars, as a distinct race, were hardly of enough consequence to keep them always in one's memory. Though they gave the name Bulgaria to the Roman province of lower Mœsia, they were soon absorbed among the Slavs, and quite lost their Tataric speech. And so, while Bulgaria played a prominent part in mediæval history, it figures only as a portion of the Slavonic world. Yet to this day, it is said, the inhabitants of Bulgaria exhibit, in their high cheek-bones, flat face, and sunken eyes, as well as in their curious attire, the characteristics of the Tatar race. In the seventh century Bulgaria was overrun by the Avars, but after these nomads were expelled the Bulgarian power developed rapidly, and was even extended back over Bessarabia and all southern Russia as far as the Sea of Azof.

5,000,000 ; Slavs, 6,000,000; Germans and Jews, 1,600,000; Rumans in Transylvania, $3,000,000$. 
These eastern conquests were not long retained, but on the other hand the semi-independent kingdom between the Danube and the Balkan Mountains became more and more formidable in its rivalry with the imperial government at Constantinople. In long and obstinate warfare the Bulgarians overcame the Serbs, and by the beginning of the tenth century they controlled nearly the whole peninsula from the Black Sea to the Adriatic. At this epoch their kingdom was perhaps as civilized as any in contemporary Europe, if literary culture alone were to be taken as a criterion. Their noble youth studied Aristotle and Demosthenes in the schools of Constantinople, and the subtleties of theological controversy occupied their attention no less than the practice of military arts. In a quarrel with the emperor, their Czar Simeon laid siege to the capital and dictated terms of peace at the Golden Horn. But in the next century all this was changed. Such arrogant vassals were not to be tolerated. In a masterly campaign, though sullied by diabolical cruelty, the Emperor Basil II. overthrew the power of the Bulgarians, and, subduing the Serbs likewise, re-established the immediate authority of Constantinople as far as the Danube.

From this time forth the contest for supremacy 
was carried on chiefly between the emperors and the Serbian chiefs. The pre-eminence of Serbia began about the end of the eleventh century, when Urosh was crowned grand duke. By the middle of the fourteenth century the whole country, with the exception of Rumelia or Thrace, was in the hands of the Serbians, and it really seemed as if the degenerate Greek Empire were about to pass into the hands of the Slav. Stephen Dushan, of the house of Urosh, a profound statesman and consummate general, was the hero who aspired to re-enact in the eastern world the part of Charles the Great. In 1356 he was proclaimed Emperor of the East, and if his life had been spared he might have made good the title. But the firmness of his monarchical rule was irritating to his turbulent vassals; and like Crsar, William the Silent, Henry IV., and Lincoln, he fell by the stupid hand of the assassin, just at the time when a few years more of life might have been of inestimable value to his people and to mankind. With the death of the "Emperor" Stephen, the formation of a Slavic nationality under Serbian leadership was indefinitely postponed. The fendal lords who had so stupidly destroyed the only genius which could guide them to victory were one by one overthrown by the imperial armies; and 
when the Turk arrived, in the next century, there was no solid power in the peniusula which could check his baleful progress.

To recount the vicissitudes of Serbia as principal battle-ground between Christian Austrian and infidel Turk would be a task as tedious as profitless. We have seen how the Slavs of the Byzantine Empire failed to become a nation, and this is the only point which need concern us. There is neither interest nor instruction in the record of incessant fighting without definite issue; and to the philosophic historian the career of Slavonic Turkey becomes almost a blank until the beginning of the present century, when the uprising of the Serbs against the Janissaries, under the leadership of the eccentric and infamous Kara George, reopened the Eastern Question, and perhaps heralded the rise of a new national life among the southern Slavs.

This sketch of the Danubian peoples has of course been but the merest outline. I have not attempted, and should indeed feel quite incompetent, to do more than define, by a few salient facts, the ethnological relations of these peoples and their position in the general history of Europe. Even so rudimentary an outline as this, however, would be incomplete without some allu. 
sion to the very important part played by the Danubian Slavs in the origination of the Protestant revolt against the ecclesiastical supremacy of Rome. The circumstances under which the Bulgarians were converted to Christianity were such that during their brief political and literary eminence in the tenth century they became the archheretics of Enrope. The Manichæan heresy, suggested by the ancient theology of Persia, in which the Devil appears as an independently existing Principle of Evil, had always been rife in Armenia ; and it was partly by Armenian missionaries, belonging to the Manichæan sect of Paulicians, that Bulgaria was converted from heathenism. In the middle of the eighth century the Emperor Constantine Copronymus transplanted a large col. ony of Paulicians from Armenia into Thrace, ${ }^{1}$ and these immigrants were not long in spreading their heresy beyond the Balkans. A century later the persecuting zeal of the orthodox emperors drove Armenia into rebellion, and for a short time an independent Paulician state maintained itself on the upper Euphrates. Early in the tenth century this little state was overthrown, and such a dire-

1 See the "Historical Sketch of Bosnia," by Mr. A. J. Evans, prefixed to his excellent work Through Bosnia and the Herzegóvina on Foot. London. 18i6. $8 \mathrm{ro}$. 
ful persecution was inaugurated that the inhabitants in great numbers sought the shelter which the Bulgarian Czar Simeon was both able and willing to give. "From this period onward," says Mr. Evans, "the Paulician heresy may be said to change its nationality, and to become Slavonic." It also acquired a new name. In their Slavonic home these heretics were called Bogomiles, from the Bulgarian Bogz'milui, or "God have mercy," in allusion to their peculiar devotion to prayer. The sect now became very powerful, as the czars, in their struggle for supremacy with the Byzantine overlords, could not afford to incur the displeasure of such a considerable body of their subjects. Bogomilian apostles, in keen rivalry with the orthodox missionaries, carried their Manichæan doctrines westward all over Serbia. After another hundred years the catastrophe which had driven this heresy from Asia into Europe was curiously repeated in its new home. After the power of the Bulgarian czars had been finally broken down by Basil II., the orthodox emperors began once more to roast the obnoxious Paulicians. A fierce persecution under Alexius Comnenus set up a current of Bogomilian migration into Serbia, and as these immigrants found no favour in the eyes of the ortho. 
dox Serbian princes, their westward pilgrimage was continued into that part of Illyricum now known as Bosnia, - a hilly region iihabited, then as now, mainly by fair-haired Serbs. From the twelfth century onward Bosnia became the headquarters of Manichæan heresy, and was a very uncomfortable thorn in the flesh of the popes, who, with the aid of pious Hungarian kings, kept up a perpetual crusade against the stubborn little country, without ever achieving any considerable success.

The Papacy had very good grounds for its anxiety, for it was from Bosnia that the great Albigensian heresy was propagated through northern Italy and southern Gaul. This connection between eastern and western Protestantism, though generally forgotten now, was well understood at the time. Matthew Paris states that the Albigensians possessed a pope of their own, whose seat of government was in Bosnia, and who kept a vicar residing in Carcassonne. By orthodox writers the western heretics were quite frequently termed "Bulgares," - a designation which became invested with the vilest opprobrium, - and a glance at the principal Bogomilian doctrines shows that the relationship was asserted on valid grounds. Like the Manichæans generally, the Bogomiles 
held that the Devil exists independent of the will of the good God, and was the creator of this evil world, which it is the work of Christ to redeem from his control. They accepted as inspired the New Testament, with the Psalms and Prophets, but set little store by the historical books of the Old Testament, and rejected the Mosiaic writings as dictated by Satan. They denied any mystical efficiency to baptism, and laughed at the doctrine of transubstantiation, maintaining that the consecrated wafer is in no wise different from ordinary bread. Some of them are said to have neglected baptism altogether. They regarded image-worship as no better than heathen idolatry, and they paid no respect to the symbol of the cross, asking, "If any man slew the son of a king with a bit of wood, how could this piece of wood be dear to the king?" 1 Their aversion to the worship of the Virgin was equally pronounced, and they despised the intercession of saints. They wore long faces, abstained from the use of wine, and commended celibacy. Some went so far as to refuse animal food, and in general their belief in the vileness of matter led them to the extremes of asceticism. Their ecclesiastical government was in many respects presbyterian; in politics 1 Evans, op. cit. p. xxx. 
they were generally democratic, with a leaning toward communism quite in keeping with their primitive Slavonic customs as well as with their strictly literal interpretation of the New Testament.

When we consider that these remarkable sectarians not only set on foot the Albigensian revolt which Innocent III. overcame with fire and sword, but were also intimately associated with the later Slavonic outbreak of which John Huss and Jerome of Prague were the leaders, it becomes evident that the part played in European history by the southern Slavs is far from insignificant. As Mr. Evans observes, it is not too much to regard Bosnia as the religious Switzerland of mediæval Europe, in whose inaccessible mountain strongholds was prolonged the defiant resistance to papal supremacy which in the West repeatedly succumbed to the overwhelming power of the Inquisition. The sudden change which followed on the invasion of the Turks is instructive as showing the political danger attendant upon excessive persecution. As the armies of Muhamad II. were making their way toward Bosnia, King Stephen of Hungary began cutting the throats of his Bogomile subjects, some forty thousand of whom are said to have fled into the Herzegovina, while 
others were sent in chains to be burned at Rome. Bosnia was again threatened with an orthodox crusade, but the people, preferring to take their chances of religious immunity with the Turk, threw themselves on him for protection, and surrendered their inexpugnable country to Muhamad without striking a blow. The surrender, indeed, went further than this; for though the Serbs of Bosnia have several times asserted their political independence, more than a third of the population have become followers of the Prophet, and furnish to-day the sole example of a native $\mathrm{Eu}$ ropean race of Mussulmans.

December, 1876. 


\section{XIII.}

\section{LIBERAL EDUCATION. ${ }^{1}$}

EARLY in the last century Sir William Temple declared that literature is constantly degenerating, and that the oldest books are always the best. Not only is Homer the greatest of poets and Esop the wittiest of fabulists, but Phalaris was a letter-writer with whom Pascal and Madame Sévigné are not fit to be compared. Thus wrote Sir W. Temple, much to his own satisfaction and to the edification of many of his contemporaries. But lapse of time and changes of circumstance bring about signal alterations in the opinions of men. The other day Dr. J. W. Draper in a book entitled "Civil Policy of America," and made up chiefly of disconnected statements about physical geography, Arabian chemists, and Jewish physicians - told us that " the grand depositories of human knowledge are not the ancient, but the modern, tongues: few, if any, are the facts worth

1 Essays on a Liberal Education. Edited by Rev. F. W. Farrar, M. A., F. R. S. London: Macmillan \& Co. 1867. 
knowing that are to be exclusively obtained by a knowledge of Latin and Greek." And doubtless this amusing statement will in some quarters meet with as much applanse as the loose assertions of Temple met with in their time. For this old controversy about the comparative merits of the ancients and the moderns has been lately resuscitated, though in somewhat altered shape. Times have changed; and what in the eighteenth century was considered good meat for strong men we should now regard as but indifferent milk for babes. We therefore no longer idly argue about the comparative amount of genius possessed by ancient and by modern writers; but we dispute quite zealously, and with sufficient one-sidedness, over the comparative value of ancient literature and modern science as means of mental discipline and branches of liberal education. University reform is a favourite subject of discussion. And among the multiplicity of things that may be taught under a reformed scheme of education, the problem of what must be taught is pressing ever more strongly for a definite solution. The difficulties inherent in the problem are greatly enhanced by the inevitable prejudices of the inquirers. One of the main obstacles in the way of a speedy and amicable settlement of the question arises from 
the frect that physical investigators as a class have no well-defined idea of the benefits to be derived from classical studies, while classical scholars and literary men are too generally ignorant of the value of physical science as a means of training the intellect. Our opinions reflect our experience with tolerable accuracy, and we can hardly be expected to have a very lively sense of the worth of pursuits in which we have never heartily engaged. If we have always smoked meerschaum we are apt to think poorly of briarwood. So when a literary man takes up a treatise on "Determinants" with the casual remark that he hates the sight of such a book, we may be pretty sure that, whatever else his opinions may be good for, he is no very competent judge of the educational value of mathematics. It is quite obvious that he dislikes the subject as some women dislike politics, because he has never mastered the rudiments of it. To him a parabola is only a neat-looking curve, as to the average classical scholar a Leyden jar is only a glass bottle with a rod stuck through the cork, and to many a student of physics the Iliad is nothing but it tiresome account of the squabbles of a parcel of barbarians, "proving nothing," as worthy Mr. Vince would have said.

So deep-seated at present is the incapacity of 
our "ancients" and "moderns" to understand each other, that when a man of catholic culture, like Mr. Mill, presents both sides of the case with equal force we find either party disposed to rely upon one half of his argument, while ignoring or disparaging the other half. Dr. Youmans, for example, in the Introduction to his valuable collection of essays on "Modern Culture," having quoted Mr. Mill's address in behalf of scientific studies, thinks it but fair to add that the same discourse contains a vigorous argument for the classics. "But while," says Dr. Youmans, "Mr. Mill urges the importance of scientific studies for all, an examination of his argument for the classics will show that it is applicable only to those who, like himself, are professional scholars, and devote their lives to philological, historical, or critical studies." Now, possibly Mr. Mill ought to have limited his argument in this way; but he certainly has not done so. He makes no such distinction: nowhere does he even faintly intimate that he is not putting one class of studies upon the same footing as the other. His whole magnificent Discourse is devoted to showing the urgent necessity which exists for a well-planned scheme of education in which both kinds of learning shall be recognized. He believes that there is 
no reason, except the stupidity of instructors, why classics and the sciences should not both be taught; and he holds that our earnest recognition of the claims of the one should never blind us to the claims of the other.

In view of this, it is pleasant to meet with a book, written chiefly by classical scholars who have taken university honours, in which the just claims of physical science and the shortcrmings of a merely literary education are adequately recognized. The writers of the nine essays forming the volume now under consideration are all graduates of Cambridge, and all but one have at one time or another obtained fellowships in that university. Most of them, therefore, may be presumed to be moderately acquainted with ancient literature, and to some extent sensible of the advantages attending the study of it. The editor, Mr. Farrar, has devoted a large part of his time to philological studies, and has written a treatise on Greek syntax, besides two volumes on the origin and development of language, all of which are works of considerable philosophical merit, though not perhaps of the highest and most accurate scholarship. Of the other writers, two at least-Professor Seeley and Lord Houghton - 
are well known as men of wide literary culture and trained judgment.

The opinions of such men upon the subject of classical education are entitled to respectful consideration; and when we find among them the most complete unanimity in the declaration that a large part of the classical instruction now given in English universities is utterly worthless, and ought to be replaced by a course in physical science, we cannot set aside the judgment on the plea of ignorant prejudice. Let not Philistinism clap its hands too hastily, however; for the object of this Cambridge book is, not to supersede, but to complement, classical studies. It declares, not against the study of antiquity (Alterthumswissenschaft), but against the pedantry with which that study is now. carried on; and one of the ablest essays in the volume is devoted to showing that physical science is habitually taught with quite as much pedantry as any branch of ancient learning.

The long career of irrational stultification, through defect in the method of instruction, is usually begun in our school-days. Most countries have rivers running through them; and in studying elementary gengraphy, we are expected duly to learn their courses. Many countries are inter. 
sected, or are parted from their neighbours, by chains of mountains; and this second class of facts we are likewise called upon to master. But we are not tnld that the two sets of phenomena are inseparably related. We are not told that, since all rivers must run down hill, therefore their positions and courses must depend upon the position of mountains, so that by knowing the latter we may be helped to the knowledge of the former. We are required to learn these facts as they stand in the elementary text-books, in "godlike isolation." We are compelled to take in a host of details by a sheer effort of unintelligent memory, while the process of association, by appealing to which alone is memory made serviceable, is appealed to as little as possible. So in grammar, when by dint of irksome mechanical repetition we have become able to state that "a verb must agree with its nominative case in number and person," we have learned a bare fact, which, apart from its explanation, is a useless fact; and that it has or admits of any explanation we are rarely led to suspect.

In approaching foreign languages we become immersed still deeper in the mire of elementary unintelligibility. We commit to memory scores of intricate paradigms, containing all possible 
forms of the noun or verb, before we have been introduced to a single sentence in which these forms are presented. In mute dismay we contemplate ingeniously framed rules of syntax, before we have been shown a glimpse of the facts upon which these rules depend. We get the generalization before the particulars, the abstract before the concrete; we learn to repeat formulas before we have the notions needful for filling them. As a natural result, our Latin and Greek seem very difficult. To enhance our perplexity, the same thing is generally introduced to us under different names, or, quite as often, different things under the same name. We are told that the genitive in Greek denotes possession, and next that it likewise denotes origin, and again that it denotes separation. We are informed that the Latin genitive, primarily denoting possession, may, however, if of the first or second declension and singular number, be used to signify place, an idea conveyed by the ablative also, which for the time being kindly neglects its proper function of expressing removal. The genitive, moreover, may express one kind of resemblance, another kind being, by a mysterious dispensation of Providence, indicated by the dative. Even if all these cumbrous rules for learning ancient languages were 
correct, instead of being many of them inaccurate, and nearly all of them antiquated, they would still be worse than useless to the young student. Thrust into his mind as they are, before he has had concrete examples of them, they are utterly meaningless. He knows not how or where to apply them. They serve only to confuse and discourage him. Nor are matters mended much when we begin to do what we should all along have been doing, - when we begin to read. We read a few sentences each day, parsing as we go along, according to the inexplicable rules just referred to, and paying little or no attention to the meaning of our author. Seldom do we read a sufficient mass of matter consecutively to have the language take any hold upon us. Thus we read Aristophanes, and hardly suspect his consummate and irresistible humour. We read Demosthenes, and remain ignorant of Athenian politics. And a few years after leaving college we are able, by dint of much thumbing of the dictionary, and with occasional reference to the grammar, to pick out the meaning of Latin and Greek sentences. This is too often the sorry result which is dignified by the name of a classical education.

Yet perhaps our scientific education, as at pres- 
ent carried on by means of text-books, is not much better. We take up a book on physics, and are told that the Newtonian theory is still one of the great rival theories of light, although it was utterly overthrown at the beginning of the present century. We take up a book on astronomy, and are told that the earth is 95,000,000 miles distant from the sun, although the researches of M. Foucault have shown that the distance is only $91,000,000$. We take up a book on physiology, and read about "a vital principle which suspends natural laws," although every competent physiologist well knows that any such "principle" is as much a distorted figment of the fancy as the basilisks which in old times were supposed to haunt secluded cellars. We hear grave lectures on psychology, in which the systems of Locke or Kant are laboriously expounded, while of the recent innovations made by writers like Bain and Maudsley we get not the slightest hint. So in history and philology we are too often taught as if Mommsen and Grote had never written. Grimm's magnificent researches, throwing light upon the whole structure of language, and presenting the history of human thought under an entirely new aspect, are non-existent to the mind of the student. He pursues the even tenour of his way in 
blissful ignorance of Sir G. C. Lewis, and sees no absurdity in the mythological theories of Euhemeros.

Now it seems to us that the reform which is most urgently needed in our system of liberal education consists not in the substitution of one branch of studies for another so much as in the more liberal, rational, and intelligent pursuit of various branches. In the main, fairness of mind, accuracy of judgment, and shrewdness of perception are to be secured as much by one kind of research as by another kind. The alleged narrowness and torpidity - the "Kronian" characteristics (to use an Aristophanic word) - of classical scholars are due far more to the irrational method in which they have pursued their studies than to those studies themselves. Let the student really fathom who Julins Cæsar was, what he thought, what he did, wherein he differed from Cato or Pompey, why his policy succeeded, and what its effects have been upon all subsequent generations down to our time, - let him duly fathom all this, and he will have gone far toward getting as good a political education as a man needs to have. Let him, again, justly estimate the value of ancient chronology; let him once have critically examined the works of Bun. 
sen and Lepsius until he has fairly detected their weak points, and he will be as little likely to surrender himself to any current delusion as the man who has studied astronomy or chemistry. The real difficulty is that our scheme of classical education does not provide for any adequate knowledge, even of classical subjects. Its energies are entirely devoted, during eight or ten years, to the imperfect acquirement of two languages which ought to be very well learned in four or five; and then no time is left for anything else.

Our system of classical education has come down to us from the close of the Middle Ages, from a time when nearly all that was valuable in literature was to be found in the writings of ancient authors. Until toward their close, the Middle Ages had accomplished little in literature worthy to be compared with the great works of Greek and Roman antiquity. And when, in the fifteenth century, the expulsion of Greeks from Constantinople and the invention of printing brought about the rapid dissemination of ancient literature among people at last socially prepared to welcome it, the effect was as if a new continent had been opened to view in the mental world as vast and inviting as that discovered by Columbus beyond the Atlantic. The exploration of the one 
was carried on as keenly as that of the other. For a long time there could be no better or more profitable study than that of ancient literature. Before a new career of progress could be inaugurated, old forgotten acquisitions must be recovered and earnestly studied in the light of new political, social, and intellectual circumstances. Accordingly, in those days there were classical scholars of gigantic calibre. From the fifteenth to the seventeenth century we have the names of Erasmus, Budæus, the Scaligers, Grotius, Reuchlin, Salmasius, Casaubon, Lipsius, Selden, Bentley, and Huet, representatives of a mighty and astonishing style of scholarship, which doubtless, from the absence of the proper social conditions, will never be seen again. Philosophers, like Bacon, Descartes, and Leibnitz, bent upon mastering the sum of human knowledge, could do no better than to read with critical eyes the writings of Plato and Aristotle. In light literature, as represented by Rabelais, Montaigne, Ben Jonson, and Burton, classical learning was equally conspicuous. And in social intercourse Latin, and to some extent Greek, held the place since usurped by French and other modern tongues. While modern languages were but little studied, the common dialect of educated Europeans was formed by the 
tongues of antiquity. These languages were therefore learned to be written and spoken, not to be dozed over, dabbled in, and forgotten. They were learned in the natural way, by concrete examples, and by assiduous practice, not out of grammars bristling with inexplicable abstractions. Homer and Virgil were read for their literary interest, not as the text for monotonous parsing-lessons and useless disquisitions on syllabic quantity.

The changes which classical education has since undergone are narrated by Mr. Parker in the first essay contained in the volume before us. We have not space to rehearse the interesting details which are there given, but must call attention to the striking remarks of $\mathrm{Mr}$. Farrar and Professor Seeley upon the method of teaching the classics now prevalent in the English universities. Mr. Farrar's essay is devoted to exposing the worthlessness of Greek and Latin verse-making as a means of culture. If there be in our day, says Mr. Farrar, any kind of achievement which is at once impossible to do and useless when done, it is the writing of good Latin or Greek verses. Our American universities, so far as we know, do not require it to be done. Once in a while they encourage students to attempt these nugce difficiles, 


\section{Liberal Education."}

in the hope of obtaining prizes or a college reputation, in case of success. But in our best colleges any student can graduate, and most do graduate, without ever having written Latin or Greek except in more or less halting prose. In England, however, there lingers in many quarters a queer superstition, that the chief end of classical education is to enable its votaries to beguile their leisure hours by stringing together hexameters. As the result of this system, we have some pretty poems in the "Arundines Cami," Mr. D'Arcy Thompson's "Prolusiones Homerice," Lord Lyttelton's "Samson Agonistes," and many hundred reams of detestable trash, written in a dialect such as Aristophanes would hardly have thought fit for the silliest geese and cockatoos of his Cloudcuckooville. In the time now wasted in verse composition in each college career, the methods and leading results of several physical sciences might easily be learned. This is the kind of "instruction" which our essayists would be glad to see done away with. They hold that the chief end of classical education is, beside affording scope for the exercise of sagacity in reasoning, to enlarge our minds by making us acquainted with the ideas, feelings, and customs of a time when men thought, felt, and acted very 
differently from now. The man who thoroughly knows Alterthumswissenschaft, or the science of Greek and Roman antiquity, differs from the man who does not, in much the same way that the man who has travelled all over the world with his eyes open differs from the man whose knowiedge of the world is limited to what is going on in his own village. But how a knowledge of ancient civilization is to be got by vain attempts to imitate the diction of Ovid or Theokritos it would be difficult to say. The proposal to study the life of modern Germany, to get an accurate idea of its political and social condition, its literature, its domestic habits, its contributions to human improvement, and the predominant sentiments which actuate its people, by writing quatrains in imitation of the hymns in "Faust," would be saluted with peals of inextinguishable laughter. Yet it would be about as sensible as the method of studying antiquity adopted by the verse-makers.

The subject of verse-making, as we have said, does not concern us so intimately as our brethren across the water, England being alone among civilized nations in the importance which she attaches to this pursuit. But though our schools and colleges do not require the writing of verses, they often waste a great deal of time and energy 
in teaching the rules of prosody, as well as by the cumbrous and inefficient method in which they conduct classical instruction in general, and particularly by their habit of beginning at the wrong end. We learn French and German with ease, because we begin with concrete examples. In studying Latin and Greek, on the other hand, we begin with abstract rules, and are not seldom compelled to memorize what we cannot understand. Hence the difficulties under which we labour are so great that, by the time they are conquered, we have too often neither leisure nor interest left for other studies. By this process the mind is in many cases stupefied rather than quickened; and the system, far from producing liberally educated men, fails even to produce good classical scholars. We believe that the only efficient way to learn foreign languages, ancient or modern, is to learn them as we learn our own in childhood. We cannot indeed have Greek and Roman nurses, but we can at least have the living phenomena of language presented to our minds, instead of the dead formulas of grammar. If this natural method were to be duly inangurated, we believe that Greek and Latin might be thoroughly learned in one third of the time now spent in learning them superficially. We should again have excellent 
Hellenists and Latinists, - not, perhaps, scholars like Erasmus and Scaliger, for we no longer need the same sort of work that was needed once, and Donaldson's notion that learned works should still be written in Latin may safely be pronounced a chimera; but we should have men among us capable of reading ancient literature with ease and pleasure, - men capable of extracting from it an amount of historical and philosophical knowledge to which the great scholars of the Renaissance were utter strangers. The scholarship of the present day is necessarily of a quite different type from that of three centuries ago. It has been reacted upon by physical, political, and historical science. Its ideal consists in the thorough knowledge of ancient life, manners, moral ideas, and superstitions, as an essential part of the whole history of mankind. Its representatives are men like Grote, Littré, and Mommsen. Properly pursued, it enlarges our sympathies, shows us the people of bygone times as men like ourselves, alike yet different, actuated by like passions, but guided by different opinions and different conceptions. It forbids us to judge of them by the standard of our own age; it corrects the prejudices inseparable from ignorance of history; it gives us lessons in political conduct; it makes us 
cosmopolitan and hospitable in mind. These are reasons why classical learning should not be given up. They are reasons why it will never be given up, but will be rationalized in its method and extended in its province.

To illustrate more fully what is meant by saying that the proper way to teach is to begin with the concrete, we shall take the case of one of the natural sciences as it has been skilfully treated by $\mathrm{Mr}$. Wilson, in his contribution to the present volume. His essay shows that science is often quite as cumbrously taught as the classics; but it also shows how it ought to be taught.

Botany and experimental physics, according to Mr. Wilson, are of all branches of science the most interesting and the most intellectually profitable to children. Let us suppose, then, that we have a class of moderately intelligent children to start in botany: how shall we begin the subject in order that it may be made at once interesting and intellectually profitable? Text-books will not help us much. For instance, Dr. Gray's excellent little book, "How Plants Grow," begins as follows :-

Plants are chiefly made up of three parts, namely, of root, stem, and leaves. These are called the plant's organs; that is, its instruments. And as these parts are all that any plant needs for its growth, or vegetation, they are called the ORGANS OF VEgETATION. 
Plants also produce flowers, from which comes the fruit, and from this the seed. These take no part in nourishing the plant. Their use is to enable it to give rise to new individuals, which increase the numbers of that kind of plant; to take the place of the parent in due time, and keep up the stock, - that is, to reproduce and perpetuate the species. So the flower, with its parts, the fruit and the seed, are called the plant's organs of REPRODUCTION.

Now this is very pleasant reading for grown people, who know something about the subject, are slightly familiar with the conceptions of nutrition, heredity, and genesis, and have learned, however rudely, to classify their notions. But for boys and girls who begin .botany at the age when it ought to be begun, this would be neither pleasant nor profitable. If set to learn the above passage by rote, in the ordinary way, they would be likely to find it irksome, and would certainly fail to gain accurate ideas corresponding to all the expressions employed in it. And, above all, those who learned their lesson would have taken the first step towards acquiring the pernicious habit of accepting statements upon authority. If questioned concerning their grounds for believing that the organs of vegetation in a plant are its root, stem, and leaves, they would perforce reply that 
they believed it becruse it was so written in the bouk. Here is the fatal vice of our common methods of education. They appeal to faith, and not to reason. It is supposed that children are properly instructed if they are told that certain things are so and so, and understand what is told them sufficiently to repeat the words of it. Nothing can be more erroneous. No mental discipline, worthy of the name, can be secured in this way. We are benefited, not by the truths which we passively accept, but by those which we actively find out. It makes little difference whether a child is told that " a plant consists of root, stem, and leaves," or that "a verb must agree with its nominative case in number and person." The former proposition is the more intelligible; but in either case the child is taught to accept on authority a generalization which he should be taught to make for himself from a due comparison of instances. With the traditional let us now contrast the rational method of studying botany. We cannot possibly do this better than in Mr. Wilson's own words : -

Suppose, then, your class of thirty or forty boys before you, as they sit at their first botanical lesson: some curious to know what is going to happen, some resigned to anything, some convinced that it is all a folly. 
You hand round to each boy several specimens, say of the herb Robert; and taking one of the flowers, you ask one of them to describe the parts of it. 'Some pink leaves,' is the reply. 'How many?' 'Five.' 'Any other parts?' 'Some little things inside.' 'Anything outside?' 'Some green leaves.' 'How many?' 'Five.' 'Very good. Now pull off the five green leaves outside, and lay them side by side; next pull off the five pink leaves, and lay them side by side; and now examine the little things inside: what do you find?' 'A lot of little stalks or things.' 'Pull them off, and count them.' They find ten. Then show them the little dust-bags at the top, and finally the curiously constructed central column and the carefully concealed seeds. By this time, all are on the alert. Then we resume: 'The parts in that flower are, outer green envelope, inner coloured envelope, the little stalks with dustbags, and the central column with the seeds. Then you give them all wall-flowers; and they are to write down what they find. By the end of the hour they have learned one great lesson, - the existence of the four floral whorls, though they have not yet heard the name.

Here, let it be noted, the students are making their own way. They are not told that a flower consists of four whorls, but they find it out for themselves, and know it henceforth on the evidence of their own senses. If they were to see or 
hear the fact disputed, they would be incredulous; they would no longer bow to authority. In the next place, they are gaining ideas before they are dosed with words. They are not wasting their energies in conning half-understood formulas about sepals, petals, stamens, and pistils; but they take note of the green leaves, the pink leaves, the stems with dust-bags, and the column with seeds in it; and by and by they find it convenient to describe these things by one word for each, thus avoiding circumlocution and waste of breath. In this way the terms calyx, corolla, etc., come to have a definite meaning; and are in no danger of being used emptily, without reference to the ideas which they ought to convey. The besetting sin of human reasoning is the employment of words without regard to their full connotation and exact meaning; and for this our systems of early education are in part responsible. It should be recognized as an inflexible rule that the student is not to be taught to use a word until he feels the need of it in order to express his ideas more readily.

Next, Mr. Wilson would let his pupils guess about the uses of the parts of the flower, - what the green leaves are for, what the central column is for, what the dust-bags are for ; and would tell 
them just enough to help them to hit upon the answer. Then he would give them an unsymmetrical flower, like the pelargonium or the garden geranium, which, on picking to pieces, they would discover to be formed on the same general plan. Then would come the daisy and dandelion, where the outer green envelope and the little dust-bags are not so easy to find. Then he would call attention to the spiral arrangement of leaves; the overlapping of sepals in the rose; and the alternance of parts; and from this to Goethe's magnificent generalizations there would be but a step, and that a step easy to be taken.

Taught in this way, whatever flower a boy sees, after a few lessons, he looks at with interest, as modifying the view of flowers he has attained to. He is tempted by his discoveries: he is on the verge of the unknown, and perpetually transferring to the known. All that he sees finds a place in his theories, and in turn reacts upon them, for his theories are growing. He is fairly committed to the struggle in the vast field of observation, and he learns that the test of a theory is its power of including facts. He learns that he must use his eyes and his reason, and that then he is equipped with all that is necessary for discovering truth. He learns that he is capable of jurlging of other people's views, and of forming an opinion of his own. He learns 
that nothing in the plant, however minute, is unimportant; that he owes only temporary allegiance to the doctrines of his master, and not a perpetual faith.

Only contrast this with the common practice of loading a boy's memory with celluies and parenchyma, protoplasm and chlorophyll, rhizomes and bulbs, endosmose and exosmose, before he has any definite and abiding conception of how a plant is put together:

Mr. Wilson's method carries with it its own recommendation; and his method of teaching botany is the method upon which all teaching, if it is to discipline the intelligence, sliould be conducted. First the facts, then the generalization, lastly the nomenclature. All the knowledge which in the conduct of life we are able to use to any good purpose is necessarily acquired in this way. If we had no knowledge of human nature save what might be gained by the memorizing of abstract ethical formulas, we should never acquire the knack of dealing sensibly with our fellow-creatures. But we notice how men act under given circumstances; day by day, and year by year, we gather and collate such facts of observation into general opinions, crude indeed as compared with the exhaustive generalizations of physical science, yet as far as they go embodying the results of 
genuine experience. Thus our knowledge of men gradually acquires the accuracy and precision needful, in order that we may act upon it securely. In gathering such knowledge, - in learning how to live rightly, - our early education ought to help us. Reasoning is reasoning, and its canons are substantially the same, whether flowers, or triangles, or participles, or human nature constitute the matter reasoned about. By reasoning out what we know, we make knowledge lead to wisdorn; we become civilized as we grow older. If the vast body of truths constituting modern science could have been miraculously told to our mediæval ancestor's, an imposing quantity of pretentious scholarship might have been called into existence, but the world would not have become civilized much the sooner. It is the conscious effort put forth in making all these discoveries which has worked the profound modification of mind and character called civilization. Humanity could not, after toilfully elaborating the laws of gravitation and chemical affinity, remain as barbarous and untutored as before. This was in part what Lessing had in his mind, when he said that if God were to hold in his right hand perfect truth, and in his left hand the untiring search for truth, he would unlesitatingly choose 
the latter. It is upon discovery, not upon rotelearning, that humanity has thrived. And if to adopt another idea of that incomparable man - civilization is but the education of the race, it is after the course of civilization that a rational course of education should in miniature be patterned.

To Professor Seeley's excellent essay on Competitive Tests we can only briefly allude. The state of things at Cambridge which it describes is exceedingly instructive. At Cambridge, if anywhere in the world, the system of competition has been put to a crucial test. The examinations are formidable, alike from their severity and from their rigid accuracy. Immense rewards await the successful scholar, and all possible means for obtaining a creditable position are placed at the disposal of the ambitious student. Yet the results thus far obtained from the competitive system are by no means brilliant. It does not apparently increase the number of eminent scholars, or even of thoroughly educated men, produced by the university. The complaint is even made that England has ceased to produce great scholars, that in point of erudition she is falling behind the Continental nations; and it is frequently remarked as a significant fact that the most learned 
of Englishmen in the present age - men like Mill and Huxley, Garnett and Grote - have not been educated at the universities. But this accusation is exaggerated and somewhat irrelevant; for the competitive system is a very modern institution, and the great scholars just mentioned are in no way the contemporaries of those bronght up under it. Yet, if we are to reason in this way, it must be said that England has no cause to be ashamed of the array of illustrious scholars which she has to show for the nineteenth century. And most of them have been university men who have graduated either with high honours, or at least with credit.

It is not so much, however, by the number of great scholar's which it turns out, as by the general standard of intelligence among its graduates, that the system of a university is to be judged. A man who lives to edit Lucretius or Aristotle, as Mr. Munro and Sir A. Grant have done, will most likely in his college days study for the sake of study, and the competitive or any other system can exert but a transient effect upon him. The English universities afford great facilities to a young man who desires to study in earnest, and is already a scholar in embryo. But the question which here especially concerns us is, What is the 
worth of the competitive system now in use as a wholesome incentive to the average young man who does not passionately love knowledge for its own sake? Does it tend to widen and render more thorough the education which he will get at the university? Experience is beginning to tell us plainly that the revers is the case. The education of young men in the English universities is narrowed and rendered more superficial by the competitive system. Whatever results may be brought forth by comparing the lists of great scholars which England and the Continental nations can respectively furnish, there can be no doubt that the average college graduate in France or Germany attains to a far higher degree of knowledge and culture than the average graduate of Oxford or Cambridge. He does not ordinarily manifest that preternatural ignorance of everything except the classics which characterizes the English student. And his study of the classics has usually enriched him with a more or less valuable stock of literary, critical, and philosophical ideas, which the Enghshman, absorbed in versewriting and prize-getting, has never caught sight of. He knows a greater number of authors, and he knows them to more profit. Now for this superficiality and narrowness of English education 
the competitive system is directly responsible. It transforms the means into the end. It makes the student think more of winning the prize than of mastering the subject in hand according to his own intellectual needs. And that there is all the difference in the world between mastering a subject and making a brilliant show with it at an examination every scholar well knows. Professor Seeley has graphically described the results of the system at Cambridge. The object of the tripos examinations being to distinguish accurately the merit of the students, it follows that those subjects in which attainments can be tested with precision take precedence of subjects in which they cannot. These latter subjects, "however important they may be, gradually cease to be valued, or taught, or learned, while the former come into repute, and acquire an artificial value. This cannot take place without an extraordinary perversion of views both in the taught and the teachers. They lear'n to weigh the sciences in a perfectly new scale, and one which gives perfectly new results. They reject as worthless for educational purposes the greatest questions which can occupy the human mind, and attach unbounded importance to some of the least." Philosophy, for instance, is rejected, while the useless details of grammar and 
prosody are made much of. On the one hand, young men may graduate with signal honour, and yet never know what great principles were at stake in the Peloponnesian War; while, on the other hand, these same young men are taught to be "ashamed of falling short of perfect knowledge in the genders of Latin nouns, which involve no principles at all, and in which a minute accuracy can hardly be attained without a certain frivolity or eccentricity of memory!"

Still worse, the competitive system vulgarizes the mind of the student. Scholarly enthusiasm, an exalted opinion of the value of knowledge, faith in culture as such, — "divine curiosity," in a word, - should be the student's incentives to labour. These are the only motives which can ever lead to any culture worthy of the name. The competitive system tends to destroy these motives, replacing them by the vulgar desire to outshine one's companions.

Instead of enlarging the range of the student's anticipations, it narrows them. It makes him careless of his future life, regardless of his higher interests, and concentrates all his thoughts upon the paltry examination upon which perhaps a fellowship depends, or success in some profession is supposed to depend. It is weil known that any cule who asks himself the question, 
284. Darwinism and Other Essays.

'Is this course of study good for me? does it favour my real progress, my ultimate success?' is not fit for the tripos. Thinking of any kind is regarded as dangerous. It is the well-known saying of a Cambridge private tutor: 'If So-and-so did not think so much, he might do very well.' I may content myself with remarking that the particular student who did think too much, and who, perhaps as a consequence, was beaten in the tripos, now stands in scientific reputation above all his contemporaries.

An adequate examination of Professor Seeley's arguments, and especially of the practical expedients by which he would do away with the evils just mentioned, would carry us far beyond our limits. The volume before us is not one which can easily be epitomized and furnished with a running commentary. So many suggestions are made and questions opened in it that any attempt to treat it thus thoroughly would end in the production of a companion volume rather than a brief article. But from what has been said it will be seen that our essayists do not belong to the number of those who disparage classical studies as unfit for the needs of our time. The Philistinism which regards everything as useless that is not utilitarian need seek for no encouragement in this book. The claims of physical science are 
urged from considerations of general culture, and not of narrow utility. And for this we heartily commend the writers. There is no reason whatever why Philistinism should be allowed the exclusive protectorship of physical science. To assail or defend the study of it, while taking into account only its utilitarian aspects, is wholly to ignore the true state of the question. It is to commit a mistake like that committed by Macaulay in his eloquent but superficial essay on Bacon. The study of science, properly conducted, is by no means subservient to objects of narrow utility. The utilitarian point of view, in the limited sense of the word, is not at all apparent in Laplace's explanation of the perturbed motions of the planets, in Gerhardt's theory of atomicity, in Cuvier's classification of animals, or in Darwin's investigations into the principles of variation. Indeed, that profound but somewhat chimerical writer, Auguste Comte, expressly finds fault with contemporary followers of science because they do not sufficiently confine themselves to investigations which have a perceptible bearing upon the interests of society. In his pontifical fashion, he authoritatively warns us against pursuing such useless inquiries as those which concern stellar astronomy, the cellular structure of organic be- 
ings, the origin of species, etc. But we have no fear that the investigating world will take heed of his misapplied caution. That inborn curiosity which, according to the Semitic myth, has already made us "like gods, knowing good and evil," will continue to inspire us until the last secret of nature is laid bare; and doubtless in the untiring search we shall uncover many priceless jewels in places where we least expect to find them. The legitimate claim which science makes is that, while drawing the mind toward investigation and activity for its own sake, it confers upon humanity unlooked-for rewards.

But in order that either a literary or a scientific education shall produce worthy results, it must be rationally conducted, with a single eye to the greatest possible perfection of culture. Nothing will be gained by giving up Greek composition, and studying botany or chemistry as a mere collection of "useful" details. The adversaries of a classical and literary culture will do well to bear this in mind. It is not by throwing overboard a valuable portion of the cargo, but by adopting improved methods of navigating the ship, that we shall make a successful voyage.

June, 1868. 


\section{XIV.}

\section{UNIVERSITY REFORM.}

IT seems to be quite generally felt that the present time is a favourable one for entertaining and discussing various projects for the improvement of the University at Cambridge. To the question of reform, in its general outlines, the attention of our readers has already been directed by able hands. ${ }^{1}$ It is here proposed to pursue the subject more into detail, and to deduce from a few general principles the rudiments of a systematic scheme of reform.

Note, first, that the idea of reform is to be kept distinctly separate from that of revolution, and that, while advocating the former, all encouragement to the latter will here be strictly withheld. The improvements from time to time aimed at should as far as possible be brought about without effacing the distinctive characteristics of the

1 See F. H. Hedge's article in the Atlantic Monthly, September, 1866. The important change in the constitution of the university, by which the Board of Overseers became an elected body, had just been effected. 
original system. We are unable to sympathize with the radical spirit which would make a bon. fire of all churches because the Pentateuch does not teach geology, or which would upset an indigenous and time-honoured government because certain social evils co-exist with it. And we cannot but think that an attempt to revolutionize our university, by assimilating it to sister institutions in England or Germany, would be productive of at least as much harm as good. If, for instance, in the hope of obtaining a perfect university, we were to abolish our dormitories, obliterate the distinction between classes, abandon the entire system of marking, and transfer the task of maintaining order from the Parietal Committee to the civil police, we should no doubt be as much disappointed as the men of 1789 , who attempted to make English institutions grow on French soil, and got a Bonaparte dynasty for their pains. There is a place as well as a time for all things, and a great deal will always have to be conceded to the habit which men have of getting used to old institutions and customs, and of disliking to see them too roughly dealt with. A German university is little else than an organized aggregate of lecture-rooms, libraries, laboratories, and other facilities for those who desire to study, - resem- 
bling in this respect our scientific and professional schools. Our New Englind colleges, founded in a Puritan environment, less imbued with the modern spirit, and in many cases even dating from an earlier period, have always combined with their instruction more or less of coercion; and have laid claim to a supervision over the demeanour of their students, in the exercise of which the liberty of the latter is often egregiously interfered with. The freedom of the undergraduate at Harvard is hampered by restrictions, many of which, if once justifiable, have in the lapse of time grown to be quite absurd, and should certainly be removed with all possible promptness: of these we shall speak presently. But to remove all restrictions whatever with one and the same sweep of our reformatory besom would excite serious and extensive popular distrust. The New England mind, which tolerates Maine liquorlaws and sabbatarian ordinances and protective tariffs, would not regard with favour such a revolutionary measure. So much liberty would bear an uncanny resemblance to license, - a resemblance which, we freely admit, might not at first be wholly imaginary. The college would lose much of its popularity; young men would be sent elsewhere to pursue their studies; and thus 
great injury would be manifestly wrought to the cause of university reform, which must needs be supported to a considerable extent by popular sentiment in order duly to prosper. A large amount of discretion must therefore be used, even in the removal of those features wherein our colleges compare unfavourably with those of other countries. But there are some respects in which the American university may claim a superiority quite unique, - some cases in which a radical change must ever be earnestly deprecated. That arrangement by virtue of which each student is a member, not only of the university, but of a particular class, is fraught with such manifold benefits that any advantages to be derived from giving it up must disappear when brought into comparison. No graduate needs to be told what a gap would be made in his social and moral culture, if all the thoughts and emotions resulting from his relations to his classmates were to be stricken from it. For the genial nurture of the sympathetic feelings, the class system affords a host of favourable conditions which can ill be dispensed with. By means of it, the facilities of the university for becoming a centre of social no less than of intellectual development are greatly enhanced. On the other hand, it is not to be 
denied that, in requiring students of all degrees of mental ability and working power to complete the same course of study in the same length of time, there is much irrationality as well as some injustice. This evil, which is so serionsly felt in American colleges, does not afllict the universities of England and Germany, where the class system is not in use. To obviate it, however, it is fortunately not necessary to resign the advantages which that system alone is competent to secure. Partly by allowing greater option in the selection of studies, partly by extending the privilege, at present occasionally granted to students, of taking their degrees one or two years after the termination of the regular course, sufficient recognition can be given to differences of mental capacity, without essentially infringing upon the individuality of the successive classes. Here, then, is a clear case in which a judicious reform might attain all the ends sought by a sweeping revolution, without incurring the grievous detriment which the latter would inevitably entail. We believe that the same principle will apply in nearly every case; that it is possible to secure all the most valuable benefits conferred by European systems, without sacrificing the fundamental elements of our own; and that, by uniformly shaping our 
ameliorative projects with conscious reference to such an end, the efficiency of our university will be most successfully maintained, and its prosperity most thoroughly insured.

Next, in order to impart to our notions of reform the requisite symmetry and coherence, the legitimate objects of university education must be clearly conceived and steadfastly borne in mind. The whole duty of a university toward those who are sheltered within its walls may be concisely summed up in two propositions. It consists, first, in stimulating the mental faculties of each stusent to varied and harmonious activity, - in supplying every available instrument for sharpening the perceptive powers, strengthening the judgment, and adding precision and accuracy to the imagination; secondly, in providing for all those students who desire it the means of acquiring a thorough elementary knowledge of any given branch of science, art, or literature. In a word, to teach the student how to think for himself, and then to give him the material to exercise his thought upon, - this is the whole duty of a university. Into that duty the inculcation of doctrines as such does not enter. The professor is not fulfilling his proper function when he incon. tinently engages in a polemic in behalf of this or 
that favourite dogma. His business is to see that the pupil is thoroughly prepared and equipped with the implements of intellectual research, that he knows how to deduce a conclusion from its premise, that he properly estimates the value of evidence and understands the nature of proof; he may then safely leave him to build up his own theory of things. His first crude conclusions may indeed be sadly erroneous, but they will be worth infinitely more than the most salutary truths acquired gratis, or lazily accepted upon the recommendation of another. It is desirable that our opinions should be correct, but it is far more desirable that they should be arrived at independently and maintained with intelligence and candour. Sceptical activity is better than dogmatic torpor; and our motto should be, Think the truth as far as possible, but, above all things, think. When a university throws its influence into the scale in favour of any party, religious or political, philosophic or æesthetic, it is neglecting its consecrated duty, and abdicating its high position. It has postponed the interests of truth to those of dogma. These are matters which our own university should seriously ponder. It does not always strive so earnestly to make its students independent thinkers as to 
imbue them with opinions currently deemed wholesome. But science will never prosper in this way. Political economy will gain nothing by one-sided arguments against Malthus and Ricardo; sound biological views will never be furthered by undiscriminating abuse of Darwinism; nor will the interests of religion be ever rightly subserved by threatening heretics with expulsion.

An endless amount of discussion has been wasted over the question whether a mathematical or a classical training is the more profitable for the majority of students. The comparative advantages of spending all one's time upon one favourite pursuit, and of devoting more or less attention to various branches of study, have also supplied the text for much vague and unsatisfactory discourse. By the view of university education here adopted, these questions are placed in a somewhat favourable position for getting disposed of. The office of the university is not to enforce doctrine, but to point out method. It is not so much to cram the mind of the student with divers facts, which in after life it may be useful for him to have learned, as to teach him the proper mode of searching for facts, and of dealing with them when he has found them. As 
Jacobs says, "It is of less importance in youth what a man learns than how he learns it." 1 A fact considered in itself is usually a very stupid and quite useless object. Viewed in relation to other facts, as the illustration of a general principle, or as an item of evidence for or against a theory, it suddenly becomes both interesting and valuable. If the truth is to be told, by far the greater number of facts which are to be encountered in the various departments of nature are to most persons utterly insignificant and unattractive; chiefly, because they have never been furnished with the means of estimating their illustrative and evidentiary value. Universal logic, therefore, - the relations of phenomena to each other, and the methods of investigation and modes of proof applicable to widely difierent subjects, - should occupy an important place in college teaching. And that this end can be secured by studying any one kind of science alone is of course impossible.

The advocate of the utility of mathematical studies, when confronted with the insurmountable fact that very little use is made of algebra and geometry in ordinary life, is wont to shelter himself behind the assertion that nevertheless these

1 Vermischte Schrifien, III., §27, p. 254. 
studies "discipline the mind." Though exquisitely vague, as thus expressed, this favourite apology is doubtless essentially valid. The almost universal distaste for mathematics, ${ }^{1}$ co-existing as it does in many persons with excellent reasoning powers, proves that the faculty of imagining abstract relations is ordinarily quite feebly developed. Not reason, but imagination, is at fault. The passage from premise to conclusion could easily be made, if the abstract relations of position or quantity which are involved could be accurately conceived and firmly held in the mind. Now the ability to imagine relations is one of the most indispensable conditions of all precise thinking. No subject can be named, in the investigation of which it is not imperatively needed; but it can nowhere else be so thoroughly acquired as in the study of mathematics. This fact alone is sufficient to justify the university in requiring its students to devote some attention to such a study. But the excellence of mathematics as an instrument of mental discipline by no means

1 Which probably attained its sublimest expression some years ago in the case of a Sophomore who, coming from Harvard Hall, where his "annual" had goaded him to desperation, was heard to declare, in language equally with Caligula's deserving immortality, his wish that the whole of mathematical science might be condensed into a single lesson, that he might "dead" on it all at once! 
ends here. It is indeed a fallacy to suppose that greater certainty is attainable in geometry than elsewhere. Not greater certainty, but greater precision, is that which distinguishes the results obtained by mathematical deduction. Dealing constantly with definite or determinable magnitudes, its processes are characterized by quantitative exactness. It is not obliged to pare off and limit its conclusions, to make them tally with concrete facts; but can treat of length as if there were no such thing as breadth, and of plane surfaces just as if solidity were unknown. It is thus the most perfect type of deductive reasoning; and if logical training is to consist, not in repeating barbarous scholastic formulas or mechanically tacking together empty majors and minors, "but in acquiring dexterity in the use of trustworthy methods of advancing from the known to the unknown, then mathematical investigation must ever remain one of its most indispensable implements. Once inured to the habit of accurately imagining abstract relations, recognizing the true value of symbolic conceptions, and familiarized with a fixed standard of proof, the mind is equipped for the consideration of quite other objects than lines and angles. The twin treatises of Adam Smith on social science, where- 
in, by deducing all human phenomena first from the unchecked action of selfishness and then from the unchecked action of sympathy, he arrives at mutually-limiting conclusions of transcendent practical importance, furnish for all time a brilliant illustration of the value of mathematical methods and mathematical discipline.

If magnitudes and quantities thus contemplated in the abstract yield such wholesome pabulum for the intellect, no less beneficial in many respects is the study of the direct applications of mathematics to the concrete phenomena of mechanics, astronomy, and physics. Not only do the numerous devices by which algebraic expressions are utilized in the solution of physical problems afford extensive scope for inventive ingenuity, but some familiarity with quantitative conceptions of the action and interaction of forces is eminently conducive to the entertainment of sound philosophic views. The reorganization of mechanics by Lagrange, and the beautiful construction by Fourier of a mathematical doctrine of heat, were innovations in philosoplyy as well as in science; and although the student can hardly be expected to gain even a rudimentary knowledge of these recondite subjects, he may at least with profit to himself be enabled to form some general notion 
of the symbolic conceptions of force which they systematically embody. Of especial importance is the study of astronomy, both philosophically, as imparting a knowledge of the cosmic relations of our planet, and logically, as exhibiting in its highest perfection the deductive investigation of concrete phenomena. The right use of that indispensable but dangerous weapon of thought, hypothesis, can nowhere be so conveniently or so satisfactorily learned as in astronomy, where hypotheses have been more skilfully framed and successfully applied than in any other province of scientific research.

But it is not by the study of mathematics and its applications alone that a comprehensive logical training can be acquired. There are other kinds of proof than mathematical proof; and the deductive method is not the only method of reasoning. In estimating the comparative advantages of mathematical and of classical discipline, too slight and too feeble recognition has been extended to the great body of inductive science, which has grown up and attained to philosophic significance only in quite modern times. Chemistry and concrete physics have their means of arriving at truth, very different from those employed in mathematics, but quite as essential to sound 
scientific thinking. 'To acquire expertness and elegance in the use of deductive methods, while remaining contentedly ignorant of the fundamental canons of induction, is to secure but a lame and one-sided mental development. It is often remarked that many men, whose opinions upon any subject with which they are familiar are sober enough, do not scruple to utter the most childish nonsense upon topics with which they are only partially acquainted. The reason is that they have learned to think correctly after some particular fashion, but know nothing of the general principles on which thinking should be conducted. They are what is fitly called narrow-minded; and since each branch of knowledge is more or less closely interlaced with every other branch, a searching scrutiny will usually show that even in their control of their own specialty there is ample room for improvement. Each science has its logical methods and its peculiar species of evidence; and to insure an harmonious development of the mental powers, there is no practicable way except to obtain a knowledge of all.

To acquire such a command of scientific methods, it is not necessary, even were it possible, to devote much study to the details of each separate science. To master the details of any single sci- 
ence is a task for the accomplishment of which a lifetime is much too short. Recollecting, however, that not doctrine, but method, is for the student the thing above all others needful, it will be seen that our scheme does not make too great demands even upon the limited time embraced in a university course. The principles of investigation involved in every one of the inductive sciences might easily be learned in the time now devoted to the acquisition of facts in chemistry alone. The college now attempts to teach chemistry as if ench student might possibly come to be a physician, metallurgist, or pharmaceutist in after life. And the amount of time spent upon it is ont of all proportion to that allotted to the other natural sciences, some of which, as anatomy and geology, are not even included in the regulin course of electives. But total ignorance of organs and tissues is too great a price to pay for even an extensive acquaintance with acids and salts. The study of chemical details should be reserved for the elective course, of which we shall presently treat. The fundamental principles of chemistry, its relation to kindred sciences, the scope which it affords for observation and experiment, the philosophical value of its unrivalled nomenclature, - these are matters of universal 
importance, and their study forms an inseparable part of a catholic education. As thus conducted, the study of chemistry need not consume more than one third of the time at present assigned it, and other sciences, now sadly neglected, might assert their just claims to attention.

Chemistry and molecular physics constitute the proper field for the employment of the purely inductive method. As we arrive at the organic sciences, deduction again assumes a prominent position. Of our three principal instruments for interrogating Nature, - observation, experiment, and comparison, - the second plays in biology a quite subordinate part. But while. on the one hand, the extreme complication of causes involved in vital processes render's the application of experiment altogether precarious in its results, on the other hand, the endless variety of organic phenomena offers peculiar facilities for the successful employment of comparison and analogy. Zoölogy and botany are pre-eminently the sciences of classification; and if skill in the use of this powerful auxiliary of thought is ever to be acquired, it must be sought in the comparative study of the vegetable and animal kingdoms. Theoretical logic may divide and sub-divide as much as it likes; but genera and species are dull 
and lifeless things, when contemplated merely in their places upon a logical chart. To become correct reasoners, it is not enough that we should know what classes and sub-classes are; we should also know how to cunningly make them. From pure considerations of discipline, therefore, biology should form one of the regular studies of the university course, and some proficiency in it should be expected of every candidate for a bachelor's degree. Practical considerations also join in urging that steps should be taken to raise the organic sciences from the insignificant position now assigned them. If some sagacious traveller from a distant world, like Voltaire's Micromégas, were to visit Harvard College, he would doubtless give vent to unpleasant sarcasms concerning the profound anatomical ignorance of its graduating classes. He would pronounce it hardly creditable to the institution that men who have received its honours should be guilty of classifying cuttle-fishes with the vertebrata (we state facts), and should betray even less acquaintance with the structure of their cwn bodies than with the physical configuration of the moon. The scientific study of life has its practical as well as its speculative advantages. For want of sound views of biological method, intelligent persons are daily seen 
yielding faith to unscientific fallacies like those embodied in homœopathy, or to wretched delusions like cranioscopic phrenology.

It is therefore recommended that the time required for the study of chemistry be limited to one term, instead of extending over three; that in the second term, along with the batany now tanght, some instruction be given in general and comparative anatomy; to be followed, in the third, by a brief but comprehensive survey of plyysiology; while such knowledge of geology as is needful for the better understanding of these subjects might be simultaneously imparted by means of lectures. An arrangement of this sort would possess the signal advantage of throwing the organic sciences into their proper place, between chemistry, upon which they partially depend, and psychology, to which they constitute the natural introduction.

There is the less need for insisting upon the value of psychology, metaphysics, and logic, as instruments of mental discipline, since few persons are disposed to call it in question. In following a difficult metaphysical discussion, all the intellectual faculties are brought into healthful activity; and although men may reason well without understanding the nature of the psychi. 
cal processes, there is no doubt that an acquaintance with psychology guarantees its possessor against the adoption of many a plausible fallacy. After the student has acquired, through his scientific studies, some dexterity in the use of logical methods, he will approach, with all the more interest and enthusiasm, the study of those methods as organized into a coherent system. In view of what has already been said, it is almost unnecessary to add that we do not regard the science of logic as consisting solely of the doctrine of the syllogism. It will no longer do to ignore the fact that induction has its tests and canons, as well as deduction. Mr. Mill's great treatise has been before the public for nearly a quarter of a century; and though far too learned and ponderous for a text-book, its introduction into the college course, in an epitomized form, would be attended with happy results. As for metaphysics, much of its value in education depends upon the catholicity of the spirit in which it is taught. Metaphysical doctrines are not so incontrovertibly established as the leading theorems of physical science. On nearly every question there are at least two mutually incompatible opinions, while on some points there are scores of such. The latest speculations do not, as usually happens in science, render an- 
tiquated the older ones; and accordingly, in teaching metaphysics, extensive use should be made of the historical method of presentation. Recitations from the text-book might profitably be combined or alternated with lectures upon the history of philosophy, in which the aim should be to indicate as graphically as possible the relations sustained by each system to its predecessors. In default of any such arrangement, the university already possesses, in the works of Sir William Hamilton, with their profound historical consciousness, as fair a substitute as mere text-books can furnish.

The study of history, with reference to the scientific methods involved in it, would in a university be utterly impracticable. That there is a causal sequence, which must sooner or later admit of being formulated, in the tangled and devious course of human affairs, we not only readily grant, but we also steadfastly maintain. But speculations of this sort are too hopelessly abstruse, and require too vast and minute a knowledge of details, to be profitably included even in the most advanced undergraduate course. Historical laws cannot, like physical laws, be obtained from the inspection of a few crucial instances. The enormous heterogeneity of social phenomena 
forbids their jecoming amenable to any such process. Only in political economy, and to some extent in ethics, where the action of certain moral forces is independently treated, can the student be expected to comprehend general truths. Far from being in a condition to appreciate general views of historic evolution, he is usually ignorant of most of the leading facts upon which they are founded. Historical instruction, therefore, must continue to consist chiefly in the exposition of details. It is important, however, that the attention should be principally directed toward those events which have constituted turning-points in human progress. It is better to confine the attention to a few cardinal epochs, like the rise of the Holy Roman Empire, the Crusades, the Reformation, or the Revolt of the Netherlands, than to try to commit to memory a compendium like Michelet's "Précis," which is nothing but a disjointed chronological table, a potpourri of unmeaning dates and unexplained occurrences, wherein trivial anecdotes and events of eternal significance are incontinently huddled together, without the slightest attempt at historical perspective. Above all, the essential unity and continuity of ancient and modern history should be kept steadily in view; and to this end, far more 
importance should be assigned to the history of Imperial Rome than is now the case. Ancient history will always, as at present, be best studied in connection with ancient languages and literature. And this remark suggests the last of the subjects requiring notice in our brief survey, in proceeding to consider which let it be premised that the most inestimable benefits arising from the study of history are here passed over, as implied in what we shall have to say about the classics.

If we have reserved the last place for the mention of classical studies, it is not because we esteem them least in value. After what has been said concerming the advantages of mathematical and scientific training, our assertion of the paramount importance of the classics will incur no risk of being ascribed to one-sided prejudice. We therefore make no scruple of recording our opinion that, both in quantity and in quality, the mental discipline obtainable from the intelligent study of the Greek and Latin languages equals that which can be acquired by any other educational means whatever. To which it may be added that, if accuracy and precision are most thoroughly imparted by the study of exact science, on the other hand practical sagacity, catholic 
sympathies, and breadth of view are the qualities most completely developed by philological and literary pursuits. Indeed, were it not for the amount of attention so generally bestowed upon the literatures and dialects of Greece and Rome, our intellectual sympathies would become contracted to a deplorable degree. As Dr. William Smith has observed, "their civilization may be said to be our civilization, their literature is our literatube, their institutions and laws have moulded and modified our institutions and laws; and the life of the western nations of Europe is but a continuation of the life of Greece and Rome." The reasons habitually adduced for studying the history of our own country and that of England, from which our political institutions most directly emanate, apply with scarcely inferior cogency to the study of that antique civilization, whence the best and most enduring elements of our social structure, our science, laws, and literature, even most of our religious ideas, are ultimately derived. And how much or how little of ancient life cim. be comprehended without a knowledge of ancient languages we are willing to let every classically educated man declare for himself. There is thus a profound reason for the fact that universities have ever made the classic 
languages the basis of their instruction. The progress of modern discovery may greatly modify the circumstances under which this arrangement was originally made, but it can never entirely do away with them. Sanskrit, for instance, the immense importance of which we would be the last to underrate, can never be placed upon an equal footing with Latin and Greek. Valmiki and Kalidasa, says Mommsen, are the precious treasures of literary botanists, but Homer and Sophokles bloom in our own garden. With Indian civilization we are but remotely connected; and our obligations to Cæsar, Paul, and Aristotle will ever be infinitely greater than to Kanada or Sakyamuni. The noble thoughts of Hellenic philosophers and Roman jurists have not only helped to inaugurate modern civilization, but have since continually reacted upon it. The impulse given to jurisprudence by the discovery of Justinian's Pandects at Amalfi may have been exaggerated by uncritical historians, as Hallam and Savigny have maintained. But the Renaissance, with its innumerable consequences, will remain forever an abiding refutation of the detractors of classical studies. Well might the renewal of intercourse with antiquity be called a new birth for the modern mind; it nerved it with vigour for its greatest 
achievements. The spirit of Aristotle and Galen dwelt not with the stupid schoolmen who, parrotlike, repeated their doctrines, but with Galileo and Harvey, who overthrew them.

Not only does classical scholarship ripen the judgment and widen the sympathies; it also affords unrivalled scope for the exercise of practical sagacity. In order to acquire tolerable proficiency in the use of an ancient language, it is necessary to go through with an endless amount of reasoning, classifying, and guessing. Hypotheses must be skilfully framed, inferences must be correctly drawn, probabilities must be carefully balanced; a high degree of shrewdness must continually be applied to the solution of questions for the moment of practical importance, and to the removal of constantly occurring practical difficulties. It is a grave error to suppose that all this mental exertion can take place without beneficial effect upon the after life of the student. Even if he is so unwise or so unfortunate as to allow his classical attainments to slip from his memory, he will be the better fitted for all the business of life, by reason of the exercise which they have entailed. Whatever native keenness and capacity for patient drudgery he may have in him will show itself developed and strengthened, just as his alert- 
ness and muscular vigour will be the better for his early rowing and cricket-playing, though he may never touch bat or oar again. Impatient utilitarianism, in directing all education to immediate practical ends, and in turning universities into polytechnic schools, sacrifices more than it gains. The example of Rawlinson, as it has been well observed, proves that a soldier does not fight the worse at Candihar because he has deciphered cuneiform inscriptions at Ecbatana: to which it may be added that Julius Cæsar was not the worse general because he wrote on philology even in the midst of his wonderful campaigns; that men like Gladstone and Lewis are not worse, but better, statesmen because of their consummate classical scholarship; and that Henry Sumner Maine is not likely to prove less competent as a member of the Supreme Council of India because he is the author of the profoundest treatise extant upon legal and social archæology.

Lastly, the current argument againșt classical studies, that, though imparting vigour and keenness to the mind, they are not immediately applicable to practical or professional purposes, is precisely one of the strongest arguments in their favour. "In proportion as the material interests of the present moment become more and more 
engrossing, more and more tyrannical in their exactions, in the same proportion it becomes more necessary that man should fall back on the common interests of humanity, and free himself from the trammels of the present by living in the past." In this age of hurry and turmoil, these words of the lamented Donaldson are daily assuming more and more of vital significance. If there is ever to be a limit to the minute sub-division of labour, if the excessive specialization of employments is not to go on unchecked by counter-processes, if man is not to be degraded into a mere producing and manufacturing antomaton, if individuality of character is destined to reassert its antique preeminence, this must be brought about by sedulously fostering those pursuits which are not directly subservient to objects of narrow utility. And to this end, no studies can be more needful and appropriate than the studies of history, language, literature, and archæology, — those studies which Steinthal, with reference to their effect upon the mind, has classinied together and aptly entitled "retrospective." 1 They enlarge our mental horizon; they reveal our indebtedness to the patient thinkers and worker's who have gone before us, and to whom we owe most of our pres-

1 De Pronomine Relativo, pp. 4. 5. 
ent comforts; they cultivate our sympathy with the joys and sorrows, the hopes and disappointments, of past generations; they preserve us from the worst effects of the petty annoyances and carking anxieties of daily life, - the $\mu \epsilon \rho \mu \nu a i \quad \beta \iota \omega-$ $\tau \iota \kappa a i$, against which the highest religious and ethical teaching has solemnly warned us. These are benefits too priceless to be thrown away, in order that our young men may gain a year or two for their professional labours; and they are amply sufficient to justify the university in continuing, as it has always done, to make classical scholarship an indispensable part of a liberal education.

Our hasty survey of these various departments of study brings to light claims on the part of edch one which cannot wisely be ignored. In order adequately to perform its first great duty of evoking the mental capacities, the university must extend some recognition to all. Some proficiency in mathematics, in each of the physical and moral sciences, in history, and in classics should be demanded of every student who wishes to take a degree. The amount of work needful to be done in each of these branches in order to satisfy the requirements of a liberal education, it is for professors and tutors to determine. But 
we may here extend to all required studies the suggestion already made in regard to chemistry, that only a minimum of attainment should be expected of the whole body of students. In the case of the sciences, only so much attention should be given to details as is requisite for the comprehension of methods and general results. For this purpose, some knowledge of special facts is of course requisite. We cannot understand the atomic theory or the doctrine of definite proportions without knowing something about oxygen, hydrogen, and the other elements; but it is not necessary to learn all the ways in which the metals are extracted from their ores. To understand methods and results in biology, we need to be acquainted with organs, fluids, and tissues, and to have some knowledge of function as well as of structure; but we need not enter into the merits and shortcomings of Mr. Gulliver's theory of inflammation, or be particular as to the proper classification of the Bryozoa. The mathematical course might perhaps be allowed to close with plane trigonometry, and the course in classics might be materially abridged. Far less attention might be given to supremely useless matters, like Greek prosody; and the time now spent in committing to memory arbitrary rules for the scan- 
ning of choral passages in Aschylus would thus be saved for the study of ancient history and politics, in which important branches the requirements of the university have not yet attained even a respectable minimum. Doubtless in many other respects the amount of compulsory study might be curtailed. But these hints are merely thrown out by way of illustration. In a matter demanding so much circumspection, only the wisdom and experience of practised instructors are competent to decide. Satisfuctory results could easily be obtained, if the head of each department were to fix the minimum to be required in his own specialty, subject to the concurrence of the representatives of all the other departments. The course of study, thus regulated, would slightly resemble what at Oxford is called the "passcourse," and all parts of it should be made compulsory for all students.

In advocating the adoption of a required course so extensive and yet so elementary, our aim is not to encourage crude smattering or vain sciolism, but to enable the student to approach his own special subject in the light thrown upon it by widely different subjects, and with the varied mental discipline which no single study is competent to furnish. Nature is not a mere juxtapo. 
sition of parts, but a complex organic whole; and the different branches of science are so closely allied that, without a general knowledge of all, we cannot have a complete comprehension of any. From the lack of a well-defined knowledge of the boundaries which divide chemistry from physiology, many eminent chemists of the present century, including such men as Raspail, Berthollet, and even Liebig, have attempted to treat physiological questions by methods of investigation applicable only to chemical questions. There has thus arisen an ill-digested mass of speculation, embracing some inquiries which are purely chemical, and others which are purely physiological, to which has been given the name of Organic Chemistry. The amount of misdirected theorizing which resulted from this confusion of subjects and methods it wonld be no light task to estimate. The doctrine of definite proportions was assailed, the distinction between ultimate and immediate analysis was lost sight of, and theories of respiration and animal heat were propounded, whose rare beauty and artistic symmetry of conception rendered only the more palpable and deplorable their extreme logical deficiency. This example, out of many which might be given, will suffice to illustrate our present position, that uni- 
versal philosophic culture is essential to the right understanding of any one science.

But a general elementary training we deem serviceable only in so far as it is ancillary to the intelligent study of special subjects; and in providing for the former, our scheme of education is only half completed. Provision must also be made for the latter. Along with the pass-course at Oxford, there is another system of study, making quite different demands upon the energies of the student, and called the class-course. Our system of minimums likewise needs to be supplemented by a course entailing far greater labour, and crowned with still higher results. In reducing, as here recommended, the amount of work in the required studies, in uniformly postponing doctrine to method, in contemplating scientific truths only in their general bearings, and in extending its instruction over so wide a field, the university will have secured but one of its great educational ends. It will have supplied the instruments for investigation; it must now supply the material. In order to discharge its second great duty of providing each student with the means of thoroughly conducting special duties, the university should introduce an extensive and well-regulated system of electives. For this we 
have an obvious analogue in the usage of our ancestral institution in England. We allude, of course, to the triposes of the University of Cambriige, so called, not from anytling triple or tripartite in their structure, but because of the "stool or tripos on which the bachelor of the day sat before the proctors during the disputations on Ash-Wednesday." Along with the course of required studies, remodelled according to the principles here laid down, a series of triposes should be instituted. The classic languages, with ancient history and ancient philosophy, would naturally constitute one tripos; a second might be made up of pure and applied mathematics; a third, of chemistry and the organic sciences; a fourth, of psychology, logic, and the history of philosophy; a fifth, of modern history, political economy, and elementary law; while a sixth might be assigned to modern languages and general philology. At the beginning of the Sophomore year, - when, as we shall presently see, matriculation should be granted and the proper university course should commence, - the student should be allowed to select one or more of these triposes, in which to pursue his studies until graduation. As in each tripos the degree of proficiency requisite in order to graduate with honour should obviously 
be placed very high, few students would think it advisable to take up more than one. Thus organized, the system of triposes would for all practical purposes correspond to the Oxford classcourse.

Many students will in every year be found willing to content themselves with the pass-course. They have no desire to do more than the minimum of work needful in order to get through college without disgrace. Or perhaps they are feeble in health, or have been imperfectly trained at school, and cannot therefore expect to do justice to the severe requirements of a tripos. These should be allowed to act their pleasure: the education they will get from the pass-course is vastly better than none; and there are better means than direct compulsion for inducing the student to follow the more laborious and profitable path. Either a higher degree should reward the perseverance of the class-man, as some have already suggested, or the maximum of credit should, for the pass-man, be reduced by one half or even by two thirds. In any case, all the honours of the university, all its scholarships, prizes, and emoluments, should be strictly reserved for those who have distinguished themselves in a tripos. Besides this, for the class-men, the constraint of com- 
pulsory attendance upon recitations and lectures should be materially diminished. Every one possessed of the requisite experience knows that, for the able and diligent student, too frequent recitation is not only a hardship, but a hindrance. The explanations of the professor, adapted as they must be to the comprehension of all his hearers, are often entirely superfluous to any one who has properly gone over the subject beforehand; while listening to the awkward blunders of dull or lazy classmates is not only a waste of time, but an irritation to the nerves. Nor could any class-man be expected to acquit himself satisfactorily upon his final examination, if three hours were to be subtracted from his time for study each day. Four or five recitations every week in the studies of the tripos would be amply sufficient. The classman should also be exempted from pursuing that portion of the pass-course covered by the subjects embraced in his tripos. Obviously, he who selects Latin and Greek for his special studies will gain nothing by following the instruction given upon those subjects to the pass-men, though in all other departments he must keep up to the minimum required. As a further means of relieving class-men from the distractions of continual recitation, and in order to provide all stu. 
dents with a wholesome incentive to exertion, a conditional exemption from recitations might be granted in the studies of the pass-course. For example, all persons attaining a certain standard of excellence in the monthly examination might be required to attend only half the stated num. ber of recitations for the month following. The next examination would afford both a test of the faithfulness with which the student had employed the time thus left to his control, and an occasion

- for withdrawing the privilege in case of its abuse. Some such system as this might be put into oper. ation even in the present state of affairs. Its merits, in creating a powerful yet thoroughly natural motive for promptness and diligence, are perfectly apparent. It goes far toward obviating the defects of the system of compulsory attendance, while it does not ignore the value of that discipline which can only be got from occasional intercourse with tutors and fellow-students in the recitation-room.

The advantages of solving problems, construing an ancient author, or rehearsing the results of one's reading in the presence of classmates and subject to professorial criticism are indeed sufficiently obvious. Skill in acquiring knowledge ought certainly to be accompanied by skill in re- 
producing it; nor would the student be likely to do credit to himself in the examination, who should fail previously to test his powers of an. swering questions on the spur of the moment. But the business of recitation should not be con. fined to going over in public what has already been gone over in private. The instructor's superior knowledge and more extensive sources of information should be applied to the elucidation of the subject in hand. Questions should be freely asked, and discussion, wherever relevant, should be encouraged. Thus conducted, the recitation would fulfil its appropriate function of making good the shortcomings inherent in a system of merely private study, of supplying illustrations which cannot be found in text-books, and of smoothing the difficulties which from time to time beset the student in his progress.

Viewed in this light, the recitation is properly an auxiliary to study, rather than a gange of the student's attainments. The latter purpose can be adequately subserved only by the examinations, on which the rank assigned to the student should exclusively depend. The marks given on individual recitations are nearly worthless as an index of scholarship. By dint of "cramming," the use of keys, translations, and other abominations, a 
delusive show of knowledge can easily be produced, which may answer the demands of the moment, but which a shrewd examination will inevitably dispel. If recitations were not allowed to influence rank, and were conducted in the conversational manner here recommended, the chief temptation to the employment of these wretched subterfuges would be at once removed. Accuracy of scholarship can never be looked for in a man who refuses to grapple with obstacles himself; and to translations in particular it may be objected that, being not always executed by competent scholar's, their interpretations of difficult passages are often quite untrustwortliy. Any system of conducting recitation, whose tendency is to banish these treacherous guides from the precincts of the university, is by that circumstance alone recommended at the outset.

The object of the triposes is to encourage misute and thorough scholarship. To this end, the distribution of honours should be determined by the results of a competitive examination held at the close of the college course, in which the requirements should be so great, and the questions so searching, as to render hopeless all attempts at şucceeding by surreptitions means. At Oxford, for instance, the final class-papers in mathematics 
include questions covering the whole subject of pure and mixed mathematics; and there is no reason why our standard of proficiency should not be equally high, since in a purely optional course neither inability nor distaste for the subject can reasonably be pleaded. From the classical student, besides thorough familiarity with the text and subject-matter of at least ten difficult authors, we should demand a knowledge of ancient history at once extensive and accurate, as well as some skill in treating the higher problems of philology and criticism. And in the other class examinations the requirements should be similar. With such an organization, it would be strange if the university did not each year send forth a considerable number of persons in every way prepared to become finished scholars. With the compulsory system reduced to the lowest practicable minimum, and the elective system carried out with the greatest possible completeness, the chief ends of a liberal education can most effectually be secured; and the most excellent features of the European university will thus be adopted without resigning any single point of superiority possessed by the American college.

As already hinted, the existing constitution of the freshman year should not be materially in. 
fringed. A course of study like the one here described cannot profitably be undertaken without more thorough elementary preparation than the student is likely to obtain at school. In such a country as England, where a dense population is confined to a small area, and where a considerable degree of uniformity prevails in the civilization of different localities, all the necessary work preliminary to a university career can easily be performed in the great public schools. If, however, the present population of England were loosely spread over all the country between the Atlantic and the Dnieper, and if, while some parts were as highly educated as London, other parts were as poorly educated as Dalmatia, the state of things would be analogous to that which now exists in our own country. It is in conformity with these different circumstances that our system of education must be organized. We have no Eton or Rugby; but we have hundreds of schools for elementary education, scattered over an immense tract of country, and differing widely in the amount and quality of the instruction which they impart to their pupils. The social environment in which they are situated is usually very different from that of Cambridge; and the especial preparation of students for Harvard College can. 
not, except, perhaps, in Massachusetts, be regarded as one of the ends for which they exist. While the student coming from New England or any of the adjacent states is likely to be well prepared to begin his studies at Harvard, the student who comes from the West or from the South is equally likely to be ill prepared. These disadvantages are now to a great extent compensated under the régime of the freshman year, and the circumstances by which they are occasioned furnish a sufficient reason for retaining that year as a period of probation, instead of giving it up altogether, or of making it a part of the regular university course. It should therefore, we think, be retained in its present form, with an examination both at its beginning and at its close, upon the latter of which the attainment of matriculation should be made to depend.

Our brief sketch of a university reform would not be complete without a few remarks upon the numerous police restrictions by which, at Harvard and elsewhere, the American student is gratuitously harassed. ${ }^{1}$ When the university undertakes to prescribe the colour of the student's dress, to determine when and where he shall smoke his cigar in the streets, and under what

1 Statutes of Harvard College, ch. x., § 101. 
conditions he shall keep a dog or a horse, it is not only exceeding its proper functions, but it is also forgetting its own dignity. Years ago, when black broadcloth was generally considered the only suitable material for a gentleman's coat, and when none but truckmen and coal-heavers smoked in the streets, these laws might have been reasomable, though they were not even therefore necessarily justifiable. Now they have neither reason nor justice to recommend them. The state of things to ineet which they were framed has entirely passed away, and the result of maintaining and even partially enforcing them is to widen, instead of closing, the social gulf which is fixed between instructors and students. Only when this chasm is removed by more familiar intercourse, and by the abolition of the petty restraints which have in times past caused students to regard with distrust and suspicion the officers placed over them, can the graver evils of college life, such as hazing and rowdyism, be effectually done away with. The self-respect awakened in the mind of the student by treating him as a gentleman will go much farther toward insuring his gentlemanly behaviour than all the censorial laws which corporations can frame and proctors execute. That undergraduates have too often de. 
meaned themselves like grown-up children follows naturally from the circumstance that they have to an extent only too great been regarded as such.

That a limited amount of penal legislation is needful, under the present constitution of our colleges, we have already admitted. If the system of compulsory attendance upon lectures, recitations, and the roll-call - currently known as " morning prayers" - is not entirely to be given up, some penalty must await non-attendance. But that this penalty should interfere with the rank of the student, should affect his apparent scholarship, is utterly absurd. There is conspicuous absurdity in the state of things which allows a man who has attained an average mark of seven eighths to graduate without honour, becanse of his irregular attendance upon college exercises. His low rank is considered by the public to be an evidence of inferior scholarship; nor will any amount of mere explanation suffice to remove the impression. The old system of fining would be far preferable to this. As for rioting, sedition, and gross indecorum, they should, after due warning, be visited with expulsion. Further than this, the penal legislation of the university camnot le. gitimately extend. 
Such in its leading outlines is the scheme of university reform which has long been present, with more or less distinctness, to the mind of the writer. We are not sufficiently vain or sanguine to hope that it will at once recommend itself to those in whose hands the work of reform has been placed. We have throughout, however, avoided the discussion of Utopian measures for the attainment of ideal excellence, and have proposed no innovations for which we do not consider the times to be fully ripe, and the means of execution entirely at command. If our suggestions shall have at all contributed to fix and give shape to the floating ideas of any graduate who may be now first approaching the subject of reform, their end will be amply subserved. Something would have been said, had space allowed, on the important subject of a post-graduate course. But for the present we must be content with directing the attention of the alumni and the public to the imperative need which exists for an arrangement whereby those graduates who desire it shall be enabled to pursue their studies indefinitely, under the shadow of the university. Only under such a system can we make due provision for thorough scholarship. Our literature cannot hope to compete with that of other countries, so long as our 
young men of literary taste and ability have no choice but to embark in an active profession, or engage in mercantile employments. To institute a number of fellowships - the essential condition of a post-graduate course - will require, no doubt, a much greater revenue than the university has now at its disposal. But the end which is not straightway attainable should still be kept steadily in view. A system of post-graduate instruction is, we repeat, the great need both of the university and of the country. Literature, science, and high scholarship have never prospered where they have not been recognized as legitimate special pursuits. Individual zeal and genius may indeed perform wonder's, but they cannot supply the place of systematic organization. Our mother university has in recent days enriched mankind by the labours of a Donaldson, a Munro, and a Merivale; and when we, by means of a wellorganized system of fellowships, are able to do likewise, our country also may hope to rival its mother in learning and scholarship, as it now rivals her in material prosperity.

October, 1866. 


\section{XV.}

\section{A LIBRARIAN'S WORK.}

I AM very frequently asked what in the world a librarian can find to do with his time, or am perhaps congratulated on my connection with Harvard College Library, on the ground that, "being virtnally a sinecure office (!), it must leave so much leisure for private study and work of a literary sort." Those who put such questions, or offer such congratulations, are naturally astonished when told that the library affords enough work to employ all my own time, as well as that of twenty assistants; and astonishment is apt to rise to bewilderment when it is added that seventeen of these assistants are occupied chiefly with "cataloguing;" for generally, I find, a library catalogue is assumed to be a thing that is somehow "made" at a single stroke, as Aladdin's palace was built, at intervals of ten or a dozen years, or whenever a "new catalogue" is thought to be needed. "How often do you make a catalogue?" or, "When will your catalogue be com- 


\section{A Librarian's Work.}

pleted?" are questions revealing such transcendent misapprehension of the case that little but further mystification can be got from the mere answer, "We are always making a catalogue, and it will never be finished." The "doctrine of special creations," indeed, does not work any better in the bibliographical than in the zoölogical world. A catalogue, in the modern sense of the term, is not something that is "made" all at once, to last until the time has come for it to be superseded by a new edition, but it is something that "grows," by slow increments, and supersedes itself only through gradual evolution from a lower degree of fulness and definiteness into a higher one. It is perhaps worth while to give some general explanation of this process of catalogue-making, thus answering once for all the question as to what may be a librarian's work. There is no better way to begin than to describe, in the case of our own library, the career of a book from the time of its delivery by the expressman to the time when it is ready for public use.

New American books, whether bonght or presented, generally come along in driblets, two or three at a time, throughout the year; large boxes of pamphlets, newspapers, broadsides, trade-catalogues, and all manner of woful rubbish (the ref- 
use of private libraries and households) are sent in from time to time; and books from Europe arrive every few weeks in lots of from fifty to three or four hundred. It is in the case of foreign books that our process is most thoroughly systematized, and here let us take up our illustrative example.

When a box containing three or four hundred foreign books has been unpacked, the volumes are placed, backs uppermost, on large tables, and are then looked over by the principal assistant, with two or three subordinates, to ascertain if the books at hand correspond with those charged in the invoice. As the titles are read from the invoice, the volumes are hunted ont and arranged side by side in the order in which their titles are read, while the entry on the invoice is checked in the margin with a pencil. These pencil-checks are afterwards copied into the margins of the book in which our lists of foreign orders are registered, so that we may always be able to determine, by a reference to this book, whether any particular work has been received or not. This order-book, with its marginal checks, is the only immediate specific register of accessions kept by us, as our peculiar system entails considerable delay in bringing up the "accessions-catalogue."

After this preliminary examination and regis 
try, the books are ready for me to look over, and I must first decide to what "fund" each book entered on the invoice must be charged. The university never buys books with its general funds, but uses for this purpose the income of a dozen or more small funds, given, bequeathed, or subscribed, expressly for the purchase of books. Sometimes the donors of such funds allow us to get whatever books we like with the money, but more often they show an inclination to favour the growth of departments in which they feel a personal interest. Thus the munificent bequest of the late Mr. Charles Sumner is appropriated to the purchase of works on politics and the fine arts, while Dr. Walker's bequest provides more especially for theology and philosophy, and the estate of Professor Farrar still guards the interests of mathematics and physics. Under such circurnstances, it is of course necessary to keep a separate account with each fund, and the data for such an account are provided by charging every new book as it arrives. On the margin of the invoice the names of the different funds are written in pencil against the entries, while the assistants separate the books into groups according to the funds to which they are charged. Five or six more assistants now arriving on the scene, the work of "collating" begins. 
Properly speaking, to "collate" is to compare two things with each other, in order to estimate or judge the one by a reference to the other taken as a standard. In our library usage the word has very nearly this sense when duplicate copies of the same work are collated, to see whether they coincide page for page. But as we currently use the word, to collate a book is simply to examine it carefully from beginning to end, to see whether every page is in its proper place and properly numbered, whether any maps or plates are missing or misplaced, whether the back is correctly lettered, or whether any leaves are so badly torn or defaced as to need replacing. In English clothbound books this scrutiny involves the cutting of the leaves, - a tedious job which in half-bound books from the Continent is seldom required. En revanche, however, the collating of an English book hardly ever brings to light any serious defect, while in the make-up of French and German books the grossest blunders are only too common. Figures are unaccountably skipped in numbermg the pages; plates are either omitted or are so bunglingly numbered that it is hard to discover whether the quota is complete or not; title-pages are inserted in the wrong places; sheets are wrongly folded, bringing the succession of pages 
into dire confusion; sometimes two or three sheets are left out, and sometimes, where a work in ten volumes is bound in five, you will find that the first of these contains two duplicate copies of Vol. I., while for any signs of a Vol. II. you may seek in vain. In all bungling of this kind the Germans are worse than the French; but both are bad enough when contrasted with the English, either of the Old World or of the New.

This work of collating is in general of lower grade than the work of cataloguing, and can be entrusted to the less experienced or less accomplished assistants; but to some extent it is shared by all, and where difficulties arise, or where some book with Arabic or Sanskrit numbering turns up, an appeal to headquarters becomes necessary. When a book has been collated, the date of its reception and the name of the fund to which it has been charged are written in pencil on the back of the title-page, and at the bottom of the title-page, to the left of the imprint, is written some modification of the letter $\mathrm{C}, \mathrm{C}^{\prime}, \mathrm{C}^{\circ}, \mathrm{C}^{1}$, etc., which is equivalent to the signature of the assistant who has done the collating and is responsible for its accuracy.

After this is all over, the books, still remaining grouped according to their "funds," are ready to 
have the "seals" put in. The seal is the label of ownership, bearing the seal of the university and the name of the fund or other source from which the book has been procured, and is pasted on the inside of the front cover. Above it, in the left corner, is pasted a little blank corner-piece, on which is to be marked in pencil the number of the alcove and shelf where the book is to be placed, or "set up."

To set up a book on a shelf is no doubt a very simple matter, yet it involves something more than the mere placing of the volume on the shelf. Each alcove in the library has a "shelf-catalogue," or list of all the books in the alcove, arranged by shelves. Such a catalogue is indispensable in determining whether each shelf has its proper complement of volumes, and whether, at the end of the year, all the books are in their proper places. When the book is duly entered on this shelf-catalogue, and has its corner-piece marked, it is at last ready to be "catalogued." After our lot of three or four hundred books have been treated in this way, they are delivered to the principal assistant, who parcels them out among various subordinate assistants for cataloguing.

Here we enter upon a very wide subject, and 
one that is not altogether easy to expound to the uninitiated. A brief historical note is needed, to begin with. In 1830 Harvard University published a printed catalogue (in two rolumes, octavo) of all the works contained in its library at that date. In 1833 a supplement was published, containing all the accessions since 1830 , and these made a moderate-sized volume. Here is the essential vice of printed catalogues. Where the number of books is fixed once for all, - as in the case of a private library, the owner of which has just died, and which is to be sold at auction, nothing is easier than to make a perfect catalogue, whether of authors or of subjects. It is very different when your library is continually growing. By the time your printed catalogue is completed and published, it is already somewhat antiquated. Several hundred books have come in which are not comprised in it, and among these new books is very likely to be the one you wish to consult, concerning which the printed catalogue can give you no information. If you publish an annual supplement, as the Library of Congress does, then your catalogue will become desperately cumbrous within five or six years. When you are in a hurry to consult a book, it is very disheartening to have to look through half a dozen alphabets, 
besides depending after all on the ready memory of some library official as to the books which have come in since the last supplement was published.

This inconvenience is so great that printed catalogues have gone into discredit in all the principal libraries of Europe. Catalogues are indeed printed, from time to time, by way of publishing the treasures of the library, and as bibliographical helps to other institutions; but for the use of those who daily consult the library, manuscript titles have quite superseded the printed catalogue. In European libraries this is done in what seems to us a rather crude way. Their catalogues are enormous brown paper blankbooks or scrap-books, on the leaves of which are pasted thin paper slips bearing the titles of the books in the library. Large spaces are left for the insertion of subsequent titles in their alphabetical order; and as a result of this method, the admirable catalogue of the library of the British Museum fills more than a thousand elephant folios! An athletic man, who has served his time at base-ball and rowing, may think little of lifting these gigantic tomes, but for a lady who wishes to look up some subject one would think it desirable to employ a pair of oxen and a windliss. 


\section{A Librarian's Work.}

All the libraries of western Europe which I have visited seem to have taken their cue from the British Museum. But in America we have hit upon a less ponderous method. To accomplish this end of keeping our titles in their proper alphabetical order, we write them on separate cards, of stiff paper, and arrange these cards in little drawers, in such a way that any one, by opening the drawer and tilting the cards therein, can easily find the title for which he is seeking. Our new catalogue at Cambridge is a marvel of practical convenience in this respect. At each end the row of stiff cards is supported by bevelled blocks, in such a way that some title lies always open to view; and by simply tilting the cards with the forefinger, any given title is quickly found, without raising the card from its place in the drawer.

In September, 1833, our library began its second supplement, consisting of two alphabetical manuscript catalogues. Volumes received after that date were catalogued upon stiff cards arranged in drawers, while pamphlets were catalogued, after the European fashion, on slips of paper pasted into great folio scrap-books. This distinction between pamphlets and volumes was a most unhappy one. To a librarian the only prac- 
tical difference between these two kinds of book is that the latter can generally be made to stand on a shelf, while the former generally tumbles down when unsupported. This physical fact makes it necessary to keep pamphlets in files by themselves until it is thought worth while to bind them. But for the purposes of cataloguing it makes no difference whether a book consists of twe $\downarrow y$ pages between paper covers or of five hundred pages bound in full calf. If you wish to find M. Léon de Rosny’s "Aperçu général des Langues sémitiques," you do not care, and very likely do not know, whether it is " "pamphlet" of fifty pages or a "volume" of three hundred, and you naturally grumble at a system which sends you to a second alphabet in order to maintain a purely arbitrary and useless distinction. In practice this double catalogue was found to be so inconvenient that in 1850, after the pamphlet titles had come to fill eight cumbrous volumes, it was abandoned, and henceforth pamphlets, as well as maps and engravings, were placed on the same alphabet with bound volumes.

Before long, however, it began to be felt neces. sary to reform this whole cumbrous system. To ascertain whether a given work was contained in the library, one had now to consult four different 
alphabets, - the old printed catalogue, the first or printed supplement, the second or card supplement, and the eight ugly folios of pamphlet titles. These later supplements, moreover, being accessible only to the librarian and his assistants, were of no use to the general public, who, for the 135,000 titles added since 1833, were obliged to get their information from some of the officials. To remedy this state of things, a new card catalogue, freely accessible to the public, and destined to embrace in a single alphabet all the titles in the library without distinction, was begun in 1861 by my predecessor, Professor Ezra Abbot. This catalogue was not intended to supersede the private card supplement begun in 1833, which for many reasons it is found desirable to keep up. But for the use of the public it will, when finished, supersede everything else, and become the sole authoritative catalogue of the library. Since 1861 all new accessions have been put into this catalogue, while the work of adding to it the older titles has gone on with varying speed; in 1869 it came nearly to a standstill, but was resumed in 1874 , and is now proceeding with great rapidity. About fifty thousand titles of volumes, and as many more of pamphlets, still remain to be added 
before this new catalogue can become the index to all the treasures of the library. ${ }^{1}$

Another great undertaking was begun simultaneously in 1861. The object of an alphabetical catilogue like those above described is "to enable a person to determine really whether ary particular work belongs to the library, and, if it does, where it is placed." If you are in search of Lloyd's "Lectures on the Wave-Theory of Light," you will look in the alphabetical catalogue under "Lloyd, Humphrey." Now this alphabetical arrangement is the only one practicable in a public library, because it is the only one on which all catalogues can be made to agree, and it is the only one sufficiently simple to be generally understood. For the purpose here required, of finding a particular work, an arrangement according to subject-matter would be entirely chimerical. Nothing short of omniscience could ever be sure of finding a given title amid such a heterogeneous multitude. Every man who can read knows the order of the alphabet, but not one in a thousand can be expected to master all the points that determine the arrangement of a catalogue of subjects, - as, for example, why one of three kindred

1 About seventeen thousand of these old titles were added during the two years ending in July, 1877. 
treatises should be classed under the rubric of Philosophy, another under Natural Religion, and a third under Dogmatic Theology. ${ }^{1}$ But while it would thus be impracticable to place our final reliance on any other arrangement than an alphiabetical one, it by no means follows that a subsidiary subject-catalogue is not extremely useful. He who knows that he wants Lloyd's book on the undulatory theory is somewhat more learned in the literature of optics than the majority of those who consult libraries. For one who knows as much as this, there are twenty who know only that they want to get some book about the undulatory theory. Now a subject-catalogue is preeminently useful in instructing such people in the literature of the subject they are studying. They have only to open a drawer that is labelled "OpTICs," and run along the cards until they come to a division marked "Optics - Wave-Theory," and there they will find perhaps a dozen or fifty titles of books, pamphlets, review articles, and memoirs of learned societies, all bearing on their subject, and enabling them to look it up with a minimum of bibliographical trouble. Such a classified catalngue immeasurably increases the usefulness of a

1 See the excellent remarks of Professor Jevons in his Principles of Science, ii. 401. 
library to the general public. At the same time, the skilful classification of books presents so many difficulties and requires so much scientific and literary training that it adds greatly to the labour of catalogue-making. For this reason great librarics rarely attempt to make subject-catalogues. At every library which I have happened to visit in England, France, Germany, and Italy, I have received the same answer: "We do not keep any subject-catalogue, for we shrink from so formidable an undertaking." With a boldness justified by the result, however, Professor Abbot began such a catalogue of the Harvard library in 1861, and carried out the work with the success that might have been expected from his truly stupendous erudition and most consummate ingenuity.

It is sometimes urged that, in deference to the feebleness of human memory, an ideal library should have yet a third catalogue, arranged alphabetically, not according to authors, but according to titles. This is to accommodate the man who knows that he wants "Lectures on the WaveTheory of Light," but has forgotten the author's name. In an "ideal" library this might perhaps be well. But in a real library, subject to the ordi. nary laws of nature, it is to be remembered that any serious addition to the amount of catalogue- 
room or to the labour of the librarian and assistants is an expense which can be justified only by the prospect of very decided advantages. In most cases, the subject-catalogue answers the purposes of those who remember the title of a work, but have forgotten the author. In the very heterogeneous classes of Drama and Fiction, where this is not so likely to be the case, the exigency is provided for in Professor Abbot's system by a full set of cross-references from titles to authors.

From this account it will be seen that any new book received to-day by our library must be entered on three catalogues, - first on the card supplement which continues the old printed catalogue, secondly on the new all-comprehensive alphabet of authors, thirdly on the classified index of subjects. In our technical slang the first of these catalogues is known under the collective name of "the long cards," the second as "the red cards," the third as "the blue cards," - names referring to the shape of the cards and to certain peculiarities of the lines with which they are ruled. When our lot of three or four hundred books is portioned out among half a dozen assistants to be catalogued, the first thing in order is to write the "long cards." Each book must have at least one long card; but most books need more 
than one, and some books need a great many. Suppose you have to catalogue Mr. Stuart-Glennie's newly-published "Pilgrim Memories." This is an exceedingly easy book for the cataloguer, but it requires two cards, because of the author's compound name. The book must be entered under "Stuart-Glennie," because that is the form in which the name appears on the title-page, and which the author is therefore supposed to prefer. It is very important, however, that a reference should be made from "Glennie" to "Stuart-Glennie," else some one, remembering only the last half of the name, would look in vain for "Glennie," and conclude that the book was not in the library.

Suppose, again, that your book is Jevons on "Money and the Mechanism of Exchange." This belongs to the "International Scientific Series," and therefore needs to be entered under "Jevons," and again on the general card which bears the superscription "International Scientific Series." Without such a general entry, books are liable to be ordered and bought under one heading when they are already in the library and catalogned under the other heading. The risk of such a mishap is small in the case of the new and well-known series just mentioned, but it is con- 
siderable in the case of the different series of "British State Papers," or the "Scelta di Curiositá Italiane ;" and of course one rule must be followed for all such cases. Suppose, again, that your book is Grimm's "Deutsches Woerterbuch," begun by the illustrious Grimm, but continued by several other hands. Here you must obviously have a distinct entry for each collaborator, and each of these entries requires a card.

In writing the long card, the first great point is to ascertain every jot and tittle of the author's name; and, as a general rule, title-pages are very poor helps toward settling this distressing question. For instance, you see from the title-pages of "Money" and "Pilgrim Memories" that the authors are " $W$. Stanley Jevons," and "John S. Stuart-Glennie;" but your duty as an accurate cataloguer is not fulfilled until you have ascertained what names the $W$. and $S$. stand for in these cases. In the alphabetical catalogue of a great library, it is a matter of the first practical importance that every name should be given with the utmost completeness that the most extreme pedantry could suggest. No one who has not had experience in these matters can duly realize that the number of published books is so enormous as to occasion serious difficulty in keeping apart the 
titles of works by authors of the same name. "Stanley Jevons" and "Stuart-Glennie" are very uncommon combinations of names; yet the occurrence of two or three different authors in an alphabetical catalogue, bearing this uncommon combination of names, would not be at all surprising.

Indeed, - to say nothing of the immense number of accidental coincidences, - I think we may lay it down as a large comprehensive sort of rule, that any man who has published a volume or pamphlet is sure to have relatives of the same name who have published volumes or pamphlets. Such a fact may have some value to people, like Mr. Galton, who are interested in the subject of hereditary talent, and who have besides a keen eye for statistics. I have never tabulated the statistics of this matter, and am stating only a general impression, gathered from miscellaneous experience, when I say that the occurrence of almost any name in a list of authors affords a considerable probability of its re-occurrence, associated with some fact of blood-relationship. One would not be likely to realize this fact in collecting a large private library, because private libraries, however large, are apt to contain only the classical works of quite exceptional men and the 
less important works which happen to be specially interesting or useful to the owner. But in a public library the treasures and the rubbish of the literary world are alike hoarded; and the works of exceptional men whom everybody remembers are lumped in with the works of all their less distinguished cousins and great-uncles, whose names the world of readers has forgotten.

A librarian has the opportunity for observing many curious facts of this sort, but be will seldom have leisure to speculate about them. For while a great library is an excellent place for study and reflection, for everybody except the librarian, his position is rather a tantalizing one. In the midst of the great ocean of books, it is "water, water every where, and not a drop to drink."

To make up for the extreme vagueness with which authors customarily designate themselves on their title-pages is the work of the assistants who write the long cards, and it is apt to be a very tedious and troublesome undertaking. Biographical and bibliographical dictionaries, the catalogues of our own and other libraries, university-catalogues, army-lists, clerical directories, genealogies of the British peerage, almanacs, "conversations-lexicons," literary histories, and volumes of memoirs, - all these aids have to be 
consulted, and too often are consulted in vain, or give conflicting testimony which serves to raise the most curious and perplexing questions. To the outside world such anxious minuteness seems useless pedantry; but any sceptic who should serve six months in a library would become convinced that without it an alphabetical catalogue would soon prove unmanageable. "Imagine the heading 'Snirth, J.,' in such a catalogue!" says Professor Abbot. Where a name is very common, we are fain to add whatever distinctive epithet we can lay hold of ; as in the case of six entries of "WILsON, William," which are differenced by the addition of "Scotch Covenanter," "poet, of London," "M. A., of Musselburgh," "of Poughkeepsie," "Vicar of Walthamstow," "Pres. of the Warrington Nat. Hist. Soc." 1

New difficulties arise when the title-page leaves it doubtful whether the name upon it is that of the author, or that of an editor or compiler. The names of editor's and translators are often omitted, and must be sought in bibliographical dictionaries. Dedicatory epistles, biographical sketches, or introductory notices are often prefixed, signed with

1 Sometimes these headings are very odd, as in the case of a host of "John Jacksons," one of whom is neatly distinguished as "JACK. son, John, murderer," - the work thus catalogued being the "con. fession" of one John Jackson who had murdered his wife. 
exasperating initials, for a clue to which you may perhaps spend an hour or two in fruitless inquiry. In accurate cataloguing, all such adjuncts to a book must be noticed, and often require distinct reference-cards. Curious difficulties are sometimes presented by the phenomena of compound or complex anthorship, as in works like the Bollandist "Acta Sanctorum," conducted by a group of men, some of whom are removed by death, while their places are supplied by new collaborators. Some other immense work, like Migne's " $\mathrm{Pa}$ trologix Cursus Completus," will give rise to nice questions owing to the indefiniteness with which its various parts are demarcated from each other. Many German books, on the other hand, are troublesome from the excessive explicitness with which they are divided, with sub-titles and subsub-titles innumerable, in accordance with some subtle principle not always to be detected at the first glance. The proper mode of entry for reports of legal cases and trials, periodicals, and publications of learned societies, governments, and boards of commissioners, is sure to call for more or less technical skill and practical discrimination. Anonymous and psendonymous works are very common, and even the best bibliographical dictionaries cannot keep pace with the issue 
of them. Where we can find, by hook or by crook, the real name of the author of a pseudonymous work, it is entered under the real name, with a cross-reference from the pseudonym. Otherwise it is entered provisionally under the fictitious name, as, for example, "Veritas, pseudon." Anonymous works are entered under the first word of the title, neglecting particles; and the head-line is left blank, so that if the author is ever discovered, his name may be inserted there, enclosed within brackets. In former times it was customary for the cataloguer to enter such works under what he deemed to be the most important word of the title, or the word most likely to be remembered; but in practice this rule has been found to cause great confusion, since people are by no means sure to agree as to the most important word. To some it may seem absurd to enter an anonymous "Treatise on the Best Method of preparing Adhesive Mucilage" under the word "Treatise "rather than under "Mucilage;" but it should be remembered that he who consults an alphabetical catalogue is supposed to know the title for which he is looking; and, in our own library at least, any one who remembers only the subject of the work he is seeking can always refer to the catalogue of subjects. 
To treat more extensively of such points as these, in which none but cataloguer's are likely to feel a strong interest, would not be consistent with the purpose of this article. For those who wonder what a librarian can find to do with his time, enough hints have been given to show that the task of "just cataloguing a book" is not, perhaps, quite so simple as they may have supposed. These hints have nevertheless been chosen with reference to the easier portions of a librarian's work, for a description of the more intricate problems of cataloguing could hardly fail to be both tedious and unintelligible to the uninitiated reader. Enough has been said to show that a cataloguer's work requires at the outset considerable judgment and discrimination, and a great deal of slow, plodding research. The facts which we take such pains to ascertain may seem petty when contrasted with the dazzling facts which are elicited by scientific researches. But in reality the grandest scientific truths are reached only after the minute scrutiny of facts which often seem very trivial. And though the little details which encumber a librarian's mind do not minister to grand or striking generalizations, though their destiny is in the main an obscure one, yet if they were not duly taken care of the usefulness 
of libraries as aids to high culture and profound investigation would be fatally impaired. To the student's unaided faculties a great library is simply a trackless wilderness; the catalogue of such a library is itself a kind of wilderness, albeit much more readily penetrated and explored; but unless a book be entered with extreme accuracy and fulness on the catalogue, it is practically lost to the investigator who needs it, and might almost as well not be in the library at all.

In the task of entering a book properly on the alphabetical catalogue, the needful researches are for the most part made by the assistants; but the questionable points are so numerous, and so unlike each other, that none of them can be considered as finally settled until approved at headquarters. After the proper entry has been decided on, the work of transcribing the title is comparatively simple in most cases. The general rule is to copy the whole of the title with strict accuracy, in its own language and without translation, including even abbreviations and mistakes or oddities in spelling. Mottoes and other really superfluous matters on the title-page are usually omitted, the omission being scrupulously indicated by points. As regards the use of capital letters, title-pages do not afford any consistent guidance, being usu. 
ally printed in capitals throughout. Our own practice is to follow in capitalizing the usage of the language in which the title is written; but many libraries adopt the much simpler rule of rejecting capitals altogether except in the case of proper names, and this I believe to be practically the better because the easier method, ${ }^{1}$ though the result may not seem quite so elegant.

After the transcription of the entire title, the number of volumes, or other divisions of the book, is set down; and next in order follows the "imprint," or designation of the place and date of publication. Finally, the size of the book (whether folio, or quarto, octavo, etc.) is designated, after an examination of the "signature marks;" the number of pages (if less than one hundred or more than six hundred) is stated ${ }^{2}$ plates, woodcuts, maps, plans, diagrams, photographs, etc., are counted and described in general terms. Any peculiarities relating not to the edition, but to the particular copy catalogued, are

1 Since this article was written, I have adopted the simpler rule, applying the French system of capitalization to all languages, with the sole concession to our English prejudices of capitalizing proper adjectives in English titles. Much time is thereby saved, and much utterly useless vexation aroided.

2 In order to point out books of an exceptionally large or small size. I believe, however, it would be better to state the number of pages in every case. 
added below in a note; such as the fact that the book is one of fifty copies on large paper, or has the author's autograph on the fly-leaf. In many cases it is found desirable to add a list of the contents of the work; and if it be a book of miscellaneous essays, each essay often has an additional entry on a card of its own. ${ }^{1}$

These details make up the sum of what is entered on the body of the long card; but in addition to all this, the left-hand margin contains the date of reception of the book, the fund to which it is charged, or the name of the donor, and the all-important "shelf-mark," which shows where the book is to be found; while on the right-hand margin is written a concise description of the appearance of the book (i.e. "5 vol., green cloth"), and a note of its price. When all this is finished, the book is regarded as catalogued, and is sent, with its card in it, to the principal assistant for revision. From the principal assistant it is passed on to me, and it is the business of both of us to see that all the details of the work have been done correctly. A pencil-note on the margin of the card shows the class and sub-class to which

1 Where the essay's are by different authors, a separate entry for each is of course always necessary, though this is not always made on the long cards. 


\section{A Librarian's Work.}

the book is to be assigned in the catalogue of subjects; and then the card is separated from the book. The book goes on to its shelf, to be used by the public; the card goes back to some one of the assistants, to be "indexed." In our libraryslang, "indexing" means the writing of the "red" and "blue" cards which answer to the "long" card; in other words, the entry of the title ${ }^{1}$ on the new alphabetical and subject-catalogues be. gun in 1861. For the most part this is merely a matter of accurate transcription, requiring no research. When these "red" and "blue" cards have been submitted to a special assistant for proof-reading, they are returned to me, and after due inspection are ready to be distributed into their catalogues. But for the original "long card" one further preliminary is required before it can be put into its catalogue.

Besides the various catalogues above described, our library keeps a "record-book" or catalogue of accessions arranged according to dates of reception. This accessions-catalogue was begun October 1, 1827, and records an accession for that year of one volume, price ten shillings and sixpence! In 1828, according to this record, the

1 The marginal portions of the long card are not transcribed in indexing. 
library received twenty-one volumes, of which eighteen were gifts, while three were bought at a total cost of $\$ 14.50$ ! But either these were exceptionally unfruitful years, or - what is more likely - the record was not carefully kept, for the ordinary rate of increase in those days was by no means so small as this, though small enough when compared with the present rate. The accessions-catalogue has grown until it now fills twenty-one large folio volumes. The entries in it are made with considerable fulness by transcription from the long cards. Usually a month's accessions are entered at once, and when this has been done the long card is ready to take its place in the catalogue.

In this account of the career of a book, from its reception to the time when it is duly entered on all the catalogues, we find some explanation of the way in which a librarian employs his time. For while the work of cataloguing is done almost entirely by assistants, yet unless every detail of it passes under the librarian's eye there is no adequate security for systematic unity in the results. The librarian must not indeed spend his time in proof-reading or in verifying authors' names; it is essential that there should be some assistants who can be depended upon for absolute accuracy 
in such matters. Nevertheless, the complexity of the questions involved requires that appeal should often be made to him, and that he should always review the work, for the correctness of which he is ultimately responsible. As for the designation of the proper entry on the subject-catalogue, the cases are rare in which this can be entrusted to any assistant. To classify the subject-matter of a book is not always in itself easy, even when the reference is only to general principles of classifications; but a subject-catalogue, when once in existence, affords a vast mass of precedents which, while they may lighten the problem to one who has mastered the theory on which the catalogue is constructed, at the same time make it the more unmanageable to any one who has not done so. To assign to any title its proper position, you must not merely know what the book is about, but you must understand the reasons, philosophical and practical, which have determined the place to which such titles have already been assigned. It is a case in which no mere mechanical following of tradition is of any avail. No general rules can be laid down which a corps of assistants can follow; for in general each case presents new features of its own, so that to follow any rule securely would require a mental training almost as 
great as that needed for making the rule. Hence when different people work independently at a classified catalogue, they are sure to get into a muddle.

Suppose, for example, you have to classify a book on the constitution of Massachusetts. I put such books under the heading "LAw - Mass. Const.," but another person would prefer "LAW - Const. - Mass.," a third would rank them under "LAw - U. S. - Const. § Mass.," a fourth under "LAw - U.S. - (Separate States) § Mass. - Const.," a fifth under "LAW - Const. § U. S. - Mass.," and so on, through all the permutations and combinations of which these terms are susceptible. Yet each of these arrangements would bring the title into a different part of the catalogue, so that it would be quite impossible to discover, by simple inspection, what the library contained on the subject of constitutional law in Massachusetts; and to this extent the catalogue would become useless. Many such defects are now to be found in our subject-catalogue, greatly to the impairment of its usefulness; and they prove conclusively that the work of classifying must always be left to a single superintendent who knows well the idiosyncrasies of the cata. logue. This work consumes no little time. The 
titles of books are by no means a safe index to their subject-matter. To treat one properly you must first peer into its contents; and then, no matter how excellent your memory, you will often lave to run to the catalogue for precedents.

As a rule, comparatively fer cards are written by the librarian or the principal assistant. Only the most difficult books, which no one else can catalogue, are brought to the superintendent's desk. Under this class come old manuscripts, early printed books without title-pages, books with Greek titles, and books in Slavonic, or Oriental, or barbarous languages. Early printed books require special and varying kinds of treatment, and need to be carefully described with the aid of such dictionaries as those of Hain, Panzer, and Graesse. One such book may afford work for a whole day. An old manuscript is likely to give even more trouble. There is nothing especially difficult in Greek titles, save for the fact. that our assistants are all women, who for the most part know little or nothing of the language. ${ }^{1}$ In general these assistants are acquainted with French, and with practice can make their way through titles in Latin and German. There are

1 We have since, I am grlad to say, found an exception to this rule, and Greek titles are now disposed of in regular course. 
some who can deal with any Romanic or Teutonic language, though more or less advice is usually needed for this. But all languages east of the Roman-German boundary require the eye of a practised linguist. 'To decipher a title, or' part of a preface, in a strange language, it is necessary that one should understand the character in which it is printed, and should be able to consult some dictionary either of the language in question or of some closely related dialect. One day I had to catalogue a book of Croatian ballads, and, not finding any Croatian dictionary in the library, set up a cross-fire on it with the help of a Serbian and a Slovenian dictionary. This served the purpose admirably, for where a cognate word did not happen to occur in the one language it was pretty sure to turn up in the other. Sometimes - in the case, say, of, a hundred Finnish pamphlets - the labour is greater than it is worth while to undertake; or somebody may give us a volume in Chinese or Tamil, which is practically undecipherable. In such cases we consider discretion the better part of valour, and under the heading " FinNish" or "Chinese" write "One hundred Finnish pamphlets," or "A Chinese book," trusting to the future for better information. Sometimes a polyglot visitor from Asia happens in, and 
is kind enough to settle a dozen such knotty questions at once.

Another part of a librarian's work is the ordering of new books, and this is something which cannot be done carelessly. Once a year a council of professors, after learning the amount of money that can be expended during the year, decides upon the amounts that may be severally appropriated to the various departments of literature. Long lists of desiderata are then prepared by different professors, and handed in to the library. Besides this a considerable sum is placed under the control of the librarian, for miscellaneous purchases, and any one who wishes a book bought at any time is expected to leave a written request for it at my desk. As often as we get materials for a list of two or three hundred titles, the list is given, before it is sent off, to one of our most trustworthy assistants, to be compared with the various catalogues as well as with the record of outstanding orders. To ascertain whether a particular work is in the library, or on its way thither, may seem to be a very simple matter; but it requires careful and intelligent research, and on such a point no one's opinion is worth a groat who is not versed in all the dark and crooked ways of cataloguing. The fact that a 
card-title is not to be found in the catalogue proves nothing of itself, for very likely the card may be "out" in the hands of some assistant. Nothing is more common than for a professor to order some well-known work in his own department of study which has been in the library for several year's, and so long as the art of cataloguing is as complicated as it now is such misunderstandings cannot be altogether avoided. Very often this is due to the variety of ways in which one and the same book may be described, and cannot be ascribed to any special cumbrousness or complexity of our system. All this necessitates a thorough scrutiny of every title that is ordered, for to waste the library's money in buying duplicates is a blunder of the first magnitude. Yet in spite of the utmost vigilance, it is seldom that a case of two or three hundred books arrives which does not contain two or three duplicates. One per cent. is perhaps not an extravagant allowance to make for human perversity, in any of the affairs of life in which the ideal standard is that of complete intelligence and efficiency.

The danger of buying a duplicate because a card-title does not happen to be in its place is one illustration of the practical inconvenience of cardcatalogues. The experience of the past fifty years 
has shown that on the whole such catalogues are far better than the old ones which they have superseded; but they have their shortcomings, nevertheless, and here we have incidentally hit upon one of them. Besides this, a card-catalogue, even when constructed with all the ingenuity that is displayed in our own, is very much harder to consult than a catalogue that is printed in a volume. On a printed page you can glance at twenty titles at once, whereas in a drawer of cards you must plod through the titles one by one. Moreover, a card-catalogue occupies an enormous space. Professor Abbot's twin catalogue of authors and subjects, begun fourteen years ago, is now contained in three hundred and thirty-six drawers occupying a case fifty-one feet in length ! During the past six weeks some four thousand cards have been added to it. What will its dimensions be a century hence, when our books will probably have begun to be numbered by millions instead of thousands? Gore Hall is to-day too small to contain our books: will it then be large enough to hold the catalogue? Suppose, again, that our library were to be burned ; it is disheartening to think of the quantity of bibliographical work that would in such an event be forever obliterated. For we should remember that while a 
catalogue like ours is primarily useful in enabling persons to consult our books, it would still be of great value, as a bibliographical aid to other libraries, even if all our own books were to be destroyed.1 This part of its function, moreover, it cannot properly fulfil even now, so long as it can be consulted only in Gore Hall. Our subjectcatalogue, if printed to-day, would afford a noble conspectus of the literature of many great departments of human knowledge, and would have no small value to many special inquirers. Much of this usefulness is lost so long as it remains in manuscript, confined to a single locality.

For such reasons as these, I believe that the card-system is but a temporary or transitional expedient, upon which we cannot always continue to rely exclusively. By the time Professor Abbot's great catalogue is finished ( $i$. e. brought up to date) and thoroughly revised, it will be on all accounts desirable to print it. The huge mass of cards up to that date will then be superseded, and might be destroyed without detriment to any one. But the card-catalogue, kept up in accordance with the present system, would continue as a sup-

1 Thus I often find valuable information in the printed catalogue of the Bodleian Library, and wish that the splendid catalogue of the million books in the British Museum were as readily accessible. 
plement to the printed catalogue. The cumbrousness of consulting a number of alphabets would be reduced to a minimum, for there would be only two to consult: the printed catalogue and its card supplement. Then, instead of issuing numberless printed supplements, there might be published, at stated intervals (say of ten years), a new edition of the main catalogue, with all the added titles inserted in their proper places. On this plan there would never be more than two alphabets to consult; and of these the more voluminous one would be contained in easily manageable printed volumes, while the smaller supplement only would remain in card-form.

It is an obvious objection that the frequent printing of new editions of the catalogue, according to this plan, would be attended with enormous expense. This objection would at first sight seem to be removed if we were to adopt Professor Jewett's suggestion, and stereotype each title on a separate plate. Let there be a separate stereotype-plate for each card, so that in every new edition new plates may be inserted for the added titles; and then tho ruinous expense of fresh composition for every new edition would seem to be avoided. It is to be feared, however, that this show of having solved the difficulty is illusory. 
For to keep such a quantity of printer's metal lying idle year after year would of itself entail great trouble and expense. The plates would take up a great deal of room and would need to be kept in a fire-proof building; and the interest lost each year on the value of the metal would by and by amount to a formidable sum. It is perhaps doubtful whether, in the long run, anything would be saved by this cumbrous method. Possibly - unless some future heliographic invention should turn to our profit - the least expensive way, after all, may be to print at long intervals, without stereotyping, and to depend throughout the intervals on card-supplements. But this question, like many others suggested by the formidable modern growth of literature, is easier to ask than to answer.

In this hasty sketch many points connected with a librarian's work remain unmentioned. But in a brief paper like this, one cannot expect to give a complete account of a subject ęmbracing so many details. As it is, I hope I have not wearied the reader in the attempt to show what a librarian finds to do with his time.

November, 1875. 


\section{INDEX.}

A.

Aввот, Ezra, 343-346.

Albigensians, 249.

Alexius Commenus, 248.

Amatongo, 114.

A moeba, 24.

Amphioxus, 23.

Anaxagoras, 104.

Aucients and moderns, 258.

Antelopes and lions, 15.

Arabs in Spain, 223.

Aristotle "s "Politics," 144.

Armenian heresies, $24 \%$.

Aryan race, 228.

Ascidiun, 23.

Atheism, 50 .

Attila, 222, 235.

Aurelian, 232.

Australian fauna, 26.

B.

B $\Lambda$ CH, J. S., 163.

Basil II. , 244, 248.

Bask language, 241.

Bateman, Dr., his ignoratio elenchi, 42.

Batrachians, 28.

Bat's wings, 25 .

Battle of life, 13 .

Batu, 222.

Bayle, P., 142.

Beaks and feet of pigeons, 17.

Bclisarius, 236.

Berkeley's psychology, 65 .

Bibliolatry, 117.

Biology, study of, $3 \cap 2$.

Birds and reptiles, 22.

Blachford, Lord, 57.

Blup-eyed tomcits, 17.

Bogomiles, 248.

Bosnia, 249.

Bossuet, 144.
Botany for children, 271-277.

Bow-wow theory, 43.

Brain and mind, $70-75$.

British II useum catulogue, 340 .

Brown, Thowas, 134.

Biichner, Louis, 50-55, 65.

Buckle, H. 'T., his History of Civilization, 143-206; his death at Damascus, 211 ; his mental impatience, 212: his lack of subtlety, 214 .

Bulgarian heresy, 249.

Bulgars, 243.

Butterflies in Jara and Celebes, 16.

C.

CANDOUR of Mr. Darwin, 34

Cause, 5.

Châtons, battle of, 222

Chaos and oriler, 104.

Chirles the Great, 222, 239.

Charles the Hammer, 222 .

Chriatlanity and "Chrlstianism," 207.

Clairaut, 2, 9 .

Class-system in American colleges, 290.

Classics, study of, 263, 308 .

Classifications of organisms, 22; of the sciences, 223.

Collish, multiplication of, 13.

Collating. 336 .

Colours of animals, 15.

Competitive tests, $279-284$.

Comte. A., 131-142, 25; his "law of the threc stagcs," 136, 216.

Condorcet, 145.

Constantiue Copronymus, $24 \%$.

Correlation of forccs, and the materi. alistic hy pothesis, 70

Correlation of growth, 17 .

"Cosmical weather," 98.

Cottin, Angrique, 129

Crookes on" "ysychic force," 122. 
D.

DACIA, 232.

Drimonion of Sokrates, 113, 116.

Darwinian theory compared with Newtonian, 1-10; theistic objection to it, 4 ; misrepresented by $\mathrm{Mi}$ vart, $11,33-39$; does not assert universal or continuous progress, 38.

Deaf tomcats, 17 .

Delphic oracle, 114.

Descartes, 75.

Vestruction of life, 13.

Donestication, 12.

Dramatic tendencies in nature, 98103.

Draper, .J. W. 253.

Dyak morality, 172.

E.

EARLY authorship, 213.

Fehidna and duck-bill, 22.

Edentata, 27.

Electric girls, 129.

Elephant and mammoth, 16.

Embryology, 24

Emotion and reason, 166.

Epilepsy, 114.

Ethnology of Europe, 227.

Exorcism, 114.

F.

FARRAR, F, W. 257

Fasting girls, 130.

Fellowships, 331.

Fetishism, 183.

Finns, 241

Fixity of species, 16.

Force, illegitimate use of the term, 5 .

Freeman, E. A., on the advantages of iteration, 62.

Frogs, shower of, 128.

Future life, $75-78$.

\section{G.}

Galapagos Islands, 27.

Galton, F., 350

Genius, 112.

Geographical distribution and geological succession of organisms, 26.

Getæe and Goths, 231.

Gills in human throat, 25.

fioethe, 109.

Gorillas and Parthenons, 49.
II.

HAECREL, 52.

Ilair and teeth of dogs, 17.

Halley's comet, 2, 9.

Inamilton, Sir W., 134, 306.

Ilainunolid, W. A. 120-130.

Harrison, F., 56, 60, 7T.

Ileraclius, 236

Ileredity in book-making, 350 ; MIr Buckle's loose talk about heredity, 159.

Ilermann, the magician, 128.

IIermes, 183 .

IIistory, study of, 307 .

Ilome, the charlatan, 122

IIorse, pedigree of, 30 .

Houdin, R., 128.

Iluggins on "psychic force," 124.

Ilungarians, 241.

Ifuns, 221.

Huxley, 'T. H., 29, 31, 5i, 58, 60, 61, $62,66,74,78,132,280$.

Ilypuotism, $12 \%$.

Ilysteria, 114.

I.

IBERIAN race, 228

Immortality of the soul, $75-78$.

Imperfections in geological record, 29.

Infancy, and the origin of mankind, 43-48.

Inspiration, 111-119.

Intellectual and moral progress, 151180.

Isaiah, 113.

J.

Justinian, 236.

K.

Kara George, 246.

Keltiberians, 229 .

Keltic race, 229

Kepler, 9, 53

Kovalevsky, 37 .

L.

LALANDE, 2.

liamettrie, 65 .

language, origin of, 48 .

Leibnitz, 2, 88, 144.

Lessing, G. E., 278. 
"Levitation," 128.

Lewes, G. H., 149, 158, 160, 191.

Liegnitz, battle of, 222.

Lions and antelopes, 15.

lions and leopards, 20.

Locke, 88.

Louis XIV., his injurious influence on science and literature, 193.

M.

Machiavelli, 145.

Mackintosh, Sir J., 170.

Maine, Sir HI., $215,312$.

Mammoth, 16

Mandril, foetal life of, 24.

Mania, 114.

Manichæans, 247.

Marathon, battle of, 220 .

Marius, 221.

Marsh's discovery of pedigree of the horse, 29-31.

Marsupials in Australia, 26.

Iaterialism, 50, 60-77

Mathematical studies, utility of, 296.

Mayer's meteoric theory, 98 .

Medicine men, 114

Mill, J. S., 133, 141, 25๊6, 305 ; com. pared with Chauncey Wright, 83 .

Mind as a product of evolution, $67-70$.

Mivart, St. G., misrepresents Darwinism, 11, 33-39 ; attacked by Wright, 105 ; ignores Wright's surrejoinder, 35.

Mohammed, 113.

Mongols, 220

Monotheism, 116.

Montesquieu, 145.

Morphology, 25.

Miiller, Max, 40, 45.

N.

NAMES of authors, 349.

Napoleon I. on Russian ethnology 233.

Natural selection, 11 ; misunderstood by Mivart, $15,36$.

Nature, constancy of, 89.

Nebular hypothesis, 98.

Neptune, discovery of, 9 .

Newtonian theory slowly received 2. Njemetch, 234.

\section{0.}

ODOACER, 238.

Ogre, 243.

Onomatopoia, 43.
Opossum, 26.

Orang-outang, infancy of, 48 .

Owen, R. D., duped by spiritualists, 129.

\section{P.}

PAChtomerms and ruminants, 28.

Pamphlets and volumes, 341.

Pascal, 144

Pass and class, 318.

Paternal theory of government, 193

Paulicians, 247.

Persecution, 177.

Peruvian selnse of smell, 163.

Philistinism and science, 285.

Phillips, TVendell, 66.

Phrenology, 139, 304.

Physics and chemistry, 299-302

Poseidou, 183.

Positivism and Lucretianism, 104

Positivists and their droll ecclesiastical tone, 60,77 .

Possession hy spirits, 113.

Protective spirit, 193.

Protococcus, 24.

"Psychic force,": 122.

K.

Radiata, 23.

Recitations, 322.

Renaissance, 264, 310.

Retrospective studies, 313.

Rhythm of motiou, 101.

Fiver-names in Europe, 229.

Roman policy toward barbarians, 220 .

IRudimentary organs, 25.

Rumania, 232.

Russia's growth checked by Mongols, 222

S.

SALAMs, battle of 220 .

Saul and $\Lambda$ gag, 169.

Scepticism, 181 .

Scholarship, nodern, 270.

School-books, stupidity of, 259-262.

Scliools, preparatory, 326.

Science and theology, 7 .

Scotch clergy, 201.

Seeley, J. R., 279.

Serbia, 245.

Shamans, 114.

Sheep and antelopes, 15 .

Siberian mammoth, 16.

Simeon of Bulgaria, 244, 248.

Skythians, 231.

Slave, etymology of the word, 234.

Slavic race, 232. 


\section{$37 \dot{4}$}

Smell, Peruvian sense of, 163.

Snakes with hind limbs, 25.

Sokrates, 113, 116.

South American fauna, 27.

Spanish civilization, 223.

Spinish ethnology, 229.

Species, fixity of, 16 .

Spencer, H., v., 47, 61, 62, 66, 68, 69, $87,90,94,95,101,103,107,131,139$, $146,149,160,182,184,194,215$.

"Spherical intelligence," 82.

Spiritualism, 120-130.

Stephen Dushan, 245.

Struggle for existence, 13.

Stuart-Glennie, J. S., 20i-218.

Subject-catalogues, 344 .

Survival of the fittest, 14.

T.

TABLE-TIPPING, 120-130.

Taine, H. A., 52.

Tatars, 233.

Teeth and hair of dogs, 17 .

Teetl in embryonic birds, 25,28 .

Telcolngy, 97, 103.

Temple, Sir W. 253.

Test of truth, 88.

Teutonic knights, 222.

Tentonic race. 230.

Theistic objection to Darwinism, 4.

Thrace, 231.

Three stages, Comte's theory of, 136 , 216.

Title pages, slovenliness of, 349 .

Tours, battle of, 222.

Trajan, 281.

Triposes, 319.

Tunicata, 23.

Turks, 223.

Tylor, E. B., 113.

Tyndall, J., 132.

U.

JNCONScious cerebration; 112.
Index.

Universe, how little we know of it, 96.

University education and its advantages, 212, 280, 294-314.

Unseen Universe, 95.

Urosh of Serbia, 245.

V.

VerSE-MAKING, Greek and Latin, 266.

Yico, 145.

Virtuc and pleasure, 37.

Voltaire, 145.

W.

WALLACE, A. R., on causes of man s intellectual supremacy, 38,46 ; his surprising credulity as to spiritualism, 127.

Wallach, 234

Weather, cosmical, 98.

Weish, 234.

Wright, Chauncey, 79-110; his criticism of Mirart, 35,105 ; his diffcult styl, 81 ; compared with J. S. Nill, 83; his distrust of broad generalizations, 86: his hostility to Spencer's philosophy, 87-104; his aversion to tcleology, 97; " cosmical weather," 98 ; his objections to nebular hypothesis, 98 ; his positivism, 103; his attack on Anaxagoras, 104 ; his personal qualities, 106-109.

Y.

Youmans, E. L., 256.

Z

ZEUS, 183.

Zulu diviners, 114. 




\section{THE WRITINGS OF JOHN FISKE.}

\section{THE DISCOVERY OF AMERICA.}

With some Account of Ancient $A$ merica and the Span.. ish Conquest. With a steel portrait of Mr. Fiske, reproductions of many old maps, several modern maps, facsimiles, and other illustrations. 2 vols. crown 8vo, \$4.00.

This work forms the beginning of Mr. Fiske's history of America. It is, perhaps, the most important single portion yet completed by him, and gives the results of vast research.

\section{THE AMERICAN REVOLUTION.}

With Plans of Battles, and a new Steel Portrait of $W$ ashington, engraved by Willcox from a miniature never before reproduced. 2 vols. crown 8vo, gilt top, $\$ 4.00$.

The reader may turn to these volumes with full assurance of faith for a fresh rehearsal of the old facts, which no time can stale, and for new views of those old facts, according to the larger framework of ideas in which they can now be set by the master of a captivating style and an expert in historical philosophy. - Nere York Evening Post.

The freshness and vivid interest of the narrative and the comprehensive generalization which springs naturally from the author's plan of a large work on American history, of which the two volumes now published are no more than a third or a fourth part, make it a book of new and permanent interest. - Spring field Republican.

\section{CIVIL GOVERNMENT IN THE UNITED STATES}

Considered with some Reference to its Origins. With Questions on the Text by Frank A. Hill, and Bibliographical Notes by Mr. Fiske. I2mo, \$I.00, net.

If this admirable volume (Fiske's "Civil Government") can be fairly taught to our rising generation, the future, we believe, will show that Mr. Fiske has never done more useful work than in its preparation. - The Congregationa. (Boston). 


\section{THE் CRITICAL PERIOD OF AMERI- CAN HISTORY. I783-1789.

\author{
With Map, Notes, etc. Crown 8vo, \$2.00.
}

The author combines in an unusual degree the impartiality of the trained schular with the fervor of the interested nar. rator... The volume should be in every library in the land. - The Congregationalist (Boston),

An admirable book. ... Mr. Fiske has a great talent for making history interesting to the $\mathrm{g}=$ neral reader. $-\Lambda$ ew York Times.

\section{THE BEGINNINGS OF NEW ENG. LAND;
Or, the Puritan Theocracy in its Relations to Civil and Religious Liberty. Crown 8vo, \$2.00.

It deals with the early colonial history of New England in the entertaining and vivid style which has marked all of $\mathrm{Mr}$. Fiske's writings on American history, and it is distinguished, like them, by its aggressive patriotism and its justice to all parties in controversy. . . The whole book is novel and fresh in treatment, philosophical and wise, and will not be laid down till one has read the last page, and remains impatient for what is still to come. - Boston Post.

\section{THE WAR OF INDEPENDENCE.}

In Riverside Library for Young People. With Maps. I6mo, 75 cents.

John Fiske's "War of Independence" is a miracle. . . . A book brilliant and effective beyond measure. . . . It is a statement that every child can comprehend, but that only a man of consummate genius could have written. - Mrs. CARoLINE H. DALL, in the Springfield Republican.

The story of the Revolution, as Mr. Fiske tells it, is one of surpassing interest. His treatment is a marvel of clearness and comprehensiveness; discarding non-essential details, he selects with a fine historic instinct the main currents of history, traces them with the utmost precision, and tells the whole story in a masterly fashion. His little volume will be a textbook for older quite as much as for young readers. - Chris. tian Union (New York).

\section{OUTLINES OF COSMIC PHILOSOPHY}

Based on the Doctrine of Evolution, with Criticisms on

the Positive Philosophy. In two volumes. 8vo, $\$ 6.00$.

"You must allow me to thank you for the very great interest with which I have at last slowly read the whole of your 
work. . . . I never in my life read so lucid an expositor (and therefore thinker) as you are; and I think that I understand nearly the whole, though perhaps less clearly about cosmic theism and causation than other parts. It is hopeless to attempt out of so much to specify what has interested me most, and probably you would not care to hear. It pleased me to find that here and there I had arrived, from my own crude thoughts, at some of the same conclusions with you, though I could seldom or never have given my reasons for such cone clusions." - CHARLES DARWIN.

This work of Mr. Fiske's may be. not unfairly designated the most important contribution yet made by America to philosophical literature. - The Academy' (London).

\section{DARWINISM, AND OTHER ESSAYS, \\ $12 m o, \$ 2.00$.}

If ever there was a spirit thoroughly invigorated by the "joy of right understanding" it is that of the author of these pieces. Even the reader catches something of his intellectual buoyancy, and is thus carried almost lightly through discussions which would be hard and dry in the hands of a less animated writer. . . No less confident and serene than his acceptance of the utmost logical results of recent scientific discovery is Mr. Fiske's assurance that the foundations of spiritual truths, so called, cannot possibly be shaken thereby. - The Atlantic Monthly (Boston).

\section{THE UNSEEN WORLD, And Other Essay's. Izmo, \$2.00.}

To each study the writer seems to have brought, besides an excellent quality of discriminating judgment, full and fresh special knowledge, that enables him to supply much information on the subject, whatever it may be, that is not to be found in the volume he is noticing. To the knowledge, analytical power, and faculty of clear statement, that appear in all these papers, Mr. Fiske adds a just independence of thought that conciliates respectful consideration of his views, even when they are most at variance with the commonly accepted ones. - Boston Advertiser.

\section{EXCURSIONS OF AN EVOLUTIONIST.}

\section{I2mo, \$2.00.}

Among our thoughtful essayists there are none more brilliant than Mr. John Fiske. His pure style suits his clear thought. He does not write unless he has something to say; and when he does write he shows not only that he has thoroughly acquainted himself with the subje: but that he has 
to a rare degree the art of so massing his matter as to bring out the true value of the leading points in artistic relief. It is this perspective which makes his work such agreeable reading even on abstruse subjects, and has enabled him to play the same part in popularizing Spencer in this country that Littré performed for Comte in France, and Dumont for Bentham in England. The same qualities appear to good ad. vantage in his new volume, which contains his later essays on his favorite subject of evolution. . . . They are well worth reperusal. - The Nation (New York).

\section{MYTHS AND MYTH-MAKERS. \\ Old Tales and Superstitions interpreted by Compara- tive Mythology. I $2 m 0, \$ 2.00$.}

Mr. Fiske has given us a book which is at once sensible and attractive, on a subject about which much is written that is crotchety or tedious. - W. R. S. Ralston, in Athenaum (London).

A perusal of this thorough work cannot be too strongly recommended to all who are interested in comparative mythology. - Revue Critique (Paris).

\section{THE DESTINY OF MAN,}

Vierved in the Light of his Origin. I6mo, gilt top, \$I.00.

Mr. Fislie has given us in his "Destiny of Man" a most attractive condensation of his views as expressed in his various other works. One is charmed by the directness and clearness of his style, his simple and pure English, and his evident knowisdge of his subject. . . . Of one thing we may be sure, that none are leading us more surely or rapidly to the full truth than men like the author of this little book, who reverently study the works of God for the lessons which he would teach his children. - Christian Union (New York).

\section{THE IDEA OF GOD,}

s. Affected by Modern Knowledge. I 6 mo, gilt top, $\$ I .00$.

The charms of John Fiske's style are patent. The secrets of its fluency, clearness, and beauty are secrets which many a maker of literary stuffs has attempted to unravel, in order to weave like cloth-of-gold. . . . A model for authors and a delight to readers. - The Critic (New York).

*** For sale by all Booksellers. Sent by mail, fostpaid, on receipt of price by the Publishers,

\section{HOUGHTON, MIFFLIN \& CO.}

\& Park Strect, Boston; II East I7th Strcet, New York. 






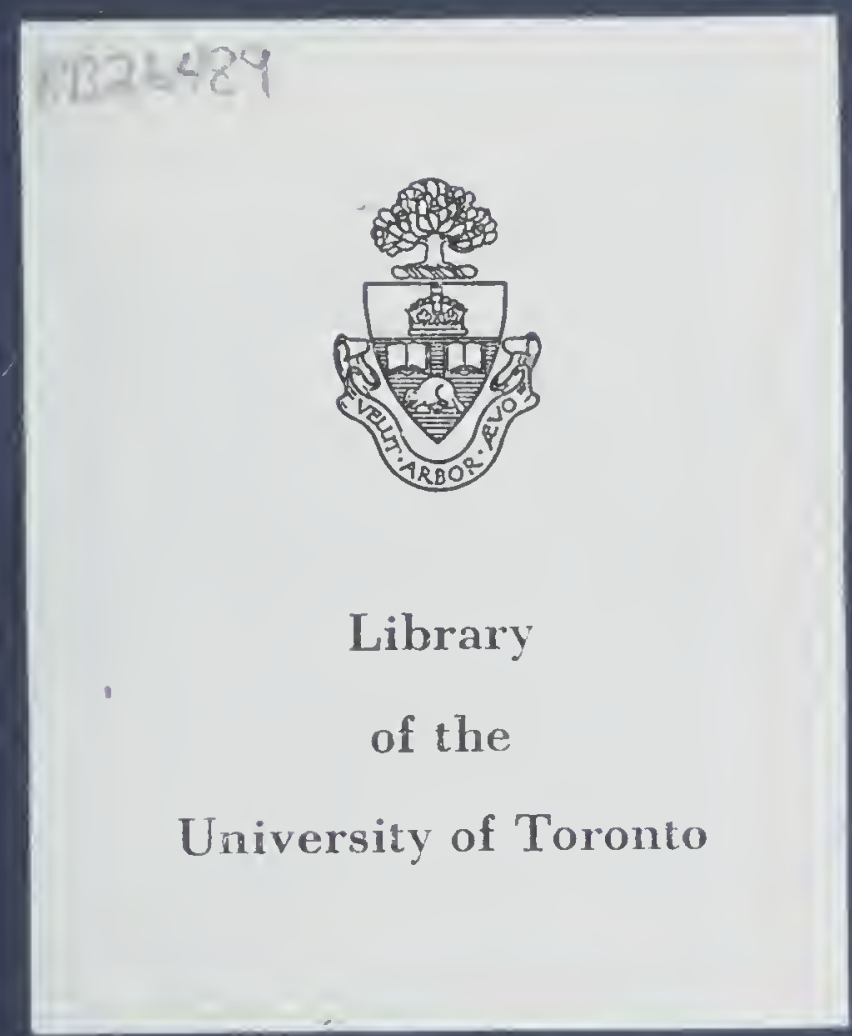




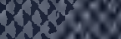

